\title{
MELANIE MENDOZA
}

\section{Versão infantil do Teste "Ler a Mente nos Olhos" ("Reading the Mind in the Eyes" Test): \\ Um Estudo de Validade}

\author{
Dissertação apresentada ao Instituto de \\ Psicologia da Universidade de São Paulo \\ como parte dos requisitos para obtenção do \\ Título de Mestre \\ Área de Concentração: \\ Psicologia Clínica \\ Orientador: \\ Prof. Dr. Francisco Baptista Assumpção Jr
}

São Paulo 


\section{AUTORIZO A REPRODUÇÃO E DIVULGAÇÃO TOTAL OU PARCIAL DESTE TRABALHO, POR QUALQUER MEIO CONVENCIONAL OU ELETRÔNICO, PARA FINS DE ESTUDO E PESQUISA, DESDE QUE CITADA A FONTE.}

Catalogação na publicação

Biblioteca Dante Moreira Leite

Instituto de Psicologia da Universidade de São Paulo

Mendoza, Melanie.

Versão infantil do Teste "Ler a Mente nos Olhos" ("Reading the Mind in the Eyes" Test): um estudo de validade / Melanie Mendoza; orientador Francisco Baptista Assumpção Junior. -- São Paulo, 2012.

$105 \mathrm{f}$.

Dissertação (Mestrado - Programa de Pós-Graduação em Psicologia. Área de Concentração: Psicologia Clinica) - Instituto de Psicologia da Universidade de São Paulo.

1. Cognição social 2. Teoria da mente 3. Psicometria I. Título. BF323.S63 


\title{
FOLHA DE APROVAÇÃO
}

\author{
Aluno: Melanie Mendoza \\ Título: Versão infantil do Teste "Ler a Mente nos Olhos" \\ ("Reading the Mind in the \\ Eyes" Test): Um Estudo de Validade
}

Dissertação de Mestrado apresentada ao Programa de Pós-Graduação em Psicologia Clínica para obtenção do Título de Mestre.

Área de Concentração: Psicologia Clínica

Orientador: Prof. Dr. Francisco Baptista Assumpção Jr

Aprovado em:

Banca Examinadora

Prof. Dr.

Instituição: Assinatura:

Prof. Dr.

Instituição: Assinatura:

Prof. Dr.

Instituição: Assinatura: 
Ao meu marido pelo apoio e incentivo infinitos. 


\section{AGRADECIMENTOS}

Ao meu orientador cujos ensinamentos foram muito além da pesquisa e da clínica.

Às minhas filhas pela paciência.

À minha mãe por toda a ajuda.

A minhas colegas de "jornada científica" e queridas amigas do Laboratórios Distúrbios do Desenvolvimento em especial Cristina Maria Pozzi, Milena de Oliveira Rossetti, Alessandra Freitas Russo e Marília Penna Bernal que contribuíram diretamente com este trabalho.

Às Profas. Ceres Araújo e Evelyn Kuczynski por suas valiosas sugestões.

Às escolas e instituições de saúde que permitiram a pesquisa. 
"aprendi até mesmo a me regozijar com a refutação de uma hipótese pela qual se tem grande estima, porque também sua refutação é uma conquista científica."

John Eccles 


\section{RESUMO}

Mendoza, M.(2012) Versão Infantil do Teste de Ler a Mente nos Olhos (Reading the Mind in the Eyes test): Um estudo de Validade. Dissertação de Mestrado. Instituto de Psicologia. Universidade de São Paulo.

A versão infantil do "Teste de Ler a Mente nos Olhos" ("Reading the Mind in Eyes Test Child Version ") de Simon Baron-Cohen, é composto por 28 fotografias da região dos olhos de indivíduos com diferentes expressões e tem como objetivo uma quantificação da habilidade do indivíduo em inferir estados mentais a partir de expressões faciais, sendo usualmente utilizado como um instrumento para avaliação de Teoria da Mente. Neste trabalho foi feito um estudo de validade de uma versão em português do teste, visando maiores esclarecimentos acerca de suas propriedades psicométricas. O teste foi aplicado em uma amostra controle de 434 crianças de dois estados brasileiros, São Paulo e Santa Catarina, cursando o ensino fundamental e em uma amostra clínica de 20 crianças diagnosticadas com Transtornos do Espectro do Autismo. Foram encontrados um índice de consistência interna (alfa de Cronbach) de 0,718 e variância estatisticamente significativa de acordo com o ano escolar. Não foram encontradas diferenças significativas com relação ao sexo e Estado. Não houve diferença estatisticamente significativa nos escores dos grupos controle e clínico. Os resultados foram, portanto, parcialmente favoráveis para validade de construto, mas não foram encontradas evidências de validade critério.

Palavras-Chave: Teoria da Mente, Psicometria, Cognição Social 


\begin{abstract}
Mendoza, M. (2012) Child Version of the Reading the Mind in the Eyes test: A validity study. Master's thesis. Institute of Psychology. University of Sao Paulo.

The "Reading the Mind in Eyes Test - Child Version" by Simon Baron-Cohen, consists of 28 photographs of the eye region of people with different expressions and aim a quantification of the individual's ability to infer mental states from facial expressions, and is usually used as an instrument for assessing Theory of Mind. This paper is a study of validity of a Portuguese version of the test, seeking further clarification about its psychometric properties. The test was applied to a control group of 434 children from two Brazilian states, Sao Paulo and Santa Catarina, in elementary school and a clinical group of 20 children diagnosed with Autism Spectrum Disorders. We found an index of internal consistency (Cronbach's alpha) of 0.718 and statistically significant variance in accordance with the school year. There were no significant differences with regard to gender and state. There was no statistically significant difference in the scores of clinical and control groups. The results were therefore partially favorable to construct validity, but there was no evidence of criterion validity.
\end{abstract}

Keywords: Theory of Mind, Psychometrics, Social Cognition 


\section{LISTA DE FIGURAS}

Figura 1 Esquema de componentes cognitivos inerentes à vida social ....................20

Figura 2 Histograma e curva de Gauss dos escores do grupo controle .....................41

Figura 3 Gráfico dos escores no Eyes-C pela idade dos participantes .....................49 


\section{LISTA DE TABELAS}

Tabela 1 Métodos empregados nos estudos de Woodworth, Plutchik, Tomkins \& McCarter, Osgood e Fridja 25

Tabela 2 Categorias de emoções propostas por Woodworth, Plutchik, Tomkins \& McCarter, Osgood e Fridja 26

Tabela 3 Comparativo dos escores e idade nas formas de aplicação coletiva e individual 42

Tabela 4 Comparativo dos escores e idade dos participantes das cidades de São Paulo e Brusque .43

Tabela 5 Comparativo dos escores por sexo dos participantes

Tabela 6 Valor de alfa de Cronbach com retirada do item do Eyes-C

Tabela 7 Carga Fatorial para solução de seis fatores .48

Tabela 8 Intervalo de confiança do Eyes-C de acordo com o ano escolar

Tabela 9 Comparativo entre os grupos controle e clínico..... .50 


\section{LISTAS DE SIGLAS}
APAE
Associação dos Pais e Amigos do Excepcional
ATA Escala de Traços Autísticos
BIREME Biblioteca Virtual em Saúde
CARS Escala de Pontuação de Autismo
DSM IV Manual Diagnóstico e Estatístico das Doenças Mentais $4^{\mathrm{a}}$ Edição
Eyes-Test Teste de Ler a Mente nos Olhos
Eyes-C Teste de Ler a Mente nos Olhos-Versão Infantil
IPUSP Instituto de Psicologia da Universidade de São Paulo
MB Cegueira-mental
PDD Laboratório Distúrbios do Desenvolvimento
SA Síndrome de Asperger
SE Sistematização-empatia
TEA Transtornos do Espectro do Autismo
ToM Teoria da Mente
WISC III Escala Weschler de Inteligência para Crianças $3^{\mathrm{a}}$ Edição 


\section{SUMÁRIO}

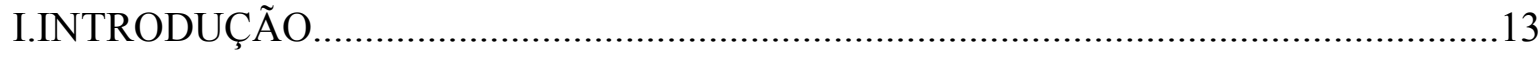

I.1.A mensuração de um traço..............................................................................15

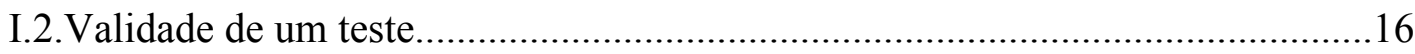

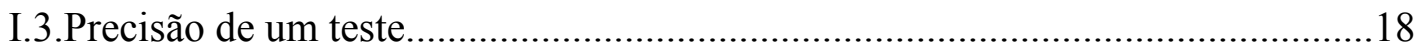

I.4.Modelo Teórico Subjacente ao Teste de Ler a Mente nos Olhos........................19

I.4.a.Cognição social.................................................................................19

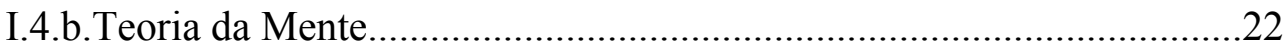

I.4.c.Medidas de Percepção Social: reconhecimento das emoções.................24

I.4.d.Modelos Cognitivos para o Autismo.......................................................30

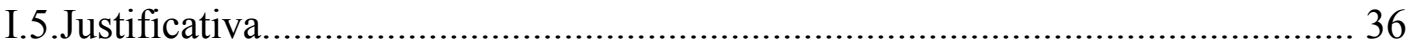

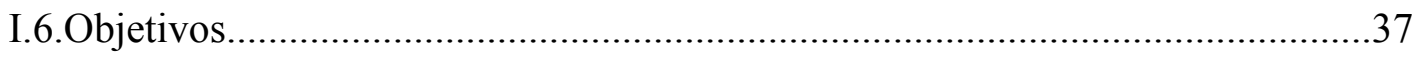

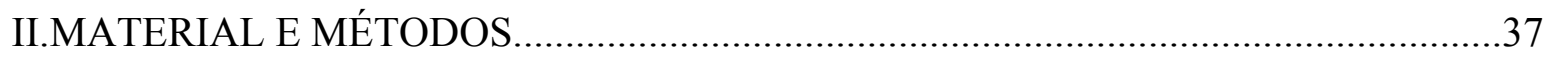

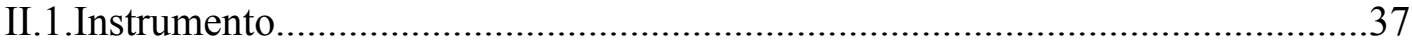

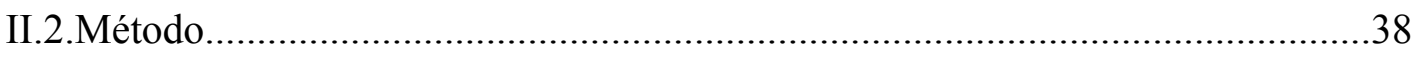

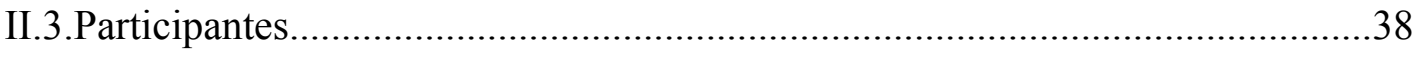

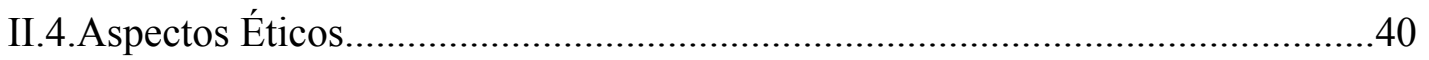

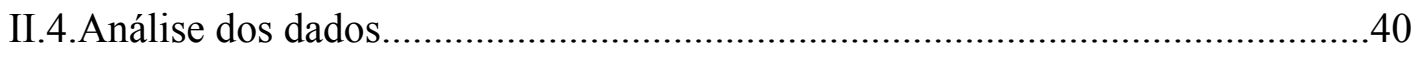

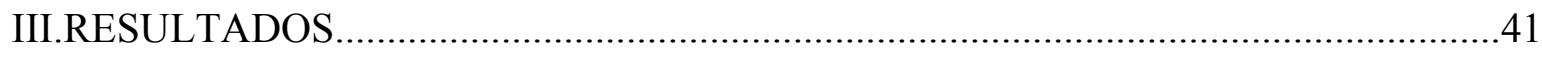

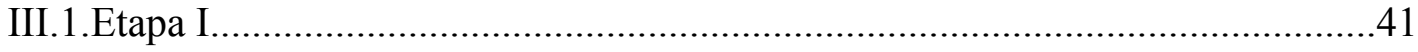

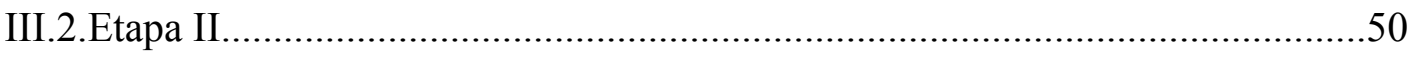

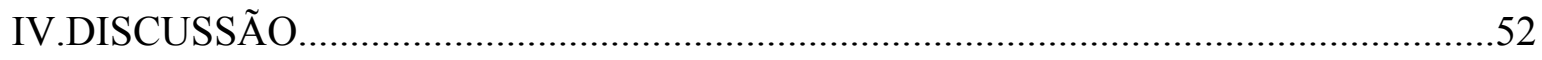

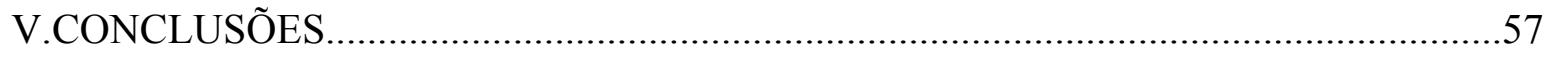

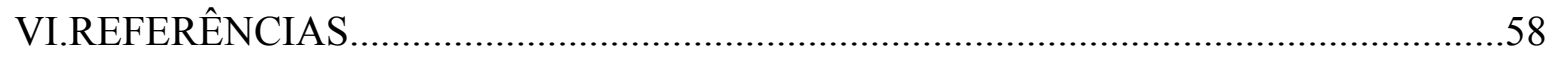

VII.ANEXOS

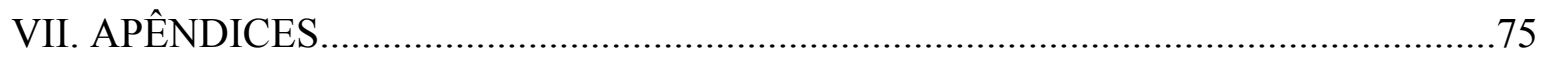




\section{I.INTRODUÇÃO}

Nas tentativas de determinar um perfil para os Transtornos do Espectro do Autismo (TEA), buscam-se modelos explicativos de déficits cognitivos e seus correlatos neurofuncionais que sintetizem os prejuízos observados nestas síndromes. Uma das hipóteses com maior penetração no meio científico preconiza que os indivíduos com autismo e Síndrome de Asperger, independentemente do Nível Intelectual, possuem dificuldades em atribuir estados mentais e emoções a outros indivíduos, compreender diferentes perspectivas, colocar-se no lugar de outro individuo e responder adaptativamente a este conhecimento. Colocando de outra forma, nos TEA existiria um déficit em cognição social, constructo que se refere às "operações mentais subjacentes às interações sociais, as quais incluem a habilidade humana de perceber as intenções e disposições de outros indivíduos e os processos cognitivos que dão subsídios aos comportamentos de responder aos outros" (Hallerbäck, Lugnegård, Hjärthag \& Gillberg, 2009).

Entre as publicações que contribuíram para este paradigma destaca-se o de BaronCohen, Leslie e Frith (1985) e de Baron-Cohen, Jolliffe, Mortimore e Robertson (1997). No primeiro estudo os autores observaram que as crianças autistas - em comparação com crianças normais e com Síndrome de Down - tinham dificuldade em compreender que outros indivíduos podem ter uma perspectiva diferente da realidade objetiva, a este déficit foi dado o nome de cegueira-mental (MB, em inglês mindblindness), definida como uma dificuldade na elaboração de uma Teoria da Mente (ToM). No trabalho de 1997 os pesquisadores elaboram um teste que visava quantificar a habilidade em atribuir estados mentais e emoções a partir de expressões faciais. Os autores verificaram que os indivíduos diagnosticados com Síndrome de Asperger (SA) tiveram mais dificuldade em reconhecer 
expressões faciais em fotografias de região dos olhos em relação aos indivíduos normais, em um instrumento denominado "Reading the Mind in the Eyes" (Eyes-Test).

Os trabalho de 1985 e 1997 foram amplamente citados e replicados pois: a) forneciam um modelo explicativo cognitivo para as muitas alterações comportamentais em um transtorno de alta prevalência (Fombone, 2009), b) eram compatíveis com a teoria da Lorna Wing (1981) acerca de continuum autístico, e c) lançavam novos dados para um campo muito promissor da Psicologia Cognitiva, o constructo Cognição Social. Por estas características a teoria $\mathrm{MB}$ e o Eyes-Test foram revisados e ampliados. O Eyes-Test foi utilizado em outras populações clínicas e serviu como medida de eficácia para procedimentos terapêuticos experimentais.

Inspirados nos resultados anteriores, e em uma tentativa de explicar algumas altas habilidades encontradas nos TEA, novos instrumentos foram desenvolvidos, como os questionários de Quociente de Empatia (Baron-Cohen \& Wheelwright, 2004) e Quociente de Sistematização (Baron-Cohen, Richler, Bisarya, Gurunathan \& Wheelwright, 2003), que visam quantificar duas habilidades independentes que seriam subjacentes ao desempenho nas relações interpessoais e nos sistemas do tipo entrada-operação-resultado. E, a partir dos estudos com TEA e da comparação entre escores de homens e mulheres, surgiu um novo modelo explicativo para esses transtornos e para variações de "estilos cognitivos" para a população normal. A essa nova proposta para os TEA, como uma variação em grau de características gerais da população, foi dado o nome de sistematização-empatia (SE) ou cérebro extremamente masculino (extreme male brain). 
Apesar do grande interesse que essas teorias despertaram, não houve no mesmo grau, um incremento no conhecimento das propriedades psicométricas das versões do Eyestest e, portanto, testes empíricos que dessem mais robustez a essas hipóteses. Em dezembro de 2011 na base de dados da Biblioteca Virtual em Saúde (BIREME) em uma busca com as palavras "Reading the Mind in the eyes", "Eyes-test" e "Theory of Mind", entre os 28 estudos que utilizavam alguma versão do instrumento desenvolvido por Baron-Cohen, apenas um artigo estudava as propriedades psicométricas de uma das versões do instrumento. Hallerbäck et al. (2009) avaliaram a precisão teste-reteste, da versão infantil em sueco aplicada em universitários, com resultados considerados apenas satisfatórios.

Dada a importância e abrangência dos modelos SE e MB, e a ampla utilização das versões do Eyes-test, na presente pesquisa foram estudadas as propriedades psicométricas de uma versão em português da versão infantil do "Reading the Mind in the Eyes-test" (Eyes-C). Para isto, serão definidos os parâmetros que norteiam a construção de um instrumento de medida e o referencial teórico no qual se inserem os construtos Cognição Social, ToM e SE.

\section{I.1.A mensuração de um traço}

Mensuração pode ser definida como um conjunto de regras para representar o comportamento em categorias ou números. Construir um instrumento para medir uma variável psicológica inclui uma série de etapas: (a) conceituação dos comportamentos que definem operacionalmente o construto em questão, (b) elaboração de itens que acessem o construto, (c) administração dos itens elaborados para amostras pré-definidas, (d) refinamento do instrumento baseado em análises dos itens e (e) realização de estudos de 
validade e fidedignidade. Essas etapas são necessárias para se garantir que os escores de um instrumento são consistentes e realmente acessam o construto que se pretende avaliar (Andrade, Laros, \& Gouveia, 2010), e que os escores dos indivíduos refletem o traço em questão (traço latente).

\section{I.2. Validade de um teste}

A validade é o grau em que o teste de fato mensura aquilo a que se propõe mensurar (Hogan, 2006).

"O que se quer dizer é que, ao se medirem os comportamentos (itens), que são a representação do traço latente, está se medindo o próprio traço latente. Tal representação é justificada se a representação comportamental for legítima. Esta legitimação somente é possível se existir uma teoria prévia do traço que fundamente que a tal representação comportamental constitui uma hipótese dedutível desta teoria. A validade do teste (este constituindo a hipótese), então, será estabelecida pela testagem empírica da verificação desta hipótese.” (Pasquali, 2009b, p. 112).

As técnicas mais utilizadas são as que constituem o modelo trinário: validade de construto, validade de conteúdo e validade de critério (American Psychological Association, 1954), definidas como:

a) Validade de Construto: é considerada a forma mais fundamental da validade dos instrumentos psicológicos, ela constitui a maneira direta de verificar a legitimidade da representação comportamental dos traços latentes, e está intimamente relacionada com o modelo teórico subjacente à elaboração dos itens do teste. De acordo com Pasquali (2006) a validade de construto pode ser trabalhada sob dois 
ângulos: análise da representação comportamental do construto e análise por hipótese. A análise da representação comportamental é calculada através da análise fatorial - verifica quantos construtos são necessários para explicar a intercorrelações entre os itens - e da consistência interna que descreveremos mais adiante. A análise por hipótese é a capacidade que o instrumento tem de discriminar ou predizer um critério que é externo a ele mesmo (Pasquali, 2009a). Neste caso se um teste se propõe a medir traços que estão intrinsecamente relacionados ao desenvolvimento cognitivo, por exemplo, ele deve ser capaz de discriminar grupos com idades diferentes.

b) Validade de Critério: “é o grau de eficácia que ele tem em predizer um desempenho especifico de um sujeito. O desempenho do sujeito torna-se, assim, o critério contra o qual a medida obtida pelo teste é avaliada." (Pasquali, 2009b, p. 123). Neste caso o desempenho do examinando é avaliado pelo instrumento e também por outras técnicas que são independentes a ele. Os dois tipos de validade são a preditiva e a concorrente sendo que a diferença fundamental entre ambas é o contraste entre os momentos de aplicação, na primeira a validade é dada após um período de tempo entre a coleta e a informação sobre o critério e na segunda isso ocorre de maneira simultânea.

c) Validade de Conteúdo: Um teste tem validade de conteúdo se ele constitui uma amostra representativa de um universo finito de comportamentos. É aplicável quando se pode delimitar a priori e claramente um universo de comportamentos, como é o caso de testes de desempenho, que pretendem cobrir um conteúdo delimitado por um curso pragmático específico, sendo portanto mais usado para medir o conhecimento acadêmico. 


\section{I.3.Precisão de um teste}

Um dos aspectos importantes da validade de um teste é a sua precisão (fidedignidade). Ela cobre aspectos diferentes de um teste, mas todos eles se referem a quanto os escores de um sujeito se mantém idênticos em ocasiões diferentes.

"Assim o conceito de fidedignidade se refere ao quanto o escore obtido no teste se aproxima do escore verdadeiro do sujeito em um traço qualquer, isto é, a fidedignidade de um teste está intimamente ligada ao conceito de variância do erro, sendo este último definido como a variabilidade nos escores produzida por fatores estranhos ao construto" (Pasquali, 2009b, p. 192)

As técnicas utilizadas para avaliar a precisão podem ser:

a) Precisão teste-reteste: consiste em calcular correlação entre a distribuição de escores obtidos num mesmo teste pelos mesmos sujeitos em duas ocasiões diferentes de tempo.

b) Precisão de formas alternativas: neste caso de precisão os sujeitos respondem a duas formas paralelas do mesmo teste, e a correlação entre as duas distribuições de escores constitui o coeficiente de precisão do teste.

c) Precisão da consistência interna: relacionada à validade de construto do instrumento. As técnicas utilizadas neste tipo de precisão visam verificar a homogeneidade da amostra de itens do teste, ou seja a consistência interna. Entre as mais utilizadas estão: duas metades, Kuder-Richardson e alfa de Cronbach. Todas elas exigem aplicação do teste em apenas uma única ocasião, evitando a questão da constância temporal (Pasquali, 2009b) 


\section{I.4.Modelo Teórico Subjacente ao teste de "Ler a Mente nos Olhos"}

O Eyes-test e o Eyes-C estão inseridos na Psicologia Cognitiva, um campo científico que utiliza modelos da Psicologia Evolutiva, da Primatologia e das Neurociências, para conhecer os processos da mente humana, a correlação entre cérebro e o comportamento, e, por conseguinte, algumas psicopatologias. Neste modelo, a mente humana, e as habilidades inerentes a ela, são um produto do processo de seleção darwiniana, ou seja, das pressões seletivas do ambiente sobre a variabilidade dos indivíduos, selecionando os mais adaptados e seus descendentes. "Nossas mentes são nossos cérebros, que são, por isso, máquinas complexas esplêndidas. A diferença entre nós e outros animais é de enorme grau, mas não de natureza metafísica” (Dennett, 1995). Parte das estruturas do sistema nervoso central e seus correlatos comportamentais foram selecionados porque forneceram soluções adaptativas para problemas surgidos durante a evolução da espécie, tais como busca de parceiros, alimentação e defesa (Tooby \& Cosmides, 2005).

\section{I.4.a.Cognição social}

Embora não exista consenso de que as pressões mais relevantes na história evolutiva dos primatas, em especial os humanos, tenham sido relativas ao modo de vida gregário, este modelo tem sido bastante aceito, com evidências de que habilidades de resolução de problemas de natureza social são relativamente independentes dos problemas ligados à lógica e alimentação (Cosmides \& Tooby, 1992). De acordo com Adolphs (2009) existem $a$ priori boas razões para acreditar que existem alguns módulos - estruturas do córtex especializados em processar desafios relacionados à vida social, pois nela existe um tipo de 
demanda com características singulares como, por exemplo, discriminar pessoas de outros elementos do ambiente e identificar sua intenção conosco; manter uma conduta adequada para amigos e estar vigilante a inimigos sem confundir um com o outro; antecipar-se ao comportamento de seus coespecíficos- seja de maneira competitiva ou cooperativa- e comportamento moral.

Partindo desse pressuposto, o ambiente de adaptação evolutiva - em bandos com complexas trocas sociais - selecionou módulos especializados na detecção de violação de regras sociais, independentes do raciocínio lógico geral (Cosmides \& Tooby, 1992; Cosmides, Barret \& Tooby, 2010; Barret, Cosmides e Tooby, 2010). As habilidades para trocas sociais, por sua vez, permitiram a vida em grupos maiores, aumentando as chances de sobrevivência e sucesso reprodutivo, "Graças a esse poder, o Homo Sapiens pode dominar grupos que não apresentassem tais recursos cognitivos com a mesma intensidade" (Caixeta \& Caixeta, 2005).

Portanto, no lugar de apenas um fluxo consciente, existem múltiplos canais de circuitos especializados de processamento em paralelo (Dennett, 1991). Cada criança teria ao nascimento "ferramentas-mentais" (mind tools) que a ajudaria a pensar e a resolver os problemas impostos ao longo da vida, entre essas ferramentas está uma disposição para adotar um postura intencional (intentional stance) (Dennett, 1995), uma estratégia de interpretar o comportamento de uma entidade, tratando-a como se fosse um agente racional que tem suas escolhas governadas por suas crenças e desejos.”(Dennett, 1996).

Infelizmente não existe, até o momento, uma definição precisa para o termo Cognição Social, e diferentes grupos de pesquisa utilizam de maneira intercambiável os 
termos percepção social, Cognição Social e ToM. Neste trabalho adotaremos como definição de Cognição Social "as operações mentais que subjazem as interações sociais tanto a percepção quanto a resposta" (Hallerbäck el cols., 2009). Um conjunto de habilidades, ou ferramentas-mentais, portanto, que tem como objetivo "prover [o indivíduo com] mecanismos e explicações acerca dos processos do complexo fenômeno social" (Winkielman \& Schooler, 2009). Além da postura intencional, também compõe a Cognição Social a empatia - da qual falaremos mais tarde ao tratarmos do modelo SE - e, como componente dela, a ToM, que por sua vez contém os módulos de percepção social - ambos tratados no próximo tópico -conforme esquematizado na Figura 1.

Figura 1. Esquema dos componentes cognitivos inerentes à vida social

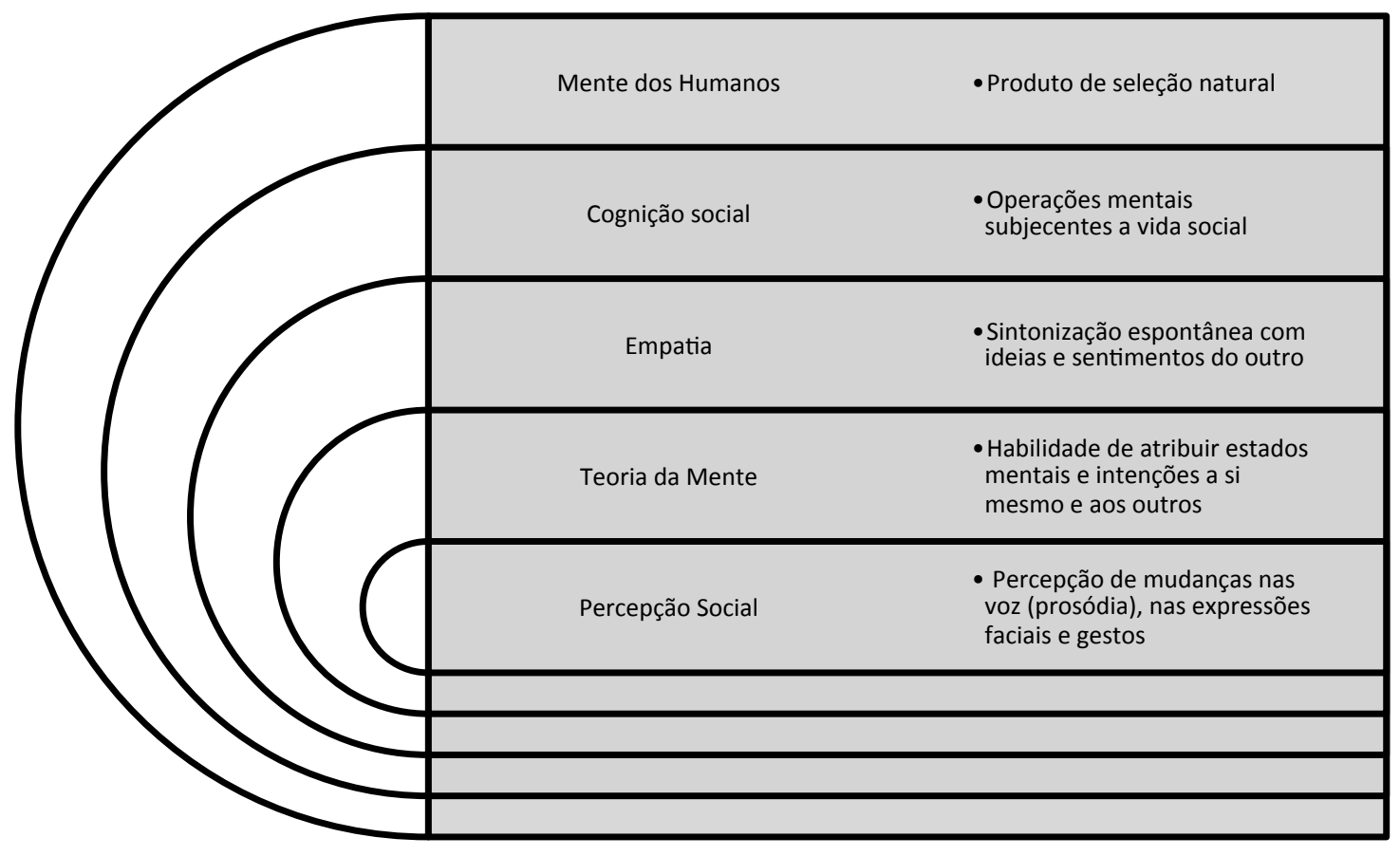




\section{I.4.b.Teoria da Mente}

A ToM "envolve a habilidade de atribuir estados mentais independentes para si mesmo e para os outros com o objetivo de explicar e prever comportamentos" (Hallerbäck et al., 2009). Refere-se à habilidade em deduzir intuitivamente as causas das ações de agentes intencionais e também é chamado de psicologia intuitiva (folk psychology). Leslie (1987) define ToM como a habilidade em elaborar uma teoria implícita e não formal acerca do comportamento dos outros, e fazer predições apoiando-se no que se sabe sobre suas crenças e desejos, no lugar de dados da realidade objetiva. Uma vez que a elaboração de uma ToM adequada depende da percepção de pistas sociais como tom de voz e expressões faciais, o estudo dos processos relacionados a esses comportamentos tem sido denominados medidas de ToM, no entanto, é preciso alguma cautela ao se assumir que ambos são equivalentes, sendo mais adequado descrever que a primeira está inserida na segunda.

O termo ToM foi utilizado inicialmente na primatologia por Premack e Woodruff em 1978. Esses autores colocaram um chimpanzé diante de vídeo de um ator desafiado por situações-problema e, após assistir o vídeo, o animal deveria escolher uma dentre uma série de fotografias. Em um número expressivo de vezes o animal selecionou como resposta fotografias com as opções corretas. Os autores concluíram que o sujeito compreendeu: a) que o vídeo apresentava uma situação-problema, b) a intenção do ator, e c) as alternativas compatíveis com essa intenção (Premack e Woodruff, 1978). O estudo de primatas, especialmente chimpanzés, constitui um dos modelos de pesquisa em ToM, como uma variável independente da linguagem, já que nos seres humanos a atribuição de estados mentais e intencionalidade é, no desenvolvimento normal, pareado com informações linguísticas. 
Dados de pesquisa, tanto em ambientes naturalísticos quanto de laboratório, tem sido convergentes no sentido de indicar que primatas não-humanos são capazes de perceber as motivações do outro indivíduo, perceber o seu campo de visão e perceber intencionalidade em uma ação, mas ainda não existem evidências de reconhecimento de falsa crença entre primatas - não são capazes de perceber uma falsa crença ou uma "crença sobre uma crença", transportando-se para o ponto-de-vista de outra pessoa - por isso não se atribui a essas espécies habilidades de ToM (Withen, 1993; Call \& Tomasello, 2008)

Em nossa espécie observa-se um incremento das habilidades que compõe a ToM e a percepção social na ontogênese. De acordo com Tomasello (2003) ao redor dos oito a nove meses, quando apresentam respostas de atenção conjunta ${ }^{1}$, as crianças já são capazes de compreender que os outros são agentes com intencionalidade, em outras palavras ela percebe que os outros são "como eu". É ainda no primeiro ano de vida que a criança distingue ações de entidades que possuem intencionalidade - animais e pessoas - das ações de entidades que não a possuem - objetos e eventos da natureza (Dennett, 1987), havendo assim, durante o período de desenvolvimento, um incremento gradual da ToM. É essa capacidade que dá à criança a possibilidade de considerar o que as outras pessoas pensam e fazem, habilidade necessária em quase todas as situações sociais (Jou \& Sperb, 1999), especialmente naquelas onde é necessário habilidades de empatia. Aos 12 meses o bebê já é capaz de compreender intenções e metas (Baron-Cohen,1994; Premack 1990) e espera que as outras pessoas expressem emoções e que elas sejam demonstradas de maneira consistente através do tom de voz e expressão do rosto (Walker, 1982). Em torno dos 14 meses, as crianças começam a produzir e entender o "faz-de-conta" (Bates, Benigni,

\footnotetext{
${ }^{1}$ Atenção conjunta ou compartilhada é a habilidade de coordenar a atenção entre o parceiro social e o objeto de interesse de ambos.
} 
Bretherton, Camioni \& Volterra, 1979; Leslie, 1987). Aos 18 meses, demonstram inquietação com a tristeza alheia (Yirmiya, Sigman, Kasari \& Mundy, 1992). Aos dois anos, o seu vocabulário inclui palavras que indicam estados mentais (Wellman \& Bartsch, 1988). Aos 4 anos, uma criança compreende que outras pessoas podem ter falsas crenças (Wimmer e Perner, 1983). E por volta dos sete anos uma criança é capaz de compreender que deve evitar dizer certas coisas para não ofender alguém (Baron-Cohen, Riordan, Stone, Jones \& Plaisted, 1999). Estudo mais recente demonstra que o reconhecimento de faces nas crianças só atinge o alto nível de complexidade adaptativa característico da espécie aos oito ou nove anos (Pimperton, Pellicano, Jeffery, \& Rhodes, 2009), como o reconhecimento de expressões mistas ou simuladas.

\section{I.4.c. Medidas de Percepção social: reconhecimento de expressões}

As expressões faciais de emoções foram estudas pela primeira vez por Charles Darwin em 1872, e descritas na obra intitulada "As expressões dos homens e dos animais" (Darwin, 2000), neste livro foram coletados julgamentos de observadores em diversos países acerca de uma expressão facial. Um dos modelos teóricos mais utilizados até o presente postula que existem categorias de emoções básicas ou, em outras palavras, afetos primários, que independem de aprendizagem social para serem expressas e reconhecidas ${ }^{2}$. Esse modelo inicia-se com Allport em 1924, embora Woodworth (1938) seja citado frequentemente como pioneiro do Século XX; Schlosberg (1954), Plutchnik (1962) e Tomkins (1962) enfatizaram o papel evolutivo nas expressões faciais; Tomkins, juntamente

${ }^{2}$ As emoções são um tipo específico de avaliação automática, fruto de seleção onto e filogenética, nessas situações o indivíduo sente que algo importante o seu bem-estar está ocorrendo em um conjunto de mudanças fisiológicas (Ekman, 2011). 
com McCarter (1964), fornecem as primeiras evidências de grande concordância no julgamento das expressões de emoções entre diferentes juízes.

Diferentemente do que ocorre no Eyes-test, os estudos empíricos citados acima informam o método de desenvolvimento de seus estímulos e tem como regra utilizar expressões faciais de pessoas expostas a diferentes contextos eliciadores de estados afetivos. Nos primeiros estudos era pedido aos juízes que escolhessem uma resposta a partir de uma ampla gama de palavras que denominam emoções. Havia alguns problemas metodológicos tais como poucos modelos (pessoas que manifestavam a emoção), emoções posadas e não eliciadas, ou registro ao vivo (Tabela 1)

Com Ekman e Izard entre o final dos anos 1960 e início de 1970 é demonstrada a universalidade na interpretação das expressões e, posteriormente desenvolvidas medidas objetivas tanto do reconhecimento das expressões (Ekman, Sorenson \& Friesen, 1969; Ekman \& Rosenberg,1997), quanto de suas manifestações (Ekman \& Friesen, 1971; Izard, 1977), além de uma preocupação maior com metodologia, validade e fidedignidade (Ekman, 1982), sendo considerado até o momento referência na área por seu rigor metodológico. Em que pesem as diferenças nos arranjos experimentais e acurácia dos métodos, os achados entre as categorias das emoções permaneceram relativamente estáveis conforme observado na Tabela 2. 
Tabela 1. Métodos empregados nos estudos de Woodworth, Plutchik, Tomkins \& McCarter, Osgood e Fridja. (Ekman, Friesen, \& Ellsworth, 1972)

\begin{tabular}{|c|c|c|c|c|c|}
\hline & $\begin{array}{c}\text { Woodworth } \\
1938\end{array}$ & $\begin{array}{c}\text { Plutchik } \\
1962\end{array}$ & $\begin{array}{c}\text { Tomkins \& } \\
\text { McCarter } \\
1964\end{array}$ & $\begin{array}{l}\text { Osgood } \\
1966\end{array}$ & $\begin{array}{c}\text { Fridja } \\
1968\end{array}$ \\
\hline Modelos & 1 & 2 & 11 & 5 & 2 \\
\hline $\begin{array}{l}\text { Número de } \\
\text { emoções } \\
\text { posadas }\end{array}$ & 10 & $*$ & 8 & 40 & $\begin{array}{c}\text { Não } \\
\text { informado }\end{array}$ \\
\hline $\begin{array}{l}\text { Número de } \\
\text { estímulos }\end{array}$ & 19 & 26 & 69 & 200 & 130 \\
\hline $\begin{array}{l}\text { Número de } \\
\text { Palavras para } \\
\text { emoções }\end{array}$ & 10 & 8 & 8 & 40 & 100 \\
\hline $\begin{array}{c}\text { Método } \\
\text { utilizado para a } \\
\text { escolha das } \\
\text { emoções ou } \\
\text { palavras }\end{array}$ & $\begin{array}{c}\text { Mais } \\
\text { freqüentemente } \\
\text { escolhidas em } \\
\text { uma lista de } 107 \\
\text { palavras }\end{array}$ & Teoria & Teoria & $\begin{array}{l}\text { Literatura } \\
\text { anterior }\end{array}$ & $\begin{array}{c}\text { Não } \\
\text { informado }\end{array}$ \\
\hline $\begin{array}{l}\text { Circunstâncias } \\
\text { Eliciadoras }\end{array}$ & Pose & $*$ & Pose & Pose & Pose \\
\hline $\begin{array}{l}\text { Técnica de } \\
\text { registro }\end{array}$ & Parado & Parado & Parado & Ao vivo & Parado \\
\hline Evidência & $\begin{array}{c}\text { Correlação } \\
\text { entre a intenção } \\
\text { do modelo e } \\
\text { interpretação do } \\
\text { juiz }\end{array}$ & $* *$ & $\begin{array}{l}\text { Concordância } \\
\text { entre os juízes }\end{array}$ & $\begin{array}{c}\text { Análise } \\
\text { Fatorial e } \\
\text { análise de } \\
\text { Cluster }\end{array}$ & $\begin{array}{l}\text { Análise } \\
\text { Fatorial }\end{array}$ \\
\hline
\end{tabular}


Tabela 2. Categorias de Emoções propostas por Woodworth, Plutchik, Tomkins \& McCarter, Osgood, Fridja e Ekman. (Ekman, Friesen, \& Ellsworth, 1972)

\begin{tabular}{|c|c|c|c|c|c|}
\hline $\begin{array}{c}\text { Woodworth } \\
1938\end{array}$ & $\begin{array}{c}\text { Plutchik } \\
1962\end{array}$ & $\begin{array}{c}\text { Tomkins \& } \\
\text { McCarter } \\
1964\end{array}$ & $\begin{array}{c}\text { Osgood } \\
1966\end{array}$ & $\begin{array}{c}\text { Fridja } \\
1968\end{array}$ & $\begin{array}{c}\text { Ekman } \\
1972\end{array}$ \\
\hline $\begin{array}{l}\text { Amor } \\
\text { Júbilo } \\
\text { Alegria }\end{array}$ & $\begin{array}{c}\text { Tranquilidade/quietude } \\
\text { Alegria } \\
\text { Felicidade }\end{array}$ & $\begin{array}{l}\text { Prazer } \\
\text { Alegria }\end{array}$ & $\begin{array}{c}\text { Complacência } \\
\text { Tranquilidade } \\
\text { com prazer } \\
\text { Prazer } \\
\text { Deleite } \\
\text { Riso } \\
\text { preocupado }\end{array}$ & Alegria & Felicidade \\
\hline Surpresa & $\begin{array}{c}\text { Surpresa } \\
\text { Espanto } \\
\text { Perplexidade }\end{array}$ & $\begin{array}{l}\text { Surpresa } \\
\text { Alarme }\end{array}$ & $\begin{array}{c}\text { Surpresa } \\
\text { Espanto } \\
\text { Incompreensão } \\
\text { Pasmo }\end{array}$ & Surpresa & Surpresa \\
\hline \multirow{3}{*}{ Sofrimento } & $\begin{array}{l}\text { Apreensão } \\
\text { Medo } \\
\text { Terror }\end{array}$ & $\begin{array}{l}\text { Medo } \\
\text { Terror }\end{array}$ & $\begin{array}{l}\text { Medo } \\
\text { Horror }\end{array}$ & Medo & Medo \\
\hline & \multirow[t]{2}{*}{$\begin{array}{l}\text { Pensativo } \\
\text { Tristeza } \\
\text { Pesar }\end{array}$} & \multirow[t]{2}{*}{$\begin{array}{l}\text { Sofrimento } \\
\text { Angústia }\end{array}$} & $\begin{array}{c}\text { Desespero } \\
\text { Entediado } \\
\text { Tristeza } \\
\text { sonhadora } \\
\end{array}$ & \multirow[t]{2}{*}{ Triste } & \multirow[t]{2}{*}{ Tristeza } \\
\hline & & & $\begin{array}{c}\text { Tristeza intensa } \\
\text { Desespero }\end{array}$ & & \\
\hline $\begin{array}{c}\text { Raiva } \\
\text { Determinação }\end{array}$ & $\begin{array}{l}\text { Aborrecimento } \\
\text { Raiva } \\
\text { Ira }\end{array}$ & $\begin{array}{l}\text { Raiva } \\
\text { Ira }\end{array}$ & $\begin{array}{c}\text { Raiva Sombria } \\
\text { Ira } \\
\text { Teimosia } \\
\text { Determinação }\end{array}$ & Raiva & Raiva \\
\hline \multirow[t]{3}{*}{ Desdém } & $\begin{array}{l}\text { Cansativo } \\
\text { Nojo } \\
\text { Ódio }\end{array}$ & $\begin{array}{c}\text { Nojo } \\
\text { Desdém }\end{array}$ & $\begin{array}{c}\text { Aborrecimento } \\
\text { Nojo } \\
\text { Desdém } \\
\text { Desprezo } \\
\text { Ódio } \\
\end{array}$ & Nojo & $\begin{array}{l}\text { Nojo } \\
\text { /Desdém }\end{array}$ \\
\hline & $\begin{array}{c}\text { Atenção } \\
\text { Expectativa } \\
\text { Antecipação }\end{array}$ & $\begin{array}{l}\text { Interesse } \\
\text { Excitação }\end{array}$ & $\begin{array}{l}\text { Expectativa } \\
\text { Interesse }\end{array}$ & Atenção & Interesse \\
\hline & $\begin{array}{c}\text { Aceitação } \\
\text { Incorporação }\end{array}$ & $\begin{array}{l}\text { Vergonha } \\
\text { Humilhação }\end{array}$ & $\begin{array}{c}\text { Pena } \\
\text { Desconfiança } \\
\text { Ansiedade }\end{array}$ & $\begin{array}{c}\text { Calma } \\
\text { Amargo } \\
\text { Orgulho } \\
\text { Ironia } \\
\text { Insegurança } \\
\text { Ceticismo }\end{array}$ & \\
\hline
\end{tabular}


Muito embora, os estudos transculturais citados anteriormente visassem buscar universais culturais, as fotografias produzidas nos estudos de Paul Ekman e colaboradores, foram utilizadas em ao menos dois trabalhos em populações com TEA e indicaram diferenças no processamento de diferentes partes do rosto. Um estudo de 1988 indicou que os autistas foram superiores ao grupo controle no reconhecimento de emoções em fotografias invertidas e inferiores para reconhecimento de emoções quando foram excluídas as regiões da testa e da boca de maneira estatisticamente significativa (Hobson, Ouston \& Lee, 1988) e em 2008, Adolphs e colaboradores, em um experimento com 53 pais de crianças com diagnostico de TEA e 20 pais de crianças com desenvolvimento típico, onde foram encontradas diferenças estatisticamente significativas em relação ao reconhecimento de emoções também na região dos olhos (Adolphs, Spezio, Parlier \& Piven, 2008). Esses estudos indicam que a escolha desta região do rosto poderia ser um método sensível de discriminação entre grupos controle e experimental.

Com propósito diferente dos instrumentos supracitados, desde o seu desenvolvimento, o Eyes-test foi extensamente utilizado em populações clínicas. A versão original tem 25 fotografias de região de olhos, e se pede que o participante escolha entre os itens que nomeiam estados mentais complexos. Esse instrumento foi desenvolvido por Simon Baron-Cohen e publicado pela primeira vez em 1997 (Baron-Cohen, Jolliffe, Mortimore, \& Robertson, 1997), com duas possibilidades de respostas. Esta versão do instrumento foi utilizada em pelo menos seis estudos com diferentes grupos de pacientes, incluídos: transtornos de linguagem (Clegg, Hollis, Mawhood \& Rutter, 2005), Alzheimer e demência (Gregory et al, 2002), pacientes com lesões bilaterais de amígdala (Stone, BaronCohen, Calder, Keane \& Young, 2003) e psicopatas (Richell et al, 2003) 
Em 2001 foi publicada uma nova versão do teste, com 36 itens e quatro alternativas de resposta para cada item, diminuindo assim o "efeito teto" ${ }^{3}$ de alguns itens observado na versão original. Esta última versão é a comumente denominada como "Eyes-test", e é a mais utilizada em estudos com adultos. Estudos clínicos utilizando Eyes-test, em sua maioria, incluem indivíduos com transtornos do espectro do autismo (Baron-Cohen, Wheelwright, Hill et al, 2001; Craig, Hatton, Craig \& Bentall, 2004; Golan et al., 2006), mas foram avaliados também pacientes com esquizofrenia (Craig et al 2004; Irani et al, 2006, Kettle, O’Brien-Simpson \& Allen, 2008; Murphy, 2006; Bailey \& Henry, 2010; Bora, Yucel \& Pantelis, 2010), depressão (Kettle et al, 2008; Lee, Harkness, Sabbagh \& Jacobson, 2005), demência de Alzheimer (Henry et al, 2009), entre outros. Em outros estudos o Eyes-test foi utilizado em 950 voluntários normais, em seis países diferentes. Entre eles estão: avaliação do efeito da aplicação de ocitocina em voluntários (Domes, Heinrichs, Michael, Berger \& Herpertz, 2007); estudo de validade e fidedignidade do Quociente de Empatia (Lawrence, Shaw, Baker, Baron-Cohen \& David, 2004), compreensão de diferenças cognitivas entre estudantes de humanidades e ciências (Carroll \& Yung, 2006). A diversidade destas populações indica o entusiasmo com que o instrumento foi recebido na comunidade científica.

Em 2001, Baron-Cohen e colaboradores apresentam o Eyes-C, composto por 25 itens selecionados do Eyes-test e três fotografias adicionais (itens 1, 2 e 28) (Baron-Cohen, Wheelwright, Hill, Raste, \& Plumb, 2001) visando avaliar duas habilidades independentes que mais tarde dariam lugar ao modelo ES: psicologia intuitiva (folk psychology) e física

\footnotetext{
${ }^{3}$ Efeito-teto é observado na presença de itens muito fáceis com pouco poder discriminativo.
} 
intuitiva (folk physics) em crianças com SA. Ao contrário do Eyes-test, até onde se sabe, o Eyes-C foi aplicado apenas em estudos comparativos entre crianças normais e com TEA.

O comparativo entre os grupos clínicos e normais utilizando o Eyes-test e o Eyes-C tem demonstrado diferenças variáveis, mas significativas entre os grupos, sendo o grupo clínico com menores médias (Craig, Hatton, Craig \& Bentall, 2004; Golan et al., 2006; Irani et al, 2006, Kettle et al, 2008; Murphy, 2006; Baron-Cohen, Wheelwright, Hill, Raste, \& Plumb, 2001). No entanto, as diferenças numéricas tem sido pequenas e há uma considerável sobreposição da distribuição dos escores entre os grupos controle clínico (Hallerbäck et al, 2009)

Em 2009, Hallerbäck e colaboradores avaliaram a precisão teste-reteste do Eyes-C em universitários suecos. Foi encontrado um intervalo de confiança de \pm 4 pontos, de um total de 24 , uma vez que quatro itens foram excluídos, pois menos de $50 \%$ dos voluntários escolheram a alternativa correta (Hallerbäck et al, 2009)

\section{I.4.d.Modelos Cognitivos para o Autismo}

Ao contrário de outros instrumentos que visam auxiliar no diagnóstico clínico dos

TEA as versões do Eyes-test visam corroborar modelos cognitivos para esses transtornos. Uma teoria cognitiva para o autismo teria como objetivo reduzir as dezenas, ou mesmo centenas, de manifestações comportamentais dos transtornos do espectro do autismo a um ou dois processos mentais subjacentes, uma vez que é no nível cognitivo que se faz a mediação entre os processos neurobiológicos e comportamentais (Baron-Cohen, 2009).

\section{Cegueira Mental}


Uma das teorias mais citadas propõe que os autistas tem um "déficit em desenvolver uma ToM, deixando-os com níveis de MB. Como consequência, o comportamento das outras pessoas é confuso e imprevisível, e até mesmo, assustador.” (Baron-Cohen,2009). Os estudos utilizando este conceito se iniciaram em um artigo de 1985, testando o paradigma dos jogos de bonecos de Wimmer e Perner (1983) em um grupo de crianças normais e em um grupo de crianças com TEA. Neste modelo experimental os pesquisadores representam, utilizando bonecos, uma sequência de eventos: 1) A criança é apresentada às bonecas Sally e Anne. O pesquisador deve assegurar-se de que ela assimilou corretamente o nome de cada uma, então Sally coloca o seu brinquedo em uma cesta; 2) Sally sai de cena, e Anne transfere o brinquedo de lugar, escondendo-o em uma caixa; 3) Sally volta e o experimentador pergunta: "Onde Sally vai procurar o seu brinquedo?". Ao responder corretamente - que Sally irá procurar no cesto - a criança assinala que compreende que a boneca possui uma falsa crença (a localização do brinquedo) sendo capaz de assumir o ponto-de-vista de outra pessoa. Por outro lado se ela responde dando a localização atual do brinquedo - a caixa - pode-se inferir que ela não elaborou adequadamente uma ToM. Crianças autistas tipicamente falham nessa tarefa, enquanto crianças normais da mesma idade e com Síndrome de Down respondem corretamente (Baron-Cohen, Leslie \& Frith, 1985). A partir desse estudo os autores concluíram que os déficits sociais do autismo poderiam ser causados por um prejuízo em ToM. No Brasil crianças autistas tiveram um desempenho significativamente inferior a crianças normais na atribuição de estados mentais a partir de expressões de alegria, tristeza, raiva e surpresa em figuras de um jogo (Assumpção-Jr, Sprovieri, Kuczynski, \& Farinha, 1999) 
De acordo com Baron-Cohen (2009) há muitos argumentos favoráveis a teoria da cegueira mental:

"Primeiro, ela explica as dificuldades em comunicação no autismo e na Síndrome de Asperger, incluindo as os prejuízos em pragmática. Segundo, a cegueiramental é universal e aplica-se a todos os indivíduos do espectro do autismo. Terceiro lugar, exames de neuroimagem funcional identificou algumas áreas do cérebro fundamentais ao comportamento pró-social (...) Em quarto, atrasos no desenvolvimento de precursores de ToM (como atenção partilhada e faz-de-conta) tem se provado fortes precursores do diagnóstico de autismo" (Baron-Cohen 2009, p.70)

Uma das limitações deste modelo é que o déficit de ToM não parece ser exclusivo dos TEA, uma vez que indivíduos com esquizofrenia e Alzheimer, também apresentaram escores mais baixos em relação aos grupos controle no Eyes-test. Além disso crianças com deficiência mental de outras etiologias que não Síndrome de Down, tiveram desempenho compatível com os autistas ( Yirmiya et al, 1998 citado por Perner, 1999)

\section{Empatia-sistematização}

Um segundo modelo, decorrente da teoria MB, mas que tenta superar as limitações desta, propõe que dois traços, duas habilidades envolvidas na compreensão de causalidades - empatia e sistematização- estão presentes em toda a população e explicam não apenas a diferença nos graus de autismo, mas também a variação em desempenho, dependendo da natureza da tarefa, na população normal (Baron-Cohen \& Belmonte, 2005). A teoria ES utiliza uma das características marcantes dos TEA, os interesses restritos, que em muitos casos tornam-se "ilhas de habilidades": 
"De maneira sucinta, esta teoria afirma que indivíduos com autismo mantém intactas, ou mesmo superiores, habilidades de sistematização, mas apresentam deficiências em empatia" (Wheelwrigth \& Baron-Cohen, 2011, p. 317).

De acordo com este modelo sistematização é definida como "um impulso de compreender e construir um sistema" - este sendo definido "como tudo o que possa ser governado por regras que especificam a relação entre dado de entrada-operação-resultado" - (Baron-Cohen, 2003). De acordo com Wheelwright e Baron-Cohen (2011) em relação aos TEA, o modelo ES explica as falhas em empatia, repousando seu modelo em parte na teoria MB e em parte na teoria afetiva de Hobson (1986), uma vez que esta segunda preconiza a resposta emocional adequada em relação ao outro, por isso os autores a consideram mais abrangente do a ToM.

O modelo ES também explica algumas diferenças cognitivas encontradas entre os sexos: mulheres atingiriam melhor desempenho em tarefas que exigem empatia, tais como reconhecimento de emoções, enquanto homens seriam mais sistematizadores, com maiores habilidades em tarefas visomotoras e raciocínio espacial (Voyer, Voyer \& Bryden, 1995; Baron-Cohen, 2002; Connellan, Baron-Cohen, Wheelwright, Batki, Ahluwalia, 2000) . Através da perspectiva da psicologia evolucionista, a diferença de desempenho nas habilidades reflete a seleção ocasionada pela necessidade de divisão das tarefas na história evolutiva humana, com fêmeas cuidando predominantemente da prole e machos caçando (Baron-Cohen, 2003). Nos TEA, por sua vez, haveria uma diferença de grau em relação à média da população do sexo masculino, sendo este modelo também chamado de cérebro “extremamente masculino" (extreme male brain) (Baron-Cohen, 2002). 
Entre as evidências que sustentam este modelo teórico, da perspectiva das habilidades de empatia, estão: aos 12 meses meninas mantém mais contato visual que meninos ( Lutchmaya, Baron-Cohen et al 2001 citados por Wheelwright \& Baron-Cohen, 2011) e crianças com SA mantém menos contato visual do que meninos normais (Swettenham et al. , 1998 citados por Wheelwright \& Baron-Cohen, 2011), no testes de faux $\mathrm{pas}^{4}$ meninas acertam mais precocemente os itens do que os meninos, e estes mais precocemente que crianças com SA (Baron-Cohen, O’Riordan, et al., 1999). No que se refere à sistematização, nem sempre a mesma tendência se mantém, e pessoas com SA atingem os mesmos escores que a população masculina em geral (Baron-Cohen, 2011). No estudo de 2001 em que foi apresentado o Eyes-C, no entanto, foi encontrado um melhor desempenho de crianças com SA nos teste de "Física Intuitiva" (folk physics) (BaronCohen, Wheelwright, Hill, Raste, \& Plumb, 2001).

A ideia subjacente de que é possível sintetizar a constelação de sinais e sintomas observados nos TEA também está presente em outras duas teorias que, muito embora, não desfrutem da mesma popularidade, se inserem igualmente no campo da Psicologia Cognitiva e utilizam instrumentos da neuropsicologia:

- Coerência Central, de maneira sucinta, afirma que a dificuldade essencial dos indivíduos com TEA é uma inabilidade em organizar a informação em um todo coerente. Essa proposta surgiu a partir de dados de pesquisa que demonstraram que indivíduos com TEA tinham facilidade em encontrar detalhes (Shah \& Frith, 1993), mas que tinham dificuldades em compor um todo a partir de partes menores.

\footnotetext{
${ }^{4}$ Testes de faux pas buscam medir a capacidade do indivíduo em perceber e julgar corretamente gafes sociais.
} 
- Déficit de Função Executiva, por outro lado, propõe que os déficits primários do autismo poderiam ser explicados por prejuízos em flexibilidade mental, manutenção de setting, planejamento e memória de trabalho (Hughes, Russell \& Robbins, 1994)

\section{I.5.Justificativa}

Muito embora o Eyes-Test e o Eyes-C sejam utilizados no estudo com populações clínicas em diversos centros de pesquisa, indicando que os instrumentos são razoavelmente sensíveis para discriminar algumas populações clínicas, ainda são escassos os estudos acerca de suas propriedades psicométricas que fundamentem de maneira mais robusta as teorias cognitivas MB e SE para o autismo.

\section{I.6.Objetivos}

O objetivo geral da pesquisa é obter mais dados acerca da viabilidade de utilização o Eyes-C como instrumento de medida em populações com TEA com o intuito de melhor compreensão destes quadros. Os objetivos específicos são:

- Conhecer as propriedades psicométricas - em especial validade de construto e de critério - da uma versão em português do teste.

- Testar empiricamente as teorias MB e SE para a população brasileira.

- Hipótese experimental I: Indivíduos do sexo feminino possuem habilidades superiores de reconhecimento de expressões faciais de emoções, pois tem maiores habilidades de empatia. Se a hipótese experimental for verdadeira, ou seja, a média dos escores no Eyes-C dos participantes do sexo feminino 
for superior à do sexo masculino, será uma evidência empírica do modelo SE.

- Hipótese experimental II: Indivíduos com TEA possuem déficit no reconhecimento de expressões de faciais de emoções, pois possuem prejuízos em percepção social e por isso elaboram uma ToM de maneira ineficiente. Se a hipótese experimental for verdadeira, ou seja, os escores do grupo clínico serão inferiores ao grupo controle, esta será uma evidência empírica do modelo MB. 


\section{II.MATERIAL E MÉTODOS}

\section{II.1.Instrumento}

Foi utilizada uma versão traduzida para o português do Eyes-C (Baron-Cohen, Wheelwright, Hill, Raste, \& Plumb, 2001) buscando verificar a validade desse instrumento em mensurar a habilidade das crianças brasileiras em inferir estados mentais. O Eyes-C consiste de 29 pranchas - 28 itens e um exemplo - cada uma delas com uma foto, de homens e mulheres, que abrange a região dos olhos (versão do estudo no Apêndice A). Cada prancha possui, além da foto, quatro alternativas que descrevem estados mentais, situadas uma em cada canto da figura. O participante é orientado a escolher a alternativa que lhe parecer que melhor descreve a expressão facial. São utilizadas 40 expressões ou palavras como alternativas, 22 expressões constituem as respostas. $\mathrm{O}$ autor não informa a origem das fotografias, a escolha dos itens ou o contexto em que as emoções foram eliciadas.

A versão utilizada na pesquisa foi construída a partir das versões do espanhol e do inglês disponibilizadas pelo autor e sua instituição (Autism Research Center) em seu website. Foi feito contato por e-mail com o autor e obtidas as condições de uso do instrumento (Anexo A). As traduções foram executadas de maneira separada por indivíduos proficientes nas duas línguas e submetidas a três juízes independentes. Os tradutores submeteram sua tradução aos juízes, quando a palavra em português era diferente nas duas versões, permaneceu a alternativa considerada a mais comum em português do Brasil por pelo menos dois dos juízes. Posteriormente foi feito um estudo piloto com 18 crianças de 10 anos do município de Cotia, com o objetivo de detectar e corrigir dificuldades de 
compreensão das palavras que compõe as alternativas nos itens do instrumento. As crianças não demonstraram dificuldades de entendimento, portanto nenhum dos itens foi corrigido.

\section{II.2.Método}

$\mathrm{O}$ estudo foi dividido em duas etapas de acordo com as propriedades psicométricas estudadas e a população avaliada:

Etapa I - Estudo da validade de construto e teste da Hipótese Experimental I

a) Aplicação Coletiva: 392 participantes do grupo controle. Foi feita a projeção em transparência dos itens do teste em uma tela. Cada criança recebeu uma folha de resposta para responder individualmente. As alternativas foram lidas em voz alta duas vezes pela pesquisadora.

b) Aplicação Individual: 42 participantes do grupo controle. A pesquisadora leu em voz alta e pediu que a criança escolhesse, verbalizando, uma alternativa. A pesquisadora anotava então a resposta.

Etapa II - Estudo exploratório de validade de critério e teste da Hipótese Experimental II

a) Aplicação Individual: 20 participantes do grupo clínico.

\section{II.3.Participantes}

Etapa I (Grupo Controle): 434 crianças, de ambos os sexos cursando escolas públicas de Brusque (SP) e São Paulo (SP). 
- Critérios de inclusão: idades entre seis e 13 anos, cujos pais autorizassem a pesquisa assinando o Termo de Consentimento Livre e Esclarecido (Anexo B);

- Critério de exclusão: apresentar diagnóstico psiquiátrico ou de transtorno de desenvolvimento documentado.

Etapa II (Grupo Clínico): 20 crianças, inscritas no Laboratório Distúrbios do Desenvolvimento do Instituto de Psicologia da Universidade de São Paulo (PDD IPUSP), na Secretaria Municipal da Saúde de Brusque ou na Associação dos Amigos do Excepcional (APAE) do Município de Cotia (Apêndice B).

- Critérios de inclusão: terem sido diagnosticadas no PDD IPUSP como apresentando um dos Transtornos Invasivos do Desenvolvimento (TID) de acordo com os critérios do DSM IV-TR, obter pontuação acima de 23 na Escala de Traços Autísticos (ATA) (Assumpção-Jr et al, 2008) (Anexo C) e 33 pontos na Escala de Pontuação do Autismo (CARS) (Matteo, Cuccolichio, Paicheco, Gomes, Simone, \& Assumpção-Jr, 2009) (Anexo D), desempenho igual ou acima da classificação Médio Inferior (oito Pontos Ponderados) no subteste Vocabulário na Escala de Inteligência Weschler para Crianças - $3^{\mathrm{a}}$ Edição (WISC III) (Weschler, 1991), idades entre seis e 13 anos na época da pesquisa, cujos pais autorizassem a participação na pesquisa assinando o Termo de Consentimento Livre e Esclarecido;

- Critérios de exclusão: ter sido diagnosticada comorbidade psiquiátrica documentada na época da pesquisa, apresentar respostas com função de esquiva de demanda que prejudicassem a fidedignidade do escore no Eyes-C. 


\section{II.4.Aspectos éticos}

A pesquisa foi aprovada pelo Comitê de Ética em Pesquisa com seres humanos da Faculdade de Ciências da Saúde de São Paulo (Registro no Ministério da Saúde nº 250047041/2007-74) em ofício no 55/2011.

\section{II.5.Análise dos dados}

Os dados foram analisados estatisticamente utilizando o pacote estatístico SPSS 12.0 para Windows. Através de um histograma e análise de variância foi verificada a distribuição paramétrica dos dados - distribuição dos dados em uma curva normal- para a escolha dos modelos estatísticos apropriados, a saber, Teste t, ANOVA e correlação Pearson. Na Etapa I, para análise diferenças estatisticamente significativas entre duas condições foi utilizado o Teste t, para comparação dos escores de acordo com os critérios forma de aplicação (coletiva e individual), região (São Paulo e Brusque) e sexo (masculino e feminino). Para comparação entre os escores de acordo com o critério Ano Escolar, foi utilizado o método ANOVA, adequado para comparação entre mais de duas condições, neste caso os primeiros cinco anos dos ciclo Fundamental. Com o intuito de calcular a magnitude do grau de relacionamento entre as variáveis idade e escore foi utilizada a correlação Pearson. Para análise da Validade de Construto foram calculados ainda a alfa de Cronbach - total e com exclusão de itens - com o intuito de se obter uma medida de consistência interna do teste, e a análise fatorial dos itens através do método de rotação Varimax.

Na Etapa II foi feito um comparativo através do Teste $t$ entre os escores e idade do grupo controle e experimental com o objetivo determinar a validade de critério do Eyes-C. 


\section{RESULTADOS}

\section{III.1.Etapa I}

Com o intuito de se conhecer a distribuição dos escores foi construído o histograma e calculada a curva de Gauss (Figura 2), embora não se tenha verificado a ocorrência de uma distribuição normal perfeitamente simétrica, foram observadas homogeneidades nas variâncias dos grupos e a inexistência de escores extremos. Optou-se, portanto, pelos modelos estatísticos para amostras paramétricas, mais poderosos para detectar diferenças entre populações.

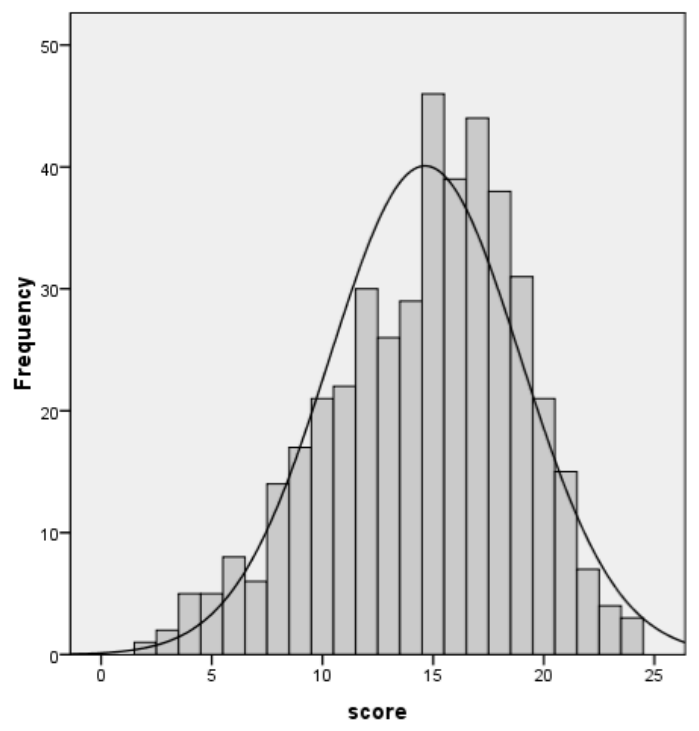

Figura 2. Histograma e curva de Gauss dos escores do grupo controle.

Foi feito um estudo exploratório entre as formas de aplicação coletiva e individual. Através do Teste t efetuado um comparativo entre os escores de acordo com a forma de aplicação e a idade dos participantes foi utilizada como critério de homogeneidade entre os grupos. 
Tabela 3. Comparativo entre escores e idade nas formas de aplicação coletiva e individual

\begin{tabular}{|c|c|c|c|c|}
\hline & & \multicolumn{2}{|c|}{ Forma de Aplicação } & \multirow{2}{*}{$\begin{array}{r}\text { Teste t } \\
\text { (p) }\end{array}$} \\
\hline & & $\begin{array}{l}\text { Individual } \\
\qquad(\mathrm{N}=42)\end{array}$ & $\begin{array}{l}\text { Coletiva } \\
(\mathrm{N}=392)\end{array}$ & \\
\hline \multirow{3}{*}{ Escore } & Média & 14,60 & 14,95 & \multirow{2}{*}{0,618} \\
\hline & Desvio-padrão & 3,81 & 4,37 & \\
\hline & Média & 8,97 & 8,7 & \multirow{2}{*}{0,253} \\
\hline Idade & Desvio-padrão & 1,76 & 1,76 & \\
\hline
\end{tabular}

Não foram encontradas diferenças significativas nos escores entre as formas de aplicação coletiva e individual do Eyes-C entre as idades dos participantes dos dois grupos.

Através do Teste $t$ foi feito um comparativo entre os escores de acordo com a região dos participantes da pesquisa, e novamente a idade foi utilizado um critério de homogeneidade entre as amostras. 
Tabela 4. Comparativo dos escores e idade dos participantes de São Paulo e Brusque.

\begin{tabular}{|c|c|c|c|c|}
\hline & & \multicolumn{2}{|c|}{ Cidade } & \multirow{2}{*}{$\begin{array}{l}\text { Teste t } \\
\text { (p) }\end{array}$} \\
\hline & & $\begin{array}{l}\text { São Paulo } \\
(\mathrm{N}=\mathbf{2 0 2})\end{array}$ & $\begin{array}{l}\text { Brusque } \\
(\mathrm{N}=232)\end{array}$ & \\
\hline \multirow{3}{*}{ Escore } & Média & 15,10 & 14,22 & \multirow{2}{*}{0,035} \\
\hline & Desvio-padrão & 4,73 & 3,88 & \\
\hline & Média & 8,86 & 9,01 & \multirow{2}{*}{0,336} \\
\hline Idade & Desvio-padrão & 1,67 & 1,58 & \\
\hline
\end{tabular}

Não foram encontradas diferenças significativas entre os escores e idade entre participantes de São Paulo e Brusque.

Visando verificar a validade por hipótese, foram analisados os escores no Eyes-C por sexo, uma vez que, de acordo com o modelo SE, as mulheres, em média, teriam mais facilidade no reconhecimento de emoções.

Tabela 5. Comparativo dos escores por sexo dos participantes.

\begin{tabular}{|c|c|c|c|c|c|}
\hline & & \multirow[b]{2}{*}{$\begin{array}{c}\text { Total } \\
(\mathrm{N}=434)\end{array}$} & \multicolumn{2}{|c|}{ Sexo } & \multirow{2}{*}{$\begin{array}{r}\text { Teste t } \\
\text { (p) }\end{array}$} \\
\hline & & & $\begin{array}{c}\text { Masculino } \\
(\mathrm{N}=\mathbf{2 1 8})\end{array}$ & $\begin{array}{l}\text { Feminino } \\
(\mathrm{N}=216)\end{array}$ & \\
\hline \multirow{3}{*}{ Escore } & Média & 14,63 & 14,65 & 14,62 & \multirow{2}{*}{0,900} \\
\hline & Desvio-padrão & 4,31 & 4,34 & 4,29 & \\
\hline & Média & 8,94 & 9,06 & 8,82 & \multirow{2}{*}{0,659} \\
\hline Idade & Desvio-padrão & 1,62 & 1,71 & 1,52 & \\
\hline
\end{tabular}


Não foram encontradas diferenças significativas entre os escores dos participantes de sexo masculino e feminino.

Com o intuito de verificar a validade de construto do Eyes-C, o alfa de Cronbach foi utilizado como forma de análise da consistência interna, que consiste na verificação da homogeneidade dos itens que compõe o teste. O escore total do teste se torna o critério de decisão, e a correlação do item com a pontuação total é um sumário desta correlação (Pasquali, 2009). O alfa de Cronbach encontrado foi de 0,718, índice considerado satisfatório. Foi calculado também o impacto sobre o índice no caso da retirada de cada um dos itens (Tabela 6). 
Tabela 6. Valor de alfa de Cronbach com retirada do item do Eyes-C

\begin{tabular}{cccc}
\hline Item & Alfa de Cronbach se o item for excluído & Item & Alfa de Cronbach se o item for excluído \\
\hline Item 1 & 0,711 & Item 15 & 0,708 \\
Item 2 & 0,712 & Item 16 & 0,711 \\
Item 3 & 0,710 & Item 17 & 0,711 \\
Item 4 & 0,711 & Item 18 & 0,707 \\
Item 5 & 0,718 & Item 19 & 0,708 \\
Item 6 & 0,717 & Item 20 & 0,707 \\
Item 7 & 0,713 & Item 21 & 0,707 \\
Item 8 & 0,704 & Item 22 & 0,707 \\
Item 9 & 0,709 & Item 23 & 0,706 \\
Item 10 & 0,707 & Item 24 & 0,709 \\
Item 11 & 0,707 & Item 25 & 0,715 \\
Item 12 & 0,710 & Item 26 & 0,713 \\
Item 13 & 0,710 & Item 27 & 0,712 \\
Item 14 & 0,711 & Item 28 & 0,711 \\
\hline
\end{tabular}

Não houve incremento do índice com retirada dos itens, indicando que todos os itens contribuem de maneira similar para o escore total.

Também com o intuito de verificar a validade de construto, foi feita uma análise fatorial exploratória por componentes principais e rotação Varimax (Kaiser) que admitiu cargas fatoriais maiores que 0,40. Verificou-se que 10 fatores explicam 55,73\% da variabilidade total dos dados. A distribuição dos itens entre os 10 fatores ocorreu de maneira heterogênea com muitos itens com altas cargas nos Fatores 1 e 2, e nenhum item 
com carga satisfatória nos fatores 7 e 8 . Os itens 6 e 17 obtiveram cargas fatoriais inferiores a $0,40 \mathrm{em}$ todos os fatores, conforme descrito a seguir:

- Itens 4,8,12,18,20,22,23,24 e 27 - predominam na definição do Fator 1

- Itens $1,3,5,11,13,19,21$ e 25 - predominam na definição do Fator 2

- Itens 25 e 26 - predominam na definição do Fator 3

- Item 8 - predomina na definição do Fator 4

- Itens 10 e 4 - predominam na definição do Fator 5

- Item 16 - predominam na definição do Fator 6

- Itens 7 e 3 - predominam na definição do Fator 9

- Item 2 - predomina na definição do Fator 10

Posteriormente verificou-se uma solução com seis fatores, baseado no modelo de seis emoções básicas. Este número de fatores que explicaram 40,78\% da variabilidade. Através do método de rotação dos fatores Varimax, a co-variância de cada fator com os itens são apresentadas abaixo por meio das cargas fatoriais que foram consideradas significativamente determinantes para um fator quando apresentaram valores aproximados a 0,40 ou mais (Tabela 7). Conforme se observa os itens 7, 9, 18, 20, 24 e 27 obtiveram cargas fatoriais inferiores a $0,40 \mathrm{em}$ todos os fatores. 
A distribuição dos itens ocorreu da seguinte forma (Tabela 7, na próxima página):

- Itens 2, 3, 5, 12 e 22 - predominam na definição do Fator 1

- Itens 6, 11, 19, 25 e 28 - predominam na definição do Fator 2

- Itens 10, 13, 15, 21 e 23 - predominam na definição do Fator 3

- Itens 14 e 17 - predominam na definição do Fator 4

- Itens $1,3,8$ e 16 - predominam na definição do Fator 5

- Item 26 - predomina na definição do Fator 6

De acordo com as palavras que representam as emoções temos:

- Fator 1: triste, simpático, persuasivo, sério, contente.

- Fator 2: preocupado, esperançoso, interessado, preocupado, contente.

- Fator 3: duvidando, persuasivo, incrédulo, interessado, amável.

- Fator 4: pensativo, um pouco preocupado.

- Fator 5: amável, simpático, lembrando de alguma coisa, decidido.

- Fator 6: nervoso. 
Tabela 7. Carga Fatorial para solução de 6 fatores

\begin{tabular}{|c|c|c|c|c|c|c|}
\hline \multirow{2}{*}{ Item } & \multicolumn{6}{|c|}{ Fator } \\
\hline & 1 & 2 & 3 & 4 & 5 & 6 \\
\hline 1 & $-0,205$ & 0,141 & 0,157 & 0,053 & $\underline{0,525}$ & $-0,206$ \\
\hline 2 & $\underline{0,551}$ & 0,034 & $-0,022$ & $-0,007$ & 0,036 & 0,183 \\
\hline 3 & $-0,347$ & $-0,005$ & 0,242 & 0,143 & $\mathbf{0 , 4 8 7}$ & 0,105 \\
\hline 4 & $\underline{0,614}$ & $-0,123$ & 0,153 & $-0,055$ & 0,109 & $-0,068$ \\
\hline 5 & $\underline{-0,645}$ & 0,320 & 0,145 & $-0,131$ & 0,133 & 0,207 \\
\hline 6 & 0,329 & $\mathbf{- 0 , 4 0 0}$ & $-0,009$ & 0,006 & 0,155 & $-0,040$ \\
\hline 7 & 0,246 & $-0,130$ & 0,052 & 0,152 & 0,231 & $-0,029$ \\
\hline 8 & 0,280 & $-0,024$ & 0,200 & 0,178 & $\underline{\mathbf{0 , 5 2 7}}$ & 0,013 \\
\hline$\underline{9}$ & 0,085 & 0,237 & 0,012 & 0,390 & 0,303 & $-0,286$ \\
\hline 10 & 0,068 & $-0,025$ & $\underline{0,682}$ & 0,001 & 0,118 & $-0,214$ \\
\hline 11 & 0,073 & $\underline{0,469}$ & 0,260 & 0,036 & 0,176 & $-0,092$ \\
\hline 12 & 0,549 & 0,000 & 0,058 & 0,412 & $-0,143$ & $-0,185$ \\
\hline 13 & $-0,296$ & 0,353 & $\underline{0,434}$ & $-0,021$ & 0,177 & 0,103 \\
\hline 14 & $-0,046$ & $-0,024$ & $-0,058$ & $\underline{0,620}$ & 0,043 & 0,232 \\
\hline 15 & 0,302 & $-0,023$ & $\underline{\mathbf{0 , 5 7 0}}$ & $-0,037$ & $-0,148$ & 0,316 \\
\hline 16 & 0,252 & 0,223 & $-0,186$ & $-0,185$ & $\underline{0,622}$ & 0,192 \\
\hline 17 & 0,059 & $-0,073$ & 0,012 & $\underline{0,520}$ & $-0,013$ & $-0,003$ \\
\hline$\underline{18}$ & 0,183 & $-0,133$ & 0,258 & 0,356 & 0,216 & 0,185 \\
\hline 19 & $-0,133$ & $\underline{0,462}$ & 0,067 & 0,344 & 0,130 & $-0,096$ \\
\hline$\underline{20}$ & 0,336 & $-0,089$ & 0,234 & 0,358 & 0,143 & 0,105 \\
\hline 21 & $-0,110$ & 0,298 & $\underline{0,520}$ & 0,059 & 0,083 & 0,241 \\
\hline 22 & $\underline{0,425}$ & 0,171 & 0,165 & 0,278 & 0,026 & 0,049 \\
\hline 23 & 0,130 & 0,105 & $\underline{0,461}$ & 0,188 & 0,151 & $-0,208$ \\
\hline$\underline{24}$ & 0,262 & 0,135 & 0,135 & 0,355 & 0,102 & $-0,283$ \\
\hline 25 & $-0,228$ & $\underline{0,551}$ & 0,154 & $-0,105$ & 0,032 & 0,006 \\
\hline 26 & $-0,002$ & 0,075 & 0,008 & 0,178 & 0,039 & $\underline{\mathbf{0 , 7 2 9}}$ \\
\hline$\underline{27}$ & 0,297 & $-0,354$ & 0,111 & 0,205 & 0,174 & $-0,096$ \\
\hline 28 & 0,217 & $\mathbf{0 , 6 3 4}$ & $-0,078$ & $-0,053$ & 0,057 & 0,052 \\
\hline
\end{tabular}

Uma vez que o traço latente que se deseja conhecer - ToM - sofre um incremento durante a ontogênese, foi calculada a correlação Pearson entre idade dos participantes 
escore no Eyes-C e encontrado um valor igual 0,440. Este achado indica a existência de uma correlação positiva e satisfatória entre os escores do Eyes-C e idade.

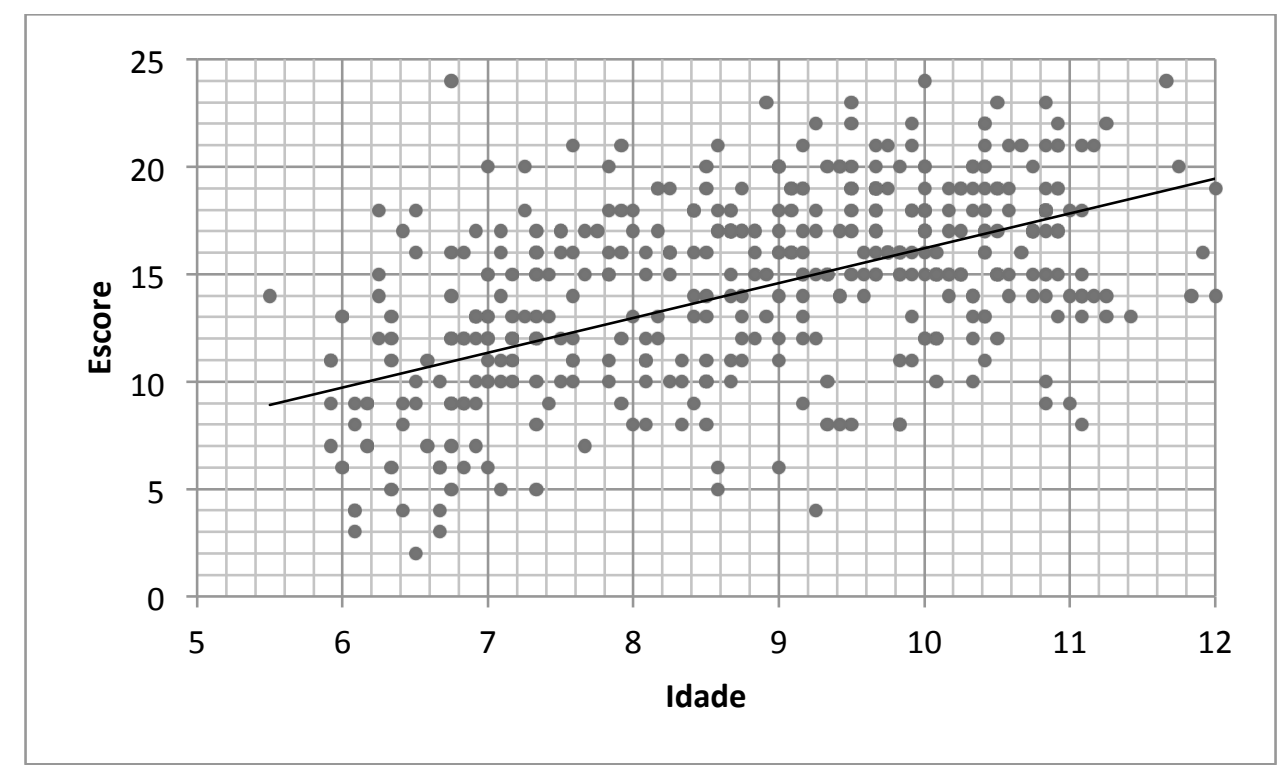

Figura 3. Gráfico dos escores no Eyes-C pela idade dos participantes. A reta representa a tendência dos dados.

Com o intuito de se avaliar se existem diferenças estatisticamente significativas de acordo com o critério ano escolar foi calculado o intervalo de confiança (95\%) de cada ano (Tabela 8)

Tabela 8. Intervalo de confiança dos escores do Eyes-C de acordo com o ano Escolar

\begin{tabular}{ccccc}
\multirow{2}{*}{ Ano Escolar } & \multicolumn{2}{c}{ Intervalo de Confiança (95\%) } & \multirow{2}{*}{ Mínimo } & \multirow{2}{*}{ Máximo } \\
\cline { 2 - 3 } & Limite inferior & Limite Superior & & \\
\hline $1^{\text {o }}$ & 9,96 & 11,48 & 2 & 18 \\
$2^{\text {o }}$ & 13,29 & 15,21 & 6 & 24 \\
$3^{\text {o }}$ & 14,75 & 16,38 & 4 & 23 \\
$4^{\text {o }}$ & 15,36 & 16,74 & 8 & 24 \\
$5^{\text {o }}$ & 16,26 & 17,74 & 8 & 24 \\
Total & 14,23 & 15,04 & 2 & 24 \\
\hline
\end{tabular}


Através do método ANOVA foi avaliada a variância de acordo com o critério ano escolar foi encontrado um $\mathrm{F}=42,04 \quad(\mathrm{p}<0,001)$, indicando que existem diferenças estatisticamente significativas nos escores de acordo com este critério.

\section{III.2.Etapa II}

A segunda etapa consistiu em estudo exploratório da Validade de Critério do EyesC, observando se o teste é capaz de diferenciar grupo clínico e grupo controle, e se é possível determinar uma pontuação de corte e, consequentemente, inferir sua especificidade e sensibilidade. Para isso foi feito um estudo comparativo entre os escores do grupo clínico e grupo controle (Tabela 9).

Tabela 9. Comparativo entre os grupos controle e clínico.

\begin{tabular}{|c|c|c|c|c|}
\hline & & \multicolumn{2}{|c|}{ Grupo } & \multirow{2}{*}{$\begin{array}{r}\text { Teste t } \\
\text { (p) }\end{array}$} \\
\hline & & $\begin{array}{l}\text { Controle } \\
(\mathrm{N}=432)\end{array}$ & $\begin{array}{l}\text { Clínico } \\
(\mathrm{N}=\mathbf{2 0})\end{array}$ & \\
\hline \multirow{3}{*}{ Escore } & Média & 14,63 & 13,90 & \multirow{2}{*}{0,500} \\
\hline & Desvio-padrão & 4,31 & 4,19 & \\
\hline & Média & 8,94 & 9,50 & \multirow{2}{*}{0,490} \\
\hline Idade & Desvio-padrão & 1,62 & 2,00 & \\
\hline
\end{tabular}


Não foram encontradas diferenças significativas entre os escores no Eyes-C do grupo clínico e controle, indicando que não é possível estabelecer uma pontuação de corte, abaixo da qual existe maior probabilidade do participante possuir diagnóstico de TEA. 


\section{IV.DISCUSSÃO}

Os Eyes-test e Eyes-C são de fácil aplicação, correção e estão disponibilizados em mais de 20 línguas no site da instituição do autor principal. O corpus teórico que o embasa associa de maneira elegante conhecimentos da primatologia, neurociências e psicologia cognitiva. No entanto, como todo instrumento de medida em psicologia, o seus índices de confiabilidade devem ser dados pela psicometria com o intuito de fornecer evidências para a teoria psicológica que o fundamenta.

Do ponto de vista de construção dos itens, no que se refere à Consistência Interna, o Eyes-C apresentou índice de Alfa de Cronbach de 0,718 considerado satisfatório, indicando que se trata de um instrumento homogêneo, e que todos os itens contribuem de maneira semelhante para o escore final.

Ainda analisando a Validade de Construto, ao se reduzir, através da Análise Fatorial, em seis fatores fundamentados no modelo de seis emoções básicas, não foi possível identificar o fator predominante nos agrupamento dos itens. Embora alguns estados emocionais iguais ou semelhantes apareçam sob um mesmo fator (duvidando e incrédulo - fator 2; pensativo e um pouco preocupado- fator 4, por exemplo) em outros itens isso não ocorre (triste e contente- fator 1, por exemplo). Uma vez que não existem dados disponíveis acerca do desenvolvimento e escolha dos itens - tanto as fotografias quanto as palavras escolhidas para nomeá-las - o agrupamento heterogêneo dos itens pode ter ocorrido por problemas em seu desenvolvimento levando a uma interpretação errônea por parte dos participantes. Um dos indicadores que contribuem para esta hipótese foi o percentual de erros nos itens: em 13 dos 28 itens (46\%) que compõe o Eyes-C, o número de acertos dos participantes foi inferior a $50 \%$, indicando que mais da metade dos participantes 
não reconheceram a emoção representada, índice superior ao encontrado por Hallerbäck et al (2009).

Foi verificado que os escores do Eyes-C sofreram um incremento de acordo com idade cronológica de 44\%, índice considerado satisfatório. Esse dado está em acordo com a hipótese de aumento da complexidade das habilidades relacionadas à cognição social durante o desenvolvimento, que inclui a maior precisão na identificação de emoções mistas, como as apresentadas no Eyes-C. No entanto, foram encontradas diferenças significativas entre as médias de acordo com o critério ano escolar, indicando que crianças com maior escolaridade obtiveram mais acertos. Possivelmente isso se deve ao aumento das habilidades linguísticas que acompanham a escolarização, de onde se infere que o reconhecimento e nomeação de expressões sofre um efeito significativo da aprendizagem no âmbito formal.

Efeito similar foi encontrado no teste de falsa-crença: em artigo de revisão, Happé (1995) verifica a relação entre Idade Mental Verbal e este teste em crianças com TEA e em crianças com desenvolvimento normal. Em ambos os grupos, quanto maior a Idade Mental Verbal maior a probabilidade de acerto no teste. Embora nos TEA fossem necessárias maiores habilidades linguísticas para se obter a mesma probabilidade de acerto das crianças sem transtorno, esses dados sugerem que os efeitos de idade cronológica observados podem apenas refletir o desenvolvimento linguístico dos participantes, passível de aprendizagem e influenciados pelo ambiente cultural, e não necessariamente módulos cognitivos inatos, com desenvolvimento análogo aos marcos do desenvolvimento neuropsicomotor.

No que se refere à Validade Concorrente, no estudo exploratório com 20 indivíduos diagnosticados com TEA não foram encontradas diferenças significativas nos escores do 
Eyes-C em relação aos escores do grupo controle, sendo este um indício que o instrumento não é adequado para discriminação entre grupos com e sem TEA em nosso meio, de onde decorre que os resultados não corroboram a hipótese da teoria MB. Em outras palavras, as crianças do grupo clínico estudado não tiveram mais dificuldade do que as crianças do grupo controle para identificar a alternativa correta para a emoção, portanto, infere-se que os prejuízos em interação social não se devem a déficits em percepção e nomeação de estados mentais - percepção social - nesta faixa etária.

No estudo original de 2001 com 15 crianças diagnosticadas com AS e 103 normais, os autores informam que as crianças do grupo experimental residiam na escola especializada em pacientes com o transtorno "refletindo a gravidade dos sintomas e os comportamentos disruptivos em escolas regulares e nas famílias" (Baron-Cohen et al, 2001). As crianças de nosso grupo experimental, por outro lado, em sua maioria $(\mathrm{n}=19)$ frequentavam classes regulares e não apresentavam comportamentos disruptivos de maior gravidade e todas moravam com as famílias. As diferenças no desempenho no Eyes-C em relação ao grupo controle nas amostras inglesa e brasileira pode ser explicada por especificidades do grupo original, e talvez não reflitam as características da SA e dos TEA como um todo.

Do ponto-de-vista metodológico, uma das limitações do instrumento parece ser a relativa facilidade da tarefa do Eyes-C que, conforme apontado anteriormente, avalia percepção social e não aspectos mais elaborados da cognição social e comportamento interpessoal. Em situações experimentais mais complexas como interpretação de histórias (Hutchins, Bonazinga, Prelock \& Taylor, 2008), nomeação de emoções próprias (Rieffe, Terwogt \& Kotronopouou, 2006) ou em interações com outros indivíduos foram encontradas diferenças significativas entre grupos (Nah \& Poon, 2010) 
Não foram encontradas igualmente diferenças significativas de acordo com o sexo dos participantes, não corroborando a hipótese de diferenças sexuais que apoia, em parte, a teoria de SE, uma vez que seria esperado que meninas, em todas as faixas etárias apresentassem melhor desempenho no Eyes-C se houvessem diferenças universais no que se refere a elementos da Cognição Social. No estudo original, meninas pontuaram menos $(\mathrm{M}=12,5 ; \mathrm{DP}=5,5)$ do que meninos $(\mathrm{M}=14,6 ; \mathrm{DP}=5,1)$ entre seis e oito anos. Nas idades posteriores, de oito a 12 anos, obtiveram maior pontuação, mas com sobreposição nos escores. Em populações adultas utilizando o Eyes-test, no entanto, foram encontradas diferenças estatisticamente significativas entre homens e mulheres (Baron-Cohen, Jolliffe, Mortimore \& Robertson, 1997). Se a tendência em ampliar as diferenças nos escores de acordo com o sexo para populações é verdadeira, então as diferenças nos escores podem se dever a fatores culturais e não neurobiológicos apenas. Embora os autores salientem que se tratam de "estilos cognitivos" e não de diferenças sexuais stricto sensu, a teoria é também chamada de teoria "do cérebro extremamente masculino" (extreme male brain) e são citadas como evidência as diferenças entre as médias entre os sexos (Baron-Cohen, 2010).

Alguns outros trabalhos discutem diretamente o constructo ToM, uma vez que alguns experimentos indicam um déficit nas Funções Executivas seriam subjacentes aos prejuízos encontrados nas tarefas de ToM (Ozonoff, Pennington \& Rogers, 1991 citado por Ozonoff \& Griffith, 2000). Russell e colaboradores demonstraram que quando se remove o componente de tomada de perspectiva de tarefas de ToM, mas a necessidade de perceber a mudança de contexto é mantida, autistas mantém o desempenho inferior (Hughes e Russel, 1993 citado por Ozonoff \& Griffith, 2000). 
Pellicano (2010), por outro lado, demonstrou em um estudo longitudinal que escores em testes de função executiva e coerência central foram capazes de predizer mudanças em testes de ToM três anos depois, mas o inverso não ocorreu (Pellicano, 2010).

Deve-se discutir ainda a viabilidade de sintetizar os comportamentos observados nos TEA em um único fenótipo comportamental. Waterhouse (2009), por exemplo, afirma que não é possível assumir que será possível encontrar um prejuízo neurofuncional que proverá uma explicação para os déficits do autismo e Hutto em 2008 afirma:

“O sugestivo nome [MB] indica que o aspecto central do autismo repousa em uma incapacidade de 'ver outras mentes'. Mas isso não é remotamente possível. Há muitos sintomas associados ao transtorno, tanto sociais, quanto não sociais. Tipicamente eles estão divididos em três grandes categorias: interação social, comunicação e imaginação (...) isso é suficiente para indicar que se os autistas são cegos para mentes (mindblind no original) eles não são apenas[em itálico no original] cegos. Uma argumentação em contrário descaracterizaria seriamente o escopo do transtorno." (Hutto, 2008, p.191)

Outro aspecto a ser considerado são as múltiplas etiologias e a ausência de marcadores biológicos nos TEA, por conta disto, ao se estudar estas síndromes podem ocorrer agrupamentos heterogêneos que inviabilizariam a descrição e posterior síntese de fenótipos comportamentais. 


\section{V.CONCLUSÕES}

Nossos resultados foram parcialmente favoráveis às propriedades psicométricas do Eyes-C para nosso meio, uma vez que o instrumento obteve bom índice de consistência interna. Por outro lado, índices igualmente relevantes como análise fatorial e validade de critério no estudo exploratório não foram considerados favoráveis.

Uma vez que as habilidades de ToM parecem intrínsecas a outros componentes cognitivos como linguagem e aprendizagem, as limitações não parecem estar apenas na representação comportamental (percepção social), mas no próprio traço latente (ToM). Embora tentadora, a síntese dos déficits do TEA em um único aspecto cognitivo talvez não leve em conta todos os aspectos relevantes da cognição social que, tais como outras funções cognitivas superiores, são intrínsecas a diversos aspectos da mente humana como linguagem, planejamento, memória, flexibilidade mental, para citar apenas alguns exemplos.

Um melhor conhecimento dos demais aspectos dos TEA não investigados nesta pesquisa como linguagem, inteligência não verbal e as funções executivas, bem como uma comparação com outras síndromes e a diferenciação entre as múltiplas etiologias no autismo, podem contribuir para maiores esclarecimentos acerca dos déficits e habilidades cognitivas nos TEA que são inerentes aos sinais sintomas encontrados nestes indivíduos. 


\section{REFERÊNCIAS}

Adolphs, R. (2009). The Social Brain: Neural Basis of Social Knowledge. Annual Revew Psychology, 60, 693-716.

American Psychological Association. (1954). Technical recommendations for psychological test and diagnostic techniques. DC: APA.

American Psychiatric Association (2002). Manual diagnóstico e estatístico dos transtornos mentais, Porto Alegre: Artmed

Andrade, J. M., Laros, J. A., \& Gouveia, V. V. (2010). O uso da teoria de resposta ao item em avaliações educacionais: diretrizes para pesquisadores. Aval. Psicol. , (9)421-435.

Assumpção-Jr, F.B., Sprovieri, M.H., Kuczynski, E. \& Farinha, V. (1999) Reconhecimento Facial e Autismo Arquivos de Neuro-psiquiatria, 57(4), 994-999

Assumpção-Jr, F. B., Gonçalves, J.D.M. , Cuccolichio, S., Amorim, L.C.D., Rego, F.; Gomes, C. \& Falcão, M.S. (2008) Escala de Avaliação de Traços Autísticos (ATA): segundo estudo de validade, Medicina de reabilitação,27(2)41-4

Bailey, P.E. \& Henry, J. (2010) Separating component processes of theory of mind in schizophrenia, British Journal of Clinical Psychology, (49)43-52

Barret, H. C., Cosmides L. \& Tooby J. (2010) Coevolution of cooperation, causal cognition and mindreading, Commun Integr Biol, 3( 6), 522-524

Baron-Cohen, S., Leslie, A.M. \& Frith, U. (1985) Does Autistic Child Have a 'Theory of Mind', Cognition, (21)37-46

Baron-Cohen, S. (1994) How to build a baby that can read minds: Cognitive mechanisms in mindreading Cognitive Current Psychology of Cognition, (13)513-552

Baron-Cohen, S., Jolliffe, T., Mortimore, C., \& Robertson, M. (1997). Another Advanced Test of Theory of Mind: Evidence from Very High Functioning Adults with Autism or Asperger Syndrome. Journal of Child Psychology and Psychiatry, 38(7), 813-822

Baron-Cohen, S., O’Riordan, M. O., Stone, V., Jones, R., \& Plaisted, K. (1999). A new test of social sensitivity: Detection of faux pas in normal children and children with Asperger syndrome, Journal of Autism and Developmental Disorders, 29, 407-18.

Baron-Cohen, S., Wheelwright, S., Hill, J., Raste, Y., \& Plumb, I. (2001). The "'Reading the Mind in the Eyes" Test revised version: A study with normal adults, and adults with Asperger syndrome or high-functioning autism. Journal of Child Psychology and 
Psychiatry and Allied Disciplines, 42, 241-251

Baron-Cohen, S., Wheelwright, S., Spong, A.; Scahill, V. e Lawson, J. et al.(2001) Are intuitive physics and intuitive psychology independent? A test with children with Asperger Syndrome, Journal of Developmental and Learning Disorders,(5)47-78

Baron-Cohen, S. (2002) The extreme male brain theory of autism Trends in Cognitive Sciences, 6 (6), 248-254

Baron-Cohen, S., Richler, J., Bisarya, D., Gurunathan, N. \& Wheelwright, S. (2003). The systemizing quotient: an investigation of adults with Asperger syndrome or highfunctioning autism, and normal sex differences. Philosophical transactions of the Royal Society of London. Series B, Biological sciences, 358(430), 361-74. doi:10.1098/rstb.2002.1206

Baron-Cohen, S. (2003) A Diferença Essencial, São Paulo: Objetiva

Baron-Cohen, S. \& Wheelwright, S. (2004). The empathy quotient: an investigation of adults with Asperger syndrome or high functioning autism, and normal sex differences. Journal of autism and developmental disorders, 34(2), 163-75. Retrieved from http://www.ncbi.nlm.nih.gov/pubmed/15162935

Baron-Cohen \& Belmonte, M.K. (2005) Autism: a window onto the development of the social and analytic brain, Annual review of Neuroscience, (28)109-26

Baron-Cohen, S. (2009). Autism: the empathizing-systemizing (E-S) theory. Annals of the New York Academy of Sciences, 1156, 68-80. doi:10.1111/j.1749-6632.2009.04467.x

Bates, E., Benigni, L., Bretherton, L.I, Camioni, L.\& Volterra, V. (1979) Cognition and communication from 9-13 months: correlational findings. In E. Bates (Ed.), The emergence of symbols: cognition and communication in infancy, New York: Academic Press

Bora, E., Yucel, M. \& Pantelis, C. (2009) Theory of Mind impaired in schizophrenia: Meta-analysis Schizophrenia Research (109) 1-9

Brunet, P., Monloch, C. \& Schmidt, L.(2010) Shy Children are Less Sensitive to Some Cues to Facial Recognition, Child Psychiatry e Human Development, (41)1-14

Caixeta, M. \& Caixeta, L.(2005) Teoria da Mente: aspectos psicológicos, neurológicos, neuropsicológicos e psiquiátricos, Campinas: Átomo

Call, J., \& Tomasello, M. (2008). Does the chimpanzee have a theory of mind ? 30 years later, Trends in Cognitive Sciences, 12(5),187-192. doi:10.1016/j.tics.2008.02.010

Connellan, J., Baron-Cohen, S., Wheelwright, S., Batki, A. \& Ahluwalia, J. (2000) Sex differences in human neonatal social perception, Infant Behavior and Development, 23, 


\section{$113-118$}

Carroll, J. M., \& Yung, C. K. (2006). Sex and discipline differences in empathising, systemising and autistic symptomatology: Evidence from a student population. Journal of Autism and Developmental Disorders, 36, 949-957

Cosmides, L., \& Tooby, J. (1992) Origins of domain-specificity: The evolution of functional organization In L. Hirschfeld e S. Gelman (Eds.), Mapping the mind: Domainspecificity in cognition, Cambridge: Cambridge University Press

Cosmides, L., Barrett, H.C. \& Tooby J. (2010) Adaptive specializations, social exchange, and the evolution of human intelligence In the Light of Evolution IV: The Human Condition, 1(2), 9007-9014

Craig,J.S., Hatton,C., Craig,F.B.\& Bentall, R.P.(2004) Persecutory beliefs, attributions and theory of mind: comparison of patients with paranoid delusions, Asperger's syndrome and healthy controls Schizophrenia research, 69(1),29-33

Darwin, C. (2000) A expressão das emoções nos homens e nos animais, São Paulo: Companhia das Letras (obra originalmente publicada em 1872)

Dennett, D.(1987) The Intentional Stance Cambridge: MIT Press/Bradford Books, Cambridge

Domes, G., Heinrichs, M., Michel, A., Berger, C., \& Herpertz, S. C. (2007). Oxytocin improves "mind-reading'" in humans Biological Psychiatry, 61, 731-733

Ekman, P. (1982). Methods for measuring facial action. In: K. Scherer, \& P. Ekman, Handbook of methods in nonverbal behavior research (pp. 45-40). Cambridge: Cambridge University Press.

Ekman, P., Friesen, W., \& Ellsworth, P. (1972). Emotion in the human face: Guidelines for research and an integration of Findings. New York: Pergamon Press.

Ekamn, P. \& Friesen, W.V (1971) Constants across cultures in the face and emotion Journal of Personality and Social Psychology,(17), 342-343

Ekman, P. \& Rosenberg, E.L. (1997) What the face reveals, Oxford: Oxford University Press

Ekman, P., Sorenson, E.R. \& Friensen, W.D. (1969) Pan-cultural elements in facial displays of emotion, Science,(164)86-8

Ekman, P. \& Friesen, W.V.(1971) Constants across cultures in the face and emotion Journal of Personality and Social Psychology, (17)124-9 
Fombonne, E. (2209) Epidemiology of Pervasive Developmental Disorders Pediatric Research (65) 591-598

Frith, U.(2004) Emanuel Miller lecture: Confusions and controversies about Asperger syndrome, Journal of Child Psychology and Psychiatry, 45(4), 672-686

Golan, O., Baron-Cohen, S., \& Hill, J. (2006). The Cambridge Mindreading (CAM) Face Voice Battery: Testing complex emotion recognition in adults with and without Asperger syndrome. Journal of Autism and Developmental Disorders, 36, 169-183.

Hallerbäck, M.U., Lugnegård, T., Hjärthag, F. \& Gillberg, C.(2009) The Reading the Mind in the Eyes Test: test-retest reliability of a Swedish version, Cognitive Neuropsychiatry, $14(2), 127-43$

Happé, F. G. E. (1995), The Role of Age and Verbal Ability in the Theory of Mind Task Performance of Subjects with Autism. Child Development, 66, 843-855

Henry, J.D., Rendell, P.G., Scicluna, A., Jackson, M. \& Phillips, L.H. (2009) Emotion Experience, Expression, and Regulation in Alzheimer's Disease, Psychology and aging, 24(1), 252-7

Hobson, R.P. (1986) The autistic child's appraisal of expressions of emotion Journal of Child Psychology and Psychiatry, 27, 321-342

Hobson, R. P. Ouston, J. \& Lee, A. (1988) What's in a face? The case of autism British Journal of Psychology, 79(4), 441-453

Hogan, T.P. (2006) Introdução à Prática dos testes psicológicos, Rio de Janeiro: LTC

Hutchins, T.L., Bonazinga, L.A., Prelock, P.A. \& Taylor, R.S.(2008) Beyond false beliefs: the development and psychometric evaluation of the perceptions of children's theory of mind measure-experimental version (PCToMM-E), Journal of Autism and Developmental Disorders, 38(1)143-55

Hutto, D.D. (2008) Folk Psychological Narratives: The sociocultural Basis of Understanding Reasons, Cambridge: The MIT Press

Irani, F., Platek, S. M., Panyavin, I. S., Calkins, M. E., Kohler, C., Siegel, S. J., et al. (2006). Self- face recognition and theory of mind in patients with schizophrenia and firstdegree relatives. Schizophrenia Research, 88, 151-160.

Izard, C. E.(1977) Human Emotions, New York: Plenum Press

Jou, G.I. \& Sperb, T.M. (1999) Teoria da Mente: diferentes abordagens Psicologia:Reflexão e Crítica, (12)287-306 
Kettle, J. W. L., O’Brien-Simpson, L., \& Allen, N. B. (2008). Impaired theory of mind in first-episode schizophrenia: Comparison with community, university and depressed controls. Schizophrenia Research, 99, 96-102

Lawrence, E., Shaw, P., Baker, D., Baron-Cohen, S., \& David, A. (2004). Measuring empathy: Reliability and validity of the Empathy Quotient. Psychological Medicine, 34, 911-919

Lee, L., Harkness, K. L., Sabbagh, M. A., \& Jacobson, J. A. (2005) Mental state decoding abilities in clinical depression Journal of Affective Disorders, 86, 247-258

Leslie, A. M. (1987) Pretense and Representation: The origins of Theory of Mind, Psychological review,(94) 412-426

Matteo, J.D., Cucolicchio, S., Paicheco, R., Gomes, C., Simone, M.F. \& Assumpção-Jr, F.B.(2009) Childhood Autism Rating Scale (CARS): um estudo de validade, Medicina de Reabilitação, 28(2),34-7

Murphy, D. (2006). Theory of mind in Asperger's syndrome, schizophrenia and personality disordered forensic patients. Cognitive Neuropsychiatry, 11, 99-111.

Nah, Y. H. \& Poon, K.K. (2011) The perception of social situations by children with autismo spectrum disorders, Autism, 15 (2), 185-203

Pasquali, L. (2006) Técnicas de Exame Psicológico- TEP (Vol. I: Fundamentos da técnica do exame psicológico, 2a Edição), São Paulo: Casa do Psicólogo/Conselho Federal de Psicologia

Pasquali, L. (2009a) Psicometria. Revista da escola de enfermagem , (43)992-999.

Pasquali, L. (2009b). Psicometria: Teoria dos testes na Psicologia e Educação, $3^{\text {a }}$ Edição, Petrópolis: Vozes

Perner, J. (1999) Theory of Mind In M. Bennett (Ed.) Developmental Psychology: Achievements \& Prospects, Hove: Psychology Press

Pellicano, E. (2010) Individual differences in executive function and central coherence predict developmental changes in theory of mind in autism. Developmental Psychology, 46(2), 530-544

Pimperton, H., Pellicano, E., Jeffery, L. \& Rhodes, G. (2009) The role of higher level adaptive coding mechanisms in the development of face recognition, Journal of Experimental Child Psychology (104) 229-238

Plutchnik, R. (1962) The emotions: facts, theories, and a new model, New York: Random House 
Premack, D. (1990) The infant's theory of self-propelled objects, Cognition,36, 1-16

Premack, D. e Woodruff, G.(1978) Does the Chimpanzee have a 'Theory of Mind', Behavioral an Brain Sciences, 4, 515-26

Rieffe, C., Terwogt, M.M. \& Kotronopoulou (2007) Awareness of Single and Multiple emotion in high-functioning children with autism, Journal of Autism and Developmental Disorders, 37, 455-465

Shah, A. \& Frith, U. (1993) Why do autistic individuals show superior performance on the Block Design task? Journal of Child Psychology and Psychiatry, 34,1351-1364

Tomasello, M. (2003) Atenção conjunta e aprendizagem cultural In M. Tomasello Origens culturais da aquisição do conhecimento humano, 77-129, São Paulo: Martins Fontes

Tomkins, S.S. \& McCarter, R.(1964) What and where are the primary affects? Some evidence for a theory, Perceptual and motor Skills, (18)119-158

Tooby, J. \& Cosmides, L.(2005) Conceptual Foundations of Evolutionary Psychology In David M. Buss (Ed.) The Handbook of Evolutionary Psychology, Indianapolis:Wiley

Voyer, D., Voyer, S. \& Bryden, M.P. (1995) Magnitude of sex differences in special abilities: A meta-analysis and consideration of critical variables, Psychological Bulletin, 117 (2), 250-270

Walker, A. S. (1982) Intermodal perception of expressive behaviors by human Infants, Journal of Experimental Child Psychology,(33)514-35

Waterhouse, L. (2009). Autism is a Portmanteau syndrome. Neuropsychology review, $19(2), 275-6$

Wellman, H. \& Bartsch, K. (1988) Young children's reasoning about beliefs, Cognition,(30)239-77

Weschler, D. (1991) WISC-III: Escala de Inteligência Weschler para Crianças (3 ${ }^{a}$ Edição) Adaptação e Padronização de uma amostra brasileira (1 ${ }^{\text {a }}$ Edição); V. L. M. Figueiredo, São Paulo: Casa do Psicólogo

Wheelwright, S. \& Baron-Cohen, S. Systemizing and Empathizing In D. A. Fein (Ed) The Neuropsychology of Autism, Nova York: Oxford University Press, pp. 317-337

Whiten, A. (1993) Evolving a theory of mind: the nature of non-verbal mentalism in other primates, In S. Baron-Cohen, H. Tager-Flusberg \& D.J. Cohen (Eds) Understanding other minds: perspectives from autism, Nova York: Oxford University Press, pp. 367-396 
Wimmer, H. \& Perner, J. (1983) Beliefs about beliefs: Representation and constraining function of wrong beliefs in young children's understanding of deception, Cognition, $13,103-128$

Wing, L. (1981) Asperger's Syndrome: a Clinical Account, Psychological Medicine, (11)115-130

Winkielman, P., \& Schooler, J. (2009). Unconscious, conscious, and meta-conscious in social cognition. In: F. Strack, \& J. Förster, Social Cognition: the basis of human interaction. Philadelphia: Psychology Press.

Woodworth, R. S. (1938), Experimental Psychology, New York: Henry Holt

Yirmiya, N., Sigman, M., Kasari, C. \& Mundy, P. (1992) Empathy and cognition in high functioning children with autism, Child Development,(63)150-60 
VII.ANEXOS 


\section{ANEXO A - Termos de uso do Eyes-test}

- RE: Test Use Authorization

De: Gaenor Moore

Dear Melanie

You do not need to request permission to use any of our tests. We just ask that you use the test responsibly and reference our work where appropriate.

Best wishes,

Gaenor

Gaenor Moore (Mrs)

Secretary to Professor Baron-Cohen

\& Administrator for the Autism Research Centre

Department of Developmental Psychiatry

University of Cambridge

Douglas House

18b Trumpington Road

Cambridge CB2 8AH

Tel: 01223746057

Fax: 01223746033

www. autismresearchcentre.com 


\title{
ANEXO B - Termo de Consentimento Livre e Esclarecido
}

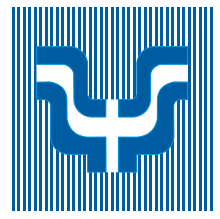

\author{
UNIVERSIDADE DE SÃO PAULO \\ INSTITUTO DE PSICOLOGIA \\ LABORATÓRIO DISTURBIOS DO DESENVOLVIMENTO \\ Av. Prof. Mello Moraes, 1721 - Bloco D - CEP:05507-000
}

TERMO DE CONSENTIMENTO LIVRE E ESCLARECIDO

Resolução n 196, de 10 de outubro de 1996, segundo Conselho Nacional de Saúde (CNS)

Disponível em $<$ http://www.usp.br/ip/pesquisa/res196.html $>$

Caro pai ou responsável de

(nome da criança)

O projeto "Estudo de Validade da versão infantil do Teste "Ler a Mente nos Olhos" ("Reading the Mind in the Eyes") em crianças brasileiras de 6 a 10 anos" é realizado por Melanie Mendoza, com orientação do Prof. Dr. Francisco Assumpção Jr. do Instituto de Psicologia da Universidade de São Paulo.

Informações mais detalhadas sobre o projeto podem ser obtidas através do telefone (11) 9184-9290 ou do e-mail melanie.mendoza@uol.com.br

Objetivo: Verificar com população de crianças brasileiras a validade de um instrumento desenvolvido por Baron-Cohen, da Cambridge University, para reconhecimento de emoções expressas através da região dos olhos.

Procedimento: Será aplicado um instrumento composto por 29 pranchas com fotografias de olhos, com quatro alternativas para cada prancha. A criança deve indicar em uma folha de respostas a alternativa que melhor corresponde à emoção associada à fotografia apresentada. A aplicação é coletiva e dura aproximadamente 20 minutos.

Benefícios: Os resultados possibilitarão uma melhor compreensão do desenvolvimento da sociabilidade, contribuindo para o aperfeiçoamento de instrumentos de pesquisa e diagnóstico.

Risco: Não haverá nenhum risco à integridade física (saúde) e moral das crianças.

Privacidade: Os dados serão confidenciais. Os resultados serão agrupados e tratados coletivamente. Poderão ser divulgados em congressos e publicações cientificas.

A participação do seu filho é voluntária, caso não concorde que ele participe da pesquisa não haverá nenhum impedimento ou alterações nas relações entre você, a Universidade e a Instituição de Ensino, podendo retirar seu consentimento e impedi-lo de participar da pesquisa em qualquer momento, inclusive antes do seu término. …............................................................................................ (nome da criança), fui informado(a) dos objetivos da pesquisa "Estudo de Validade da versão infantil do Teste "Ler a Mente nos Olhos" ("Reading the Mind in the Eyes") em crianças brasileiras de 6 a 11 anos" acima de maneira clara e detalhada. Recebi informação a respeito dos procedimentos e esclareci quaisquer dúvidas que tivesse. Sei que em qualquer momento poderei solicitar novas informações e modificar minha decisão de permitir a participação de meu filho se assim eu desejar. Certificaram-me de que todos os dados desta pesquisa serão confidenciais e terei liberdade de retirar meu consentimento de participação na pesquisa em qualquer momento da mesma. 


\title{
ANEXO C - Escala de Traços Autísticos
}

\author{
ESCALA DE TRAÇOS AUTÍSTICOS \\ Ballabriga et al., 1994
}

Esta escala, embora não tenha o escopo de avaliar especificamente uma função psíquica, é utilizada para avaliação de uma das patologias mais importantes da Psiquiatria Infantil - o Autismo. Seu ponto de corte é de 24. Pontua-se zero se não houver a presença de nenhum sintoma, 1 se houver apenas um sintoma e 2 se houver mais de um sintoma em cada um dos 36 itens, realizando-se uma soma simples dos pontos obtidos.

\section{DIFICULDADE NA INTERAÇÃO SOCIAL}

O. desvio da sociabilidade pode oscilar entre formas leves como, por exemplo, um certo negativismo e a não aceitação do contato ocular, até formas mais graves, como um intenso isolamento.

1.Não sorri ; 2.Ausência de aproximações espontâneas; 3.Não busca companhia;

4. Busca constantemente seu cantinho (esconderijo); 5.Evita pessoas; 6.É incapaz de manter um intercâmbio social; 7.Isolamento intenso

\section{MANIPULAÇÃO DO AMBIENTE}

O problema da manipulação do ambiente pode apresentar-se a nível mais ou menos grave, como, por exemplo, não responder às solicitações e manter-se indiferente ao ambiente. O fato mais comum é a manifestação brusca de crises de birra passageira, risos incontroláveis e sem motivo, tudo isso com o fim de conseguir ser o centro da atenção

1. Não responde às solicitações; 2. Mudança repentina de humor; 3.Mantém-se indiferente, sem expressão; 4. Risos compulsivos; 5. Birra e raiva passageira; 6. Excitação motora ou verbal (ir de um lugar a outro, falar sem parar)

\section{UTILIZAÇÃO DAS PESSOAS A SEU REDOR}

A relação que mantém com o adulto quase nunca é interativa, dado que normalmente utiliza-se do adulto como o meio para conseguir o que deseja.

1. Utiliza-se do adulto como um objeto, levando-o até aquilo que ele deseja; 2.0 adulto Ihe serve como apoio para conseguir o que deseja (p.ex.: utiliza o adulto como apoio para pegar bolacha); 3.0 adulto é o meio para suprir uma necessidade que não é capaz de realizar só ( p.ex.: amarrar sapatos); 4 . Se o adulto não responde as suas demandas, atua interferindo na conduta desse adulto.

\section{RESISTÊNCIA À MUDANÇA}

A resistência à mudança pode variar da irritabilidade até a franca recusa.

1. Insistente em manter a rotina; 2.Grande dificuldade em aceitar fatos que alteram sua rotina, tais como mudanças de lugar, de vestuário e na alimentação; 3.Apresenta resistência a mudanças, persistindo na mesma resposta ou atividade

\section{BUSCA DE UMA ORDEM RÍGIDA}

Manifesta tendência a ordenar tudo, podendo chegar a uma conduta de ordem obsessiva, sem a qual não consegue desenvolver nenhuma atividade.

1. Ordenação dos objetos de acordo com critérios próprios e pré-estabelecidos; 2.Prende-se a uma ordenação espacial (Cada coisa sempre em seu lugar); 3.Prende-se a uma seqüência temporal (Cada coisa em seu tempo); 4.Prende-se a uma correspondência pessoa-lugar (Cada pessoa sempre no lugar determinado)

VI. FALTA DE CONTATO VISUAL. OLHAR INDEFENIDO

A falta de contato pode variar desde um olhar estranho até o constante evitar dos estímulos visuais

1. Desvia os olhares diretos, não olhando nos olhos; 2.Volta a cabeça ou o olhar quando é chamado (olhar para fora); 3.Expressão do olhar vazio e sem vida; 4.Quando segue os estímulos com os olhos, somente o faz de maneira intermitente; 5.Fixa os objetos com uma olhada periférica, não central; 6.Dá a sensação de que não olha 
VII. MÍMICA INEXPRESSIVA

A inexpressividade mímica revela a carência da comunicação não verbal. Pode apresentar desde uma certa expressividade até uma ausência total de resposta.

1. Se fala, não utiliza a expressão facial, gestual ou vocal com a freqüência esperada; 2.Não mostra uma reação antecipatória; 3.Não expressa através da mímica ou olhar aquilo que quer ou o que sente; 4.Imobilidade facial

\section{DISTÚRBIOS DE SONO}

Quando pequeno dorme muitas horas e, quando maior, dorme poucas horas, se comparado ao padrão esperado para a idade. Esta conduta pode ser constante, ou não.

1. Não quer ir dormir; 2.Se levanta muito cedo; 3.Sono irregular (em intervalos); 4.Troca ou dia pela noite; 5.Dorme muito poucas horas.

\section{ALTERAÇÃO NA ALIMENTAÇÃO}

Pode ser quantitativa e/ou qualitativa. Pode incluir situações, desde aquela em que a criança deixa de se alimentar até aquela em que se opõe ativamente.

1. Seletividade alimentar rígida (ex.: come o mesmo tipo de alimento sempre); 2.Come outras coisas além de alimentos (papel, insetos); 3.Quando pequeno não mastigava; 4.Apresenta uma atividade ruminante; 5.Vômitos; 6.Come grosseiramente, esparrama a comida ou a atira; 7.Rituais ( esfarela alimentos antes da ingestão); 8.Ausência da paladar (Falta de sensibilidade gustativa)

\section{DIFICULDADE NO CONTROLE DOS ESFÍNCTERES}

O controle dos esfíncteres pode existir, porém a sua utilização pode ser uma forma de manipular ou chamar a atenção do adulto.

1. Medo de sentar-se no vaso sanitário; 2.Utiliza os esfíncteres para manipular o adulto; 3.Utiliza os esfíncteres como estimulação corporal, para obtenção de prazer; 4.Tem controle diurno, porém o noturno é tardio ou ausente

\section{EXPLORAÇÃO DOS OBJETOS (APALPAR, CHUPAR)}

Analisa os objetos sensorialmente, requisitando mais os outros órgãos dos sentidos em detrimento da visão, porém sem uma finalidade específica

1. Morde e engole objetos não alimentares; 2.Chupa e coloca as coisas na boca; 3.Cheira tudo; 4.Apalpa tudo. Examina as superfícies com os dedos de uma maneira minuciosa

\section{USO INAPROPRIADO DOS OBJETOS}

Não utiliza os objetos de modo funcional, mas sim de uma forma bizarra.

1. Ignora os objetos ou mostra um interesse momentâneo; 2.Pega, golpeia ou simplesmente os atira no chão; 3.Conduta atípica com os objetos (segura indiferentemente nas mãos ou gira); 4.Carrega insistentemente consigo determinado objeto; $5 . S e$ interessa somente por uma parte do objeto ou do brinquedo; 6.Coleciona objetos estranhos; 7.Utiliza os objetos de forma particular e inadequada

\section{FALTA DE ATENÇÃO}

Dificuldades na fixação e concentração. Às vezes, fixa a atenção em suas próprias produções sonoras ou motoras, dando a sensação de que se encontra ausente.

1. Quando realiza uma atividade, fixa a atenção por curto espaço de tempo ou é incapaz de fixá-la; 2.Age como se fosse surdo; 3.Tempo de latência de resposta aumentado; 4.Entende as instruções com dificuldade (quando não lhe interessa, não as entende); 5.Resposta retardada; 6.Muitas vezes dá a sensação de ausência

\section{AUSÊNCIA DE INTERESSE PELA APRENDIZAGEM}

Não tem nenhum interesse por aprender, buscando solução nos demais. Aprender representa um esforço de atenção e de intercâmbio pessoal, é uma ruptura em sua rotina. 
1. Não quer aprender; 2.Se cansa muito depressa, ainda que em atividade que goste; 3.Esquece rapidamente; 4.Insiste em ser ajudado, ainda que saiba fazer; 5.Insiste constantemente em mudar de atividade

\section{FALTA DE INICIATIVA}

Busca constantemente a comodidade e espera que the dêem tudo pronto. Não realiza nenhuma atividade funcional por iniciativa própria.

1. É incapaz de ter iniciativa própria; 2.Busca a comodidade; 3.Passividade, falta de interesse; 4.Lentidão; 5.Prefere que outro faça o trabalho para ele

\section{ALTERAÇÃO DE LINGUAGEM E COMUNICAÇÃO}

É uma característica fundamental do autismo, que pode variar desde um atraso de linguagem até formas mais severas, com uso exclusivo de fala particular e estranha.

1. Mutismo; 2.Estereotipias vocais; 3.Entonação incorreta; 4.Ecolalia imediata e/ou retardada; 5.Repetição de palavras ou frases que podem ou não ter valor comunicativo; 6.Emite sons estereotipados quando está agitado e em outras ocasiões, sem nenhuma razão aparente; 7.Não se comunica por gestos; 8.As interações com adulto não são nunca um diálogo

\section{NÃO MANIFESTA HABILIDADES E CONHECIMENTOS}

Nunca manifesta tudo aquilo que é capaz de fazer ou agir, no que faz referência a seus conhecimentos e habilidades, dificultando a avaliação dos profissionais.

1. Ainda que saiba fazer uma coisa, não a realiza, se não quiser; 2.Não demonstra o que sabe até que tenha uma necessidade primária ou um interesse iminentemente específico; 3.Aprende coisas, porém somente a demonstra em determinados lugares e com determinadas pessoas; 4.As vezes surpreende por suas habilidades inesperadas

\section{REAÇÕES INAPROPRIADAS ANTE A FRUSTRAÇÃO}

Manifesta desde o aborrecimento à reação de cólera, ante a frustração.

1. Reações de desagrado caso seja esquecida alguma coisa; 2.Reações de desagrado caso seja interrompida alguma atividade que goste; 3.Desgostoso quando os desejos e as expectativas não se cumprem; 4.Reações de birra

XIX NÃO ASSUME RESPONSABILIDADES

Por princípio, é incapaz de fazer-se responsável, necessitando de ordens sucessivas para realizar algo.

1. Não assume nenhuma responsabilidade, por menor que seja; 2.Para chegar a fazer alguma coisa, há que se repetir muitas vezes ou elevar o tom de voz

XX. HIPERATIVIDADE/ HIPOATIVIDADE

A criança pode apresentar desde agitação, excitação desordenada e incontrolada, até grande passividade, com ausência total de resposta. Estes comportamentos não tem nenhuma finalidade.

1. A criança está constantemente em movimento; 2.Mesmo estimulada, não se move; 3.Barulhento. Dá a sensação de que é obrigado a fazer ruído/barulho; 4.Vai de um lugar a outro, sem parar; 5.Fica pulando (saltando) no mesmo lugar; 6.Não se move nunca do lugar onde está sentado

\section{MOVIMENTOS ESTEREOTIPADOS E REPETITIVOS}

Ocorrem em situações de repouso ou atividade, com início repentino.

1. Balanceia-se; 2.Olha e brinca com as mãos e os dedos; 3.Tapa os olhos e as orelhas; 4.Dá pontapés; 5.Faz caretas e movimentos estranhos com a face; 6.Roda objetos ou sobre si mesmo; 7.Caminha na ponta dos pés ou saltando, arrasta os pés, anda fazendo movimentos estranhos; 8.Torce o corpo, mantém uma postura desequilibrada, pernas dobradas, cabeça recolhida aos pés, extensões violentas do corpo

\section{IGNORA O PERIGO}

Expõe-se sem ter consciência do perigo

1.Não se dá conta do perigo; 2.Sobe em todos os lugares; 3.Parece insensível a dor 


\section{ANEXO D - Escala de Pontuação do Autismo}

ESCALA DE PONTUAÇÃO DO AUTISMO

(Childhood Autism Rating Scale - CARS)

Schopler E, Renner BR, 1988

NOME:

RG:

SEXO: M

IDADE:

DATA DA AVALIAÇÃO:

RESULTADO:

DN:

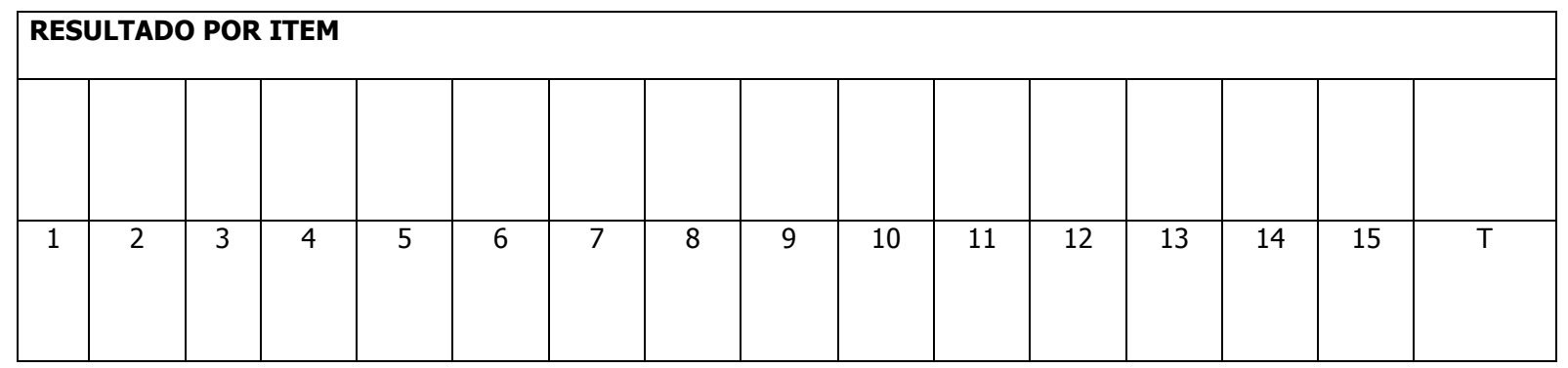

RESULTADO FINAL

Normal: 15-29,5

Autismo leve/ moderado: $30-36,5$

Autismo grave: acima de 37

\begin{tabular}{|l|l|}
\hline \multicolumn{2}{|c|}{ 1- RELACIONAMENTO INTER-PESSOAL } \\
\hline 1 & Sintomas \\
\hline 1,5 & $\begin{array}{l}\text { Sem evidência de dificuldade ou anormalidade: comportamento adequado para a idade. Pode existir } \\
\text { timidez, inquietude, mas em níveis similares ao observados em crianças da mesma idade. }\end{array}$ \\
\hline 2 & $\begin{array}{l}\text { Anormalidade Leve: A criança evita olhar o adulto nos olhos e demonstra dificuldades quando é forçado } \\
\text { a tal; extremamente tímido; dificuldades no trato social com os adultos, quando comparado aos de sua } \\
\text { idade; agarra-se mais intensamente aos familiares que os demais. }\end{array}$ \\
\hline 2,5 & $\begin{array}{l}\text { Anormalidade Moderada: Em certos momentos, a criança se isola. Necessita reforço persistente para } \\
\text { manter sua atenção. Pouca iniciativa para contatos e contato impessoal. }\end{array}$ \\
\hline 3 & $\begin{array}{l}\text { Anormalidade Grave: Isola-se de fato, não percebendo o que o adulto faz; nunca responde às iniciativas } \\
\text { do adulto ou inicia um contato. Apenas tentativas intensas para chamar sua atenção tem algum efeito } \\
\text { positivo. }\end{array}$ \\
\hline 3,5 & \multicolumn{1}{|c|}{ 2- IMITAÇÃo } \\
\hline 4 & \multicolumn{2}{|l|}{} \\
\hline \multicolumn{1}{|c|}{ Pontos } & Sintomas \\
\hline 1 & Adequada: Imita sons, palavras e movimentos próprios de sua etapa de desenvolvimento. \\
\hline 1,5 & $\begin{array}{l}\text { Anormalidade leve: Imita comportamentos simples, tais como: bater palmas, falar palavras isoladamente. } \\
\text { Às vezes reproduz um gesto após certo tempo de latência. }\end{array}$ \\
\hline 2 & $\begin{array}{l}\text { Anormalidade Moderada: Só imita às vezes e. mesmo assim, após grande insistência e auxílio do adulto. } \\
\text { Reproduz com freqüência e atraso a imitação de alguns gestos. }\end{array}$ \\
\hline 2,5 & \\
\hline 3 & \\
\hline
\end{tabular}


\begin{tabular}{|l|l|}
\hline 4 & Anormalidade Grave: Imita sons, palavras e gestos dos adultos muito raramente e com grande latência \\
\hline
\end{tabular} no tempo, ou nunca.

\begin{tabular}{|c|c|}
\hline \multicolumn{2}{|r|}{ 3- RESPOSTA EMOCIONAL } \\
\hline Pontos & Sintomas \\
\hline 1 & $\begin{array}{l}\text { Adequada para cada situação e de acordo com sua idade: Emocionalmente mostra sintonia entre as } \\
\text { expressões faciais, posturas corporais e comportamento. }\end{array}$ \\
\hline \multicolumn{2}{|r|}{ 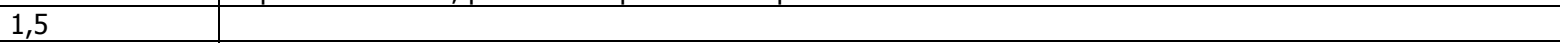 } \\
\hline 2 & $\begin{array}{l}\text { Anormalidade Leve: Ocasionalmente demonstra alguma inadequação na forma e intensidade de suas } \\
\text { reações emocionais. Algumas reações não se relacionam a objetos ou acontecimentos do entorno. }\end{array}$ \\
\hline \multicolumn{2}{|l|}{2,5} \\
\hline 3 & $\begin{array}{l}\text { Anormalidade Moderada: Presença definitiva de sinais inapropriados, na forma e intensidade, de suas } \\
\text { reações emocionais que podem ser inibidas, exageradas e, algumas vezes, sem relação com as situações } \\
\text { vividas no momento. Faz caretas, ri ou fica parado sem que existam acontecimentos que justifiquem tais } \\
\text { reações. }\end{array}$ \\
\hline \multicolumn{2}{|l|}{3,5} \\
\hline 4 & $\begin{array}{l}\text { Anormalidade Grave: Raramente as respostas emocionais são adequadas às situações. Difí́il a mudança } \\
\text { de humor, mesmo que se mudem as condições que o geraram. Grande diversidade de reações emocionais } \\
\text { em espaços curtos de tempo, sem que ocorram mudanças no meio que as justifiquem. }\end{array}$ \\
\hline
\end{tabular}

\begin{tabular}{|l|l|}
\hline \multicolumn{2}{|c|}{ 4- EXPRESSÃO CORPORAL } \\
\hline \multicolumn{1}{|c|}{ Pontos } & \multicolumn{1}{c|}{ Sintomas } \\
\hline 1 & Adequada: Movimentação fácil, agilidade e coordenação em acordo com a idade. \\
\hline 1,5 & $\begin{array}{l}\text { Anormalidade Leve: Peculiaridades menores podem estar presentes, tais como: movimentos } \\
\text { desajeitados, coordenação pobre, ou presença de movimentos inusitados (descritos no próximo item). }\end{array}$ \\
\hline 2 & $\begin{array}{l}\text { Anormalidade Moderada: Comportamento nitidamente estranhos, inusitados nas outras crianças de sua } \\
\text { idade. Posturas peculiares dos dedos (serpenteamentos) ou do corpo, fenômenos de auto-agressão, } \\
\text { balanceios, movimentos giratórios, contorcionismos, andar na ponta dos pés, etc. }\end{array}$ \\
\hline 3,5 & $\begin{array}{l}\text { Anormalidade Grave: os movimentos descritos no item anterior podem estar presentes de maneira } \\
\text { persistente, a despeito de tentativas persistentes de modificar seu comportamento corporal e podem } \\
\text { persistir mesmo durante o tempo em que se envolve com algumas atividades. }\end{array}$ \\
\hline 3,5
\end{tabular}

\begin{tabular}{|l|l|}
\hline \multicolumn{2}{|c|}{ 5- USO DE OBJETOS } \\
\hline \multicolumn{1}{|c|}{ Pontos } & \multicolumn{1}{c|}{ Sintomas } \\
\hline 1 & $\begin{array}{l}\text { Uso e interesse adequados: A criança demonstra interesse adequado em brinquedos e outros objetos } \\
\text { relacionados ao seu nível de desenvolvimento. Há uso funcional dos brinquedos. }\end{array}$ \\
\hline 1,5 & \multicolumn{1}{|c|}{} \\
\hline 2 & $\begin{array}{l}\text { Anormalidade Leve: Demonstra um interesse menor pelos brinquedos além de manipulação e uso } \\
\text { inadequado dos mesmos (golpeia os objetos ou leva à boca). }\end{array}$ \\
\hline 2,5 & $\begin{array}{l}\text { Anormalidade Moderada: Pouco interesse pelos brinquedos e objetos em geral e seu uso é pouco } \\
\text { funcional. Pode interessar-se muito particularmente por uma parte do brinquedo, ficar fascinado pelo } \\
\text { reflexo da luz sobre o objeto, ou eleger apenas e exclusivamente um certo objeto, excluindo os demais. } \\
\text { Esse comportamento pode ser parcial e temporariamente modificável. }\end{array}$ \\
\hline 3,5 & $\begin{array}{l}\text { Anormalidade Grave: Pode apresentar os sintomas descritos no item anterior com maior intensidade e } \\
\text { freqüência. É difícil distrair sua atenção quando está "ocupada" com essas atividades inadequadas e muito } \\
\text { difícil modificar o uso inadequado dos objetos. }\end{array}$ \\
\hline 4 &
\end{tabular}

\begin{tabular}{|l|l|}
\hline \multicolumn{2}{|c|}{ 6- ADAPTAÇÃo A MUDANÇAS } \\
\hline Pontos & \multicolumn{1}{c|}{ Sintomas } \\
\hline 1 & $\begin{array}{l}\text { Sem anormalidade: Apesar da criança notar e comentar sobre as mudanças de rotina, há uma aceitação } \\
\text { sem grandes distúrbios. }\end{array}$ \\
\hline 1,5 & $\begin{array}{l}\text { Anormalidade Leve: Quando o adulto tenta modificar algumas rotinas, a criança continua com a mesma } \\
\text { atividade ou no uso dos mesmos materiais, mas pode ficar facilmente "confusa", assim como aceitar a } \\
\text { mudança. Ex: fica muito agitada quando é levada a uma padaria diferente/ o caminho para a escola é } \\
\text { mudado, mas acalma-se facilmente. }\end{array}$ \\
\hline 2 & \\
\hline 2,5 &
\end{tabular}




\begin{tabular}{|l|l|}
\hline 3 & $\begin{array}{l}\text { Anormalidade Moderada: Há resistência a mudanças de rotina. Há uma tentativa de persistir na } \\
\text { atividade costumeira e é difícil acalmá-la: ficam raivosos ou tristes quando há modificação. }\end{array}$ \\
\hline 3,5 & \multicolumn{1}{|l}{$\begin{array}{l}\text { Anormalidade Grave: Quando ocorrem mudanças, a criança apresenta reações graves, que são difíceis } \\
\text { de serem eliminadas. Se são forçadas a modificarem a rotina, podem ficar extremamente irritadas/raivosas } \\
\text { ou não cooperativas e talvez respondam com birras. }\end{array}$} \\
\hline 4
\end{tabular}

\begin{tabular}{|c|c|}
\hline \multicolumn{2}{|r|}{ 7- USO DO OLHAR } \\
\hline Pontos & Sintomas \\
\hline 1 & $\begin{array}{l}\text { Sem Anormalidade: O uso do olhar é normal para a idade. A visão é usada junto com os outros sentidos, } \\
\text { como a audição e o tato, como forma de explorar os objetos. }\end{array}$ \\
\hline \multicolumn{2}{|r|}{ 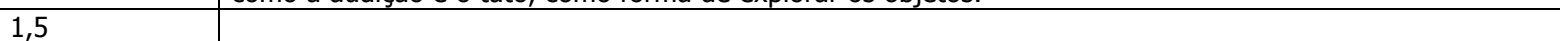 } \\
\hline 2 & $\begin{array}{l}\text { Anormalidade Leve: A criança precisa ser lembrada de vez em quando para olhar para os objetos. A } \\
\text { criança pode estar mais interessada em olhar para espelhos e luzes que outras crianças da mesma idade, } \\
\text { ou ficar olhando para o espaço de forma vaga. Pode haver evitação do olhar. }\end{array}$ \\
\hline \multicolumn{2}{|r|}{ A } \\
\hline 3 & $\begin{array}{l}\text { Anormalidade Moderada: A criança precisa ser lembrada a olhar o que está fazendo. Podem ficar } \\
\text { olhando para o espaço de forma vaga; evitação do olhar; olhar para objetos de modo peculiar; colocar } \\
\text { objetos muito próximos aos olhos apesar de não terem déficit visual. }\end{array}$ \\
\hline \multicolumn{2}{|l|}{3,5} \\
\hline 4 & $\begin{array}{l}\text { Anormalidade Grave: Há uma persistente recusa em olhar para pessoas ou certos objetos e podem } \\
\text { apresentar outras peculiaridades no uso do olhar em graus extremos como os descritos acima. }\end{array}$ \\
\hline
\end{tabular}

\begin{tabular}{|l|l|}
\hline \multicolumn{2}{|c|}{ 8- USO DA AUDIÇÃo } \\
\hline 1 & Sintomas \\
\hline 1,5 & $\begin{array}{l}\text { Sem Anormalidade: O uso da audição é normal para a idade. A audição é usada junto com os outros } \\
\text { sentidos, como a visão e o tato. }\end{array}$ \\
\hline 2 & $\begin{array}{l}\text { Anormalidade Leve: Pode haver falta de resposta a certos sons, assim como uma hiper-reatividade. Às } \\
\text { vezes, a reação é atrasada; às vezes, é necessário a repetição de um determinado som para "ativar" a } \\
\text { atenção da criança. A criança pode apresentar uma resposta catastrófica a sons estranhos a ela. }\end{array}$ \\
\hline 2,5 & $\begin{array}{l}\text { Anormalidade Moderada: A resposta aos sons pode variar: ignorá-los das primeiras vezes, ficar } \\
\text { assustado com sons de seu cotidiano, tampar os ouvidos. }\end{array}$ \\
\hline 3 & $\begin{array}{l}\text { Anormalidade Grave: Há uma sub- ou hiper-reatividade aos sons, de uma forma extremada, } \\
\text { independentemente do tipo de som. }\end{array}$ \\
\hline 4,5 &
\end{tabular}

\begin{tabular}{|l|l|}
\hline \multicolumn{2}{|c|}{ 9- USO DO PALADAR, OLFATO E TATO } \\
\hline Pontos & Sintomas \\
\hline 1 & $\begin{array}{l}\text { Sem Anormalidade: A criança explora novos objetos de acordo com a idade, geralmente através dos } \\
\text { sentidos. O paladar e o olfato são usados apropriadamente quando o objeto é percebido como comível. } \\
\text { Quando há dor resultante de batida, queda ou pequenos machucados, a criança expressa seu desconforto, } \\
\text { mas sem uma reação desmedida. }\end{array}$ \\
\hline 1,5 & $\begin{array}{l}\text { Anormalidade Leve: A criança persiste no levar e manter objetos na boca, em discrepância de outras da } \\
\text { mesma idade. Pode cheirar ou colocar na boca, de vez em quando, objetos não comestíveis. A criança pode } \\
\text { ignorar ou reagir de forma exacerbada a um beliscão ou alguma dor leve que numa criança normal seria } \\
\text { expressa de forma adequada (leve). }\end{array}$ \\
\hline 2 & $\begin{array}{l}\text { Anormalidade Moderada: Pode haver um comportamento de grau moderado de tocar, cheirar, lamber } \\
\text { objetos ou pessoas. Pode haver uma reação não habitual à dor em grau moderado, assim como sub- ou } \\
\text { hiper-reação. }\end{array}$ \\
\hline 3,5 & $\begin{array}{l}\text { Anormalidade Grave: Há um comportamento de cheirar, colocar na boca, ou pegar objetos - pela } \\
\text { sensação em si - sem o objetivo de exploração do objeto. Pode haver uma completa falta de resposta à } \\
\text { dor, assim como uma hiper-reação a algo que é só levemente desconfortável. }\end{array}$ \\
\hline 3,5 &
\end{tabular}




\begin{tabular}{|l|l|}
\hline \multicolumn{1}{|c|}{ Pontos } & 10- MEDO E NERVOSISMO \\
\hline 1 & Sintomas \\
\hline 1,5 & \multicolumn{1}{|c|}{$\begin{array}{l}\text { Anormalidade Leve: De vez em quando a criança demonstra medo e nervosismo que é levemente } \\
\text { inapropriado (para mais ou menos) quando comparado a outras de mesma idade. }\end{array}$} \\
\hline 2 & $\begin{array}{l}\text { Anormalidade Moderada: A criança apresenta um pouco mais ou um pouco menos de medo que uma } \\
\text { criança normal, mesmo quando comparada a outra de menor idade colocada em situação idêntica. Pode ser } \\
\text { difícil entender o que está causando o comportamento de medo apresentado, assim como é difícil confortá- } \\
\text { la nesta situação. }\end{array}$ \\
\hline 3,5 & $\begin{array}{l}\text { Anormalidade Grave: Há manutenção do medo mesmo após repetidas experiências de esperado bem- } \\
\text { estar. Na consulta de avaliação a criança pode estar amedrontada sem razão aparente. É extremamente } \\
\text { difícil acalmá-la. Pode também não apresentar medo/ sentido de auto-conservação a cachorros não } \\
\text { conhecidos, a riscos da rua e trânsito, como outras que as da mesma idade evitam. }\end{array}$ \\
\hline 3,5 &
\end{tabular}

\begin{tabular}{|c|c|}
\hline \multicolumn{2}{|r|}{ 11- COMUNICAÇÃO VERBAL } \\
\hline Pontos & Sintomas \\
\hline 1 & Normal: Fala adequada para sua faixa etária. \\
\hline \multicolumn{2}{|r|}{ ( } \\
\hline 2 & $\begin{array}{l}\text { Anormalidade Leve: Atraso global da fala; conteúdo verbal significativo na maior parte podendo, } \\
\text { entretanto, existir ecolalia ou inversão pronominal em relação ao esperado para sua idade. Usa algumas } \\
\text { palavras peculiares e ocasionalmente há jargonofasia. }\end{array}$ \\
\hline \multicolumn{2}{|l|}{2,5} \\
\hline 3 & $\begin{array}{l}\text { Anormalidade Moderada: Eventualmente não fala. Quando presente a comunicação verbal mistura } \\
\text { conteúdo significativo com fala peculiar, jargões, comerciais de TV, jogo de futebol, reportagem sobre o } \\
\text { tempo; ecolalia; inversão pronominal. Mesmo quando tem significado, o discurso se caracteriza por } \\
\text { questionamentos em excesso e preocupações com tópicos específicos. }\end{array}$ \\
\hline \multicolumn{2}{|r|}{ ( } \\
\hline 4 & $\begin{array}{l}\text { Anormalidade Grave: Não há fala significativa, a criança grunhe e emite sons que lembram animais; } \\
\text { pode até emitir sons mais complexos que se aproximam da fala humana. Pode haver uso persistente, } \\
\text { bizarro, de algumas palavras ou frases. }\end{array}$ \\
\hline
\end{tabular}

\begin{tabular}{|l|l|}
\hline \multicolumn{2}{|c|}{ 12- COMUNICAÇÃO NÃO VERBAL } \\
\hline 1 & Sintomas \\
\hline 1,5 & Normal: Comunicação adequada para sua faixa etária e às situações. \\
\hline 2 & $\begin{array}{l}\text { Anormalidade Leve: Uso imaturo da comunicação não verbal, apontando ou mostrando sem precisão o } \\
\text { que quer, diferentemente de uma criança de sua idade que aponta com maior precisão e usa gestos mais } \\
\text { significativos. }\end{array}$ \\
\hline 2,5 & $\begin{array}{l}\text { Anormalidade Moderada: De regra a criança é incapaz de exprimir suas necessidades e desejos através } \\
\text { de gestos assim como também é incapaz de entender os gestos dos outros. Agarram a mão dos adultos, } \\
\text { levando-os ao objeto desejado, sendo incapazes de mostrá-lo através de gestos. }\end{array}$ \\
\hline 3 & \multicolumn{1}{|l|}{} \\
\hline 3,5 & $\begin{array}{l}\text { Anormalidade Grave: Usa apenas gestos bizarros e peculiares sem significado aparente. Parecem não } \\
\text { conhecer o significado de gestos ou expressões faciais de terceiros. }\end{array}$ \\
\hline
\end{tabular}

\begin{tabular}{|l|l|}
\hline \multicolumn{1}{|c|}{ Pontos } & \multicolumn{1}{c|}{ 13- ATIVIDADE } \\
\hline 1 & Normal: Apropriada para a situação e para a idade cronológica. \\
\hline 1,5 & \multicolumn{1}{|c|}{$\begin{array}{l}\text { Anormalidade Leve: Pode existir alguma inquietude ou lentidão de movimentos. Seu grau de atividade } \\
\text { interfere de maneira leve na performance da criança. É possível mantê-la com um nível de atividade } \\
\text { adequado. }\end{array}$} \\
\hline 2 & $\begin{array}{l}\text { Anormalidade Moderada: Apresenta-se inquieta e com dificuldades para ficar quieta. Aparenta enorme } \\
\text { energia, não querendo parar para dormir. Pode ainda ser letárgica e exigir grandes esforços para modificar } \\
\text { esse comportamento. Costumam evitar jogos que exijam atividade física, passando por "preguiçosos". }\end{array}$ \\
\hline 3,5 & \multicolumn{1}{|c|}{} \\
\hline 3,5 & Anormalidade Grave: Níveis de atividades extremas variando do hiper ao hipo e c/ facilidade em passar \\
\hline 4
\end{tabular}




\begin{tabular}{|l|l|}
\hline & $\begin{array}{l}\text { de um a outro nível. Difícil de manipular. A hiperatividade, quando presente, manifesta-se em todas as } \\
\text { atividades do cotidiano, exigindo acompanhamento contínuo. Se hipoativa, é difícil motivá-la para qualquer } \\
\text { coisa. }\end{array}$ \\
\hline
\end{tabular}

\begin{tabular}{|l|l|}
\hline \multicolumn{1}{|c|}{ Pontos } & \multicolumn{1}{c|}{ 14- GRAU E CONSISTÊNCIA DAS RESPOSTAS DA INTELIGÊNCIA } \\
\hline 1 & $\begin{array}{l}\text { Normal: A criança é inteligente, como qualquer criança normal de sua idade, não se detectando } \\
\text { inabilidades ou problemas. }\end{array}$ \\
\hline 1,5 & $\begin{array}{l}\text { Anormalidade Leve: A criança não é tão inteligente como outra de sua idade e, quanto às suas } \\
\text { habilidades, apresenta atraso global e homogêneo em todas as áreas. }\end{array}$ \\
\hline 2 & $\begin{array}{l}\text { Anormalidade Moderada: De regra é uma criança não tão inteligente quanto os de sua idade porém, em } \\
\text { algumas áreas, seu desempenho intelectual situa-se próximo ao normal. }\end{array}$ \\
\hline 2,5 & $\begin{array}{l}\text { Anormalidade Grave: mesmo com uma inteligência inferior ao de uma criança normal destaca-se, até } \\
\text { mesmo com bom desempenho, em algumas áreas, como por ex. : talento p/ música, facilidade com } \\
\text { números. }\end{array}$ \\
\hline 4,5 &
\end{tabular}

\begin{tabular}{|c|c|}
\hline \multicolumn{2}{|r|}{ 15- IMPRESSÃO GERAL } \\
\hline Pontos & 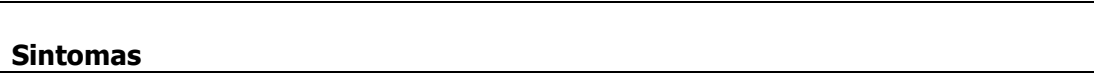 \\
\hline 1 & Não há autismo. A criança não apresentou nenhum sintoma característico de autismo. \\
\hline 1,5 & \\
\hline 2 & Autismo Leve: alguns, poucos, sintomas ou grau leve de autismo. \\
\hline 2,5 & \\
\hline 3 & Autismo Moderado : vários sintomas de autismo. \\
\hline 3,5 & \\
\hline 4 & Autismo Grave: muitos sintomas de autismo. \\
\hline
\end{tabular}


VIII.APÊNDICES 
APÊNDICE A - Versão em português do Eyes-C

\section{Exemplo}

\section{CIUMENTO}

ASSUSTADO

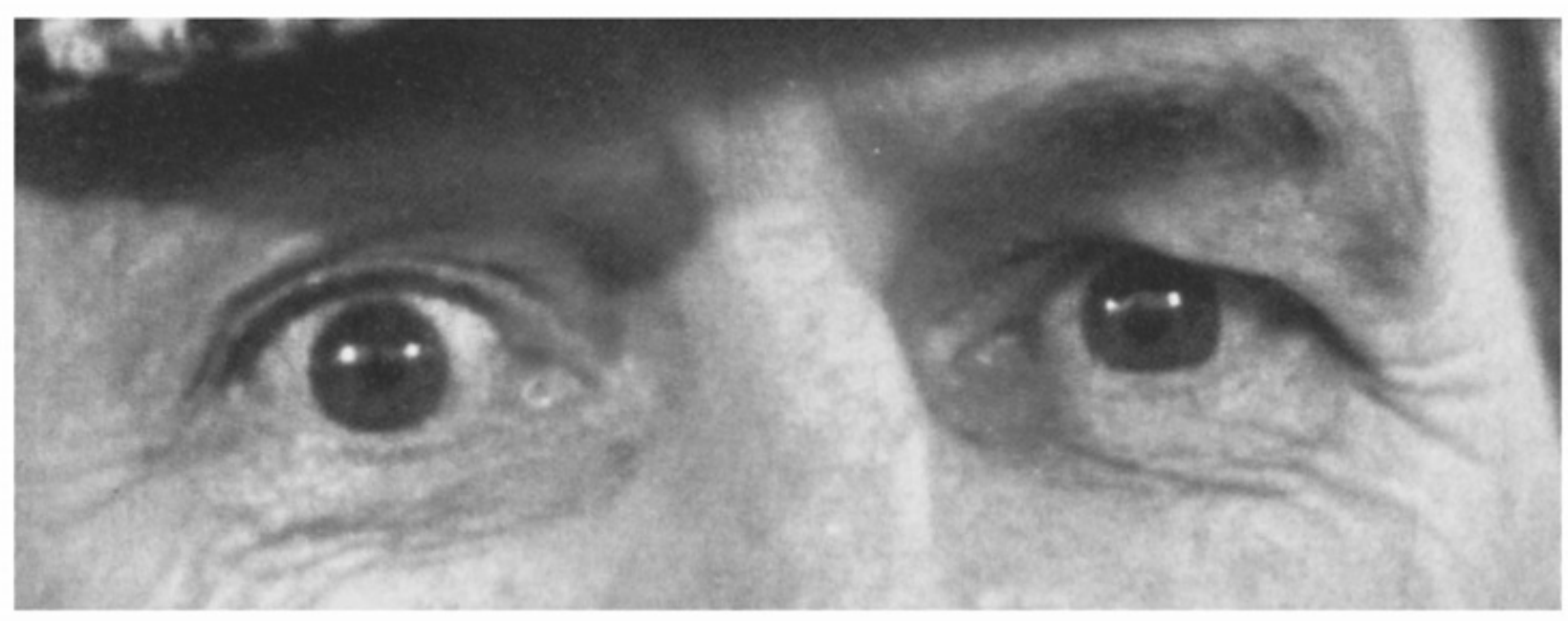

RELAXADO

COM CARA DE ÓDIO 
1

CARA DE ÓDIO
SURPRESO

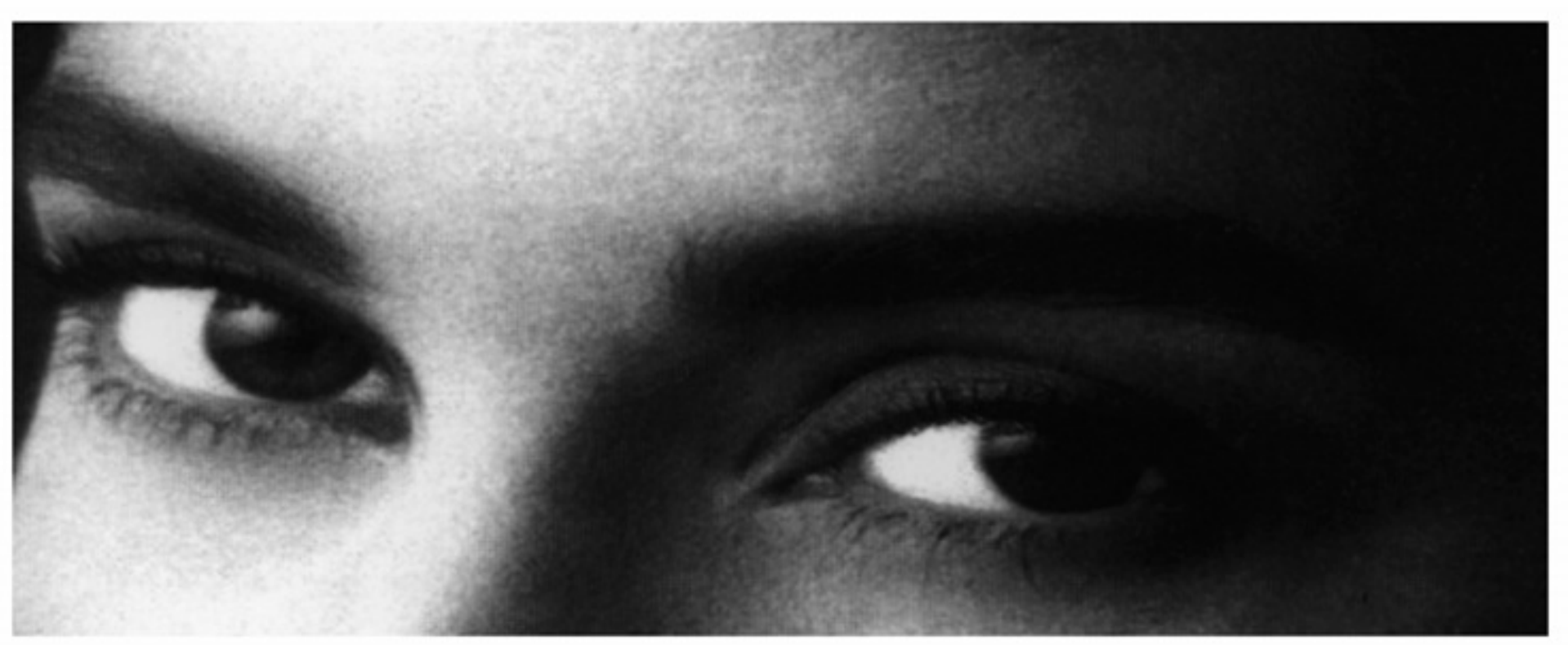

AMÁVEL

ZANGADO

(GENTIL) 
2

MEIO BRAVO
ZANGADO 
3

SIMPÁTICO

TRISTE

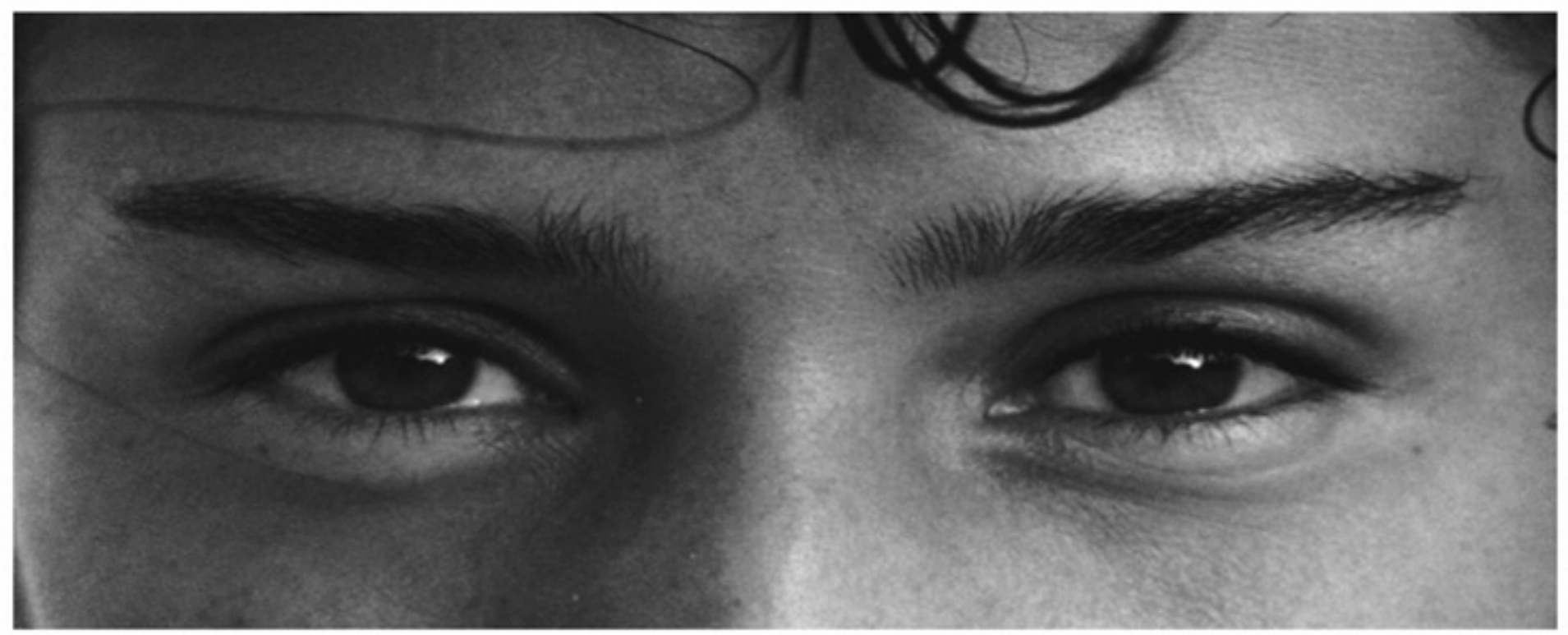

SURPRESO

PREOCUPADO 
4

TRANQUILO

CHATEADO

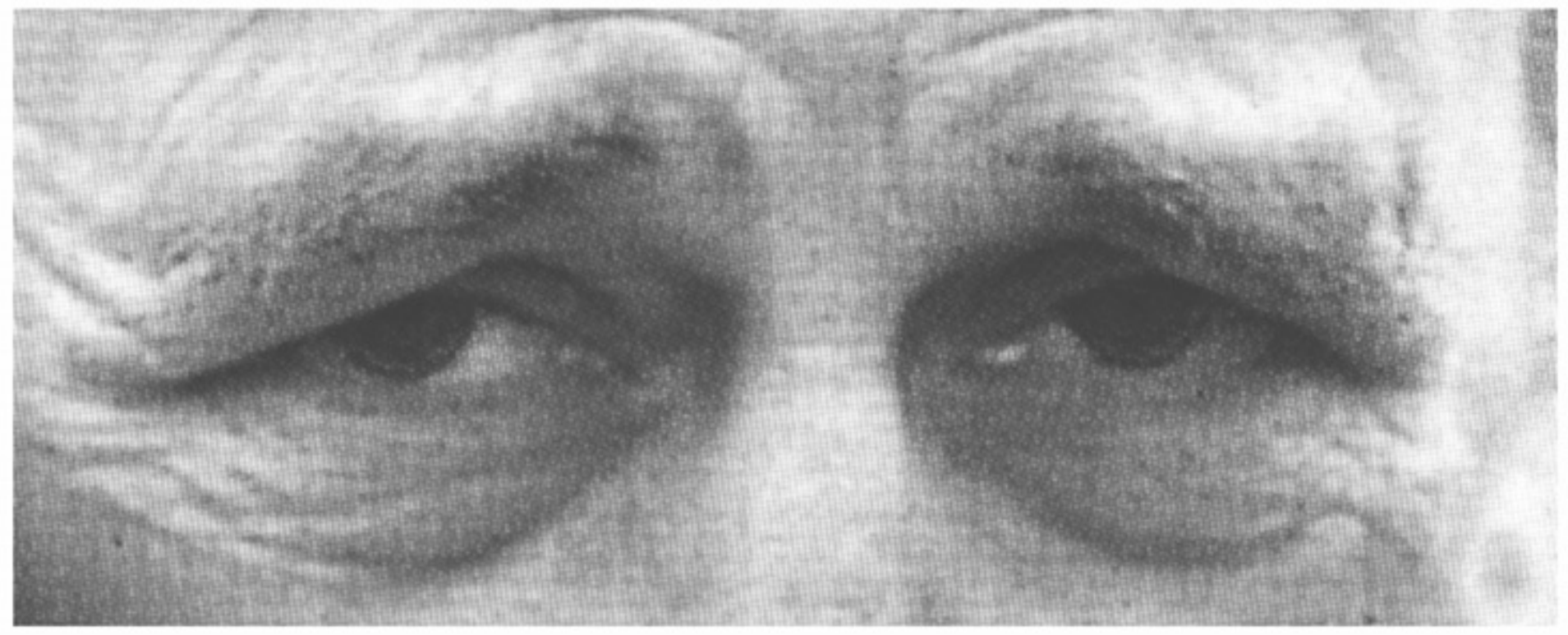

SURPRESO

ANIMADO 
5

ARREPENDIDO
PERSUASIVO (CONVENCENDO ALGUÉM A FAZER ALGO)

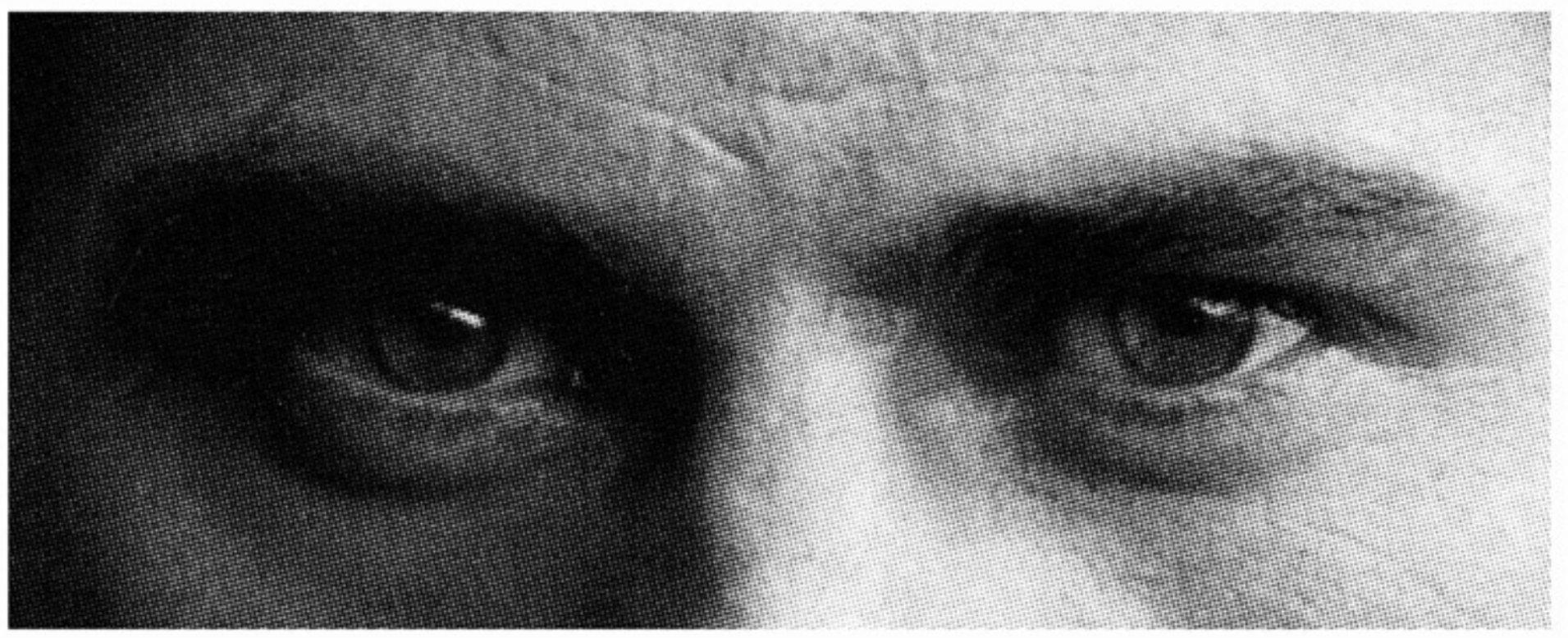


6

CARA DE ÓDIO

CRUEL

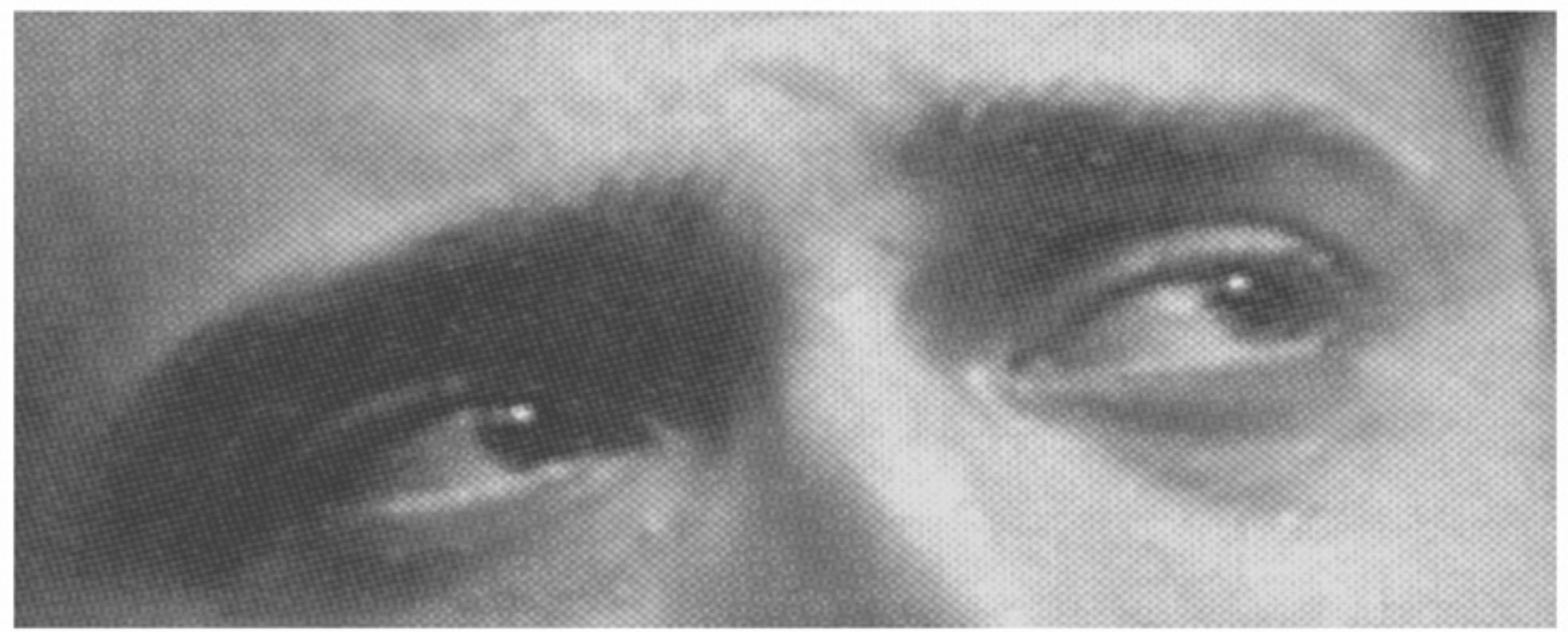

PREOCUPADO 
7

ARREPENDIDO
ENTEDIADO

(ACHANDO CHATO)

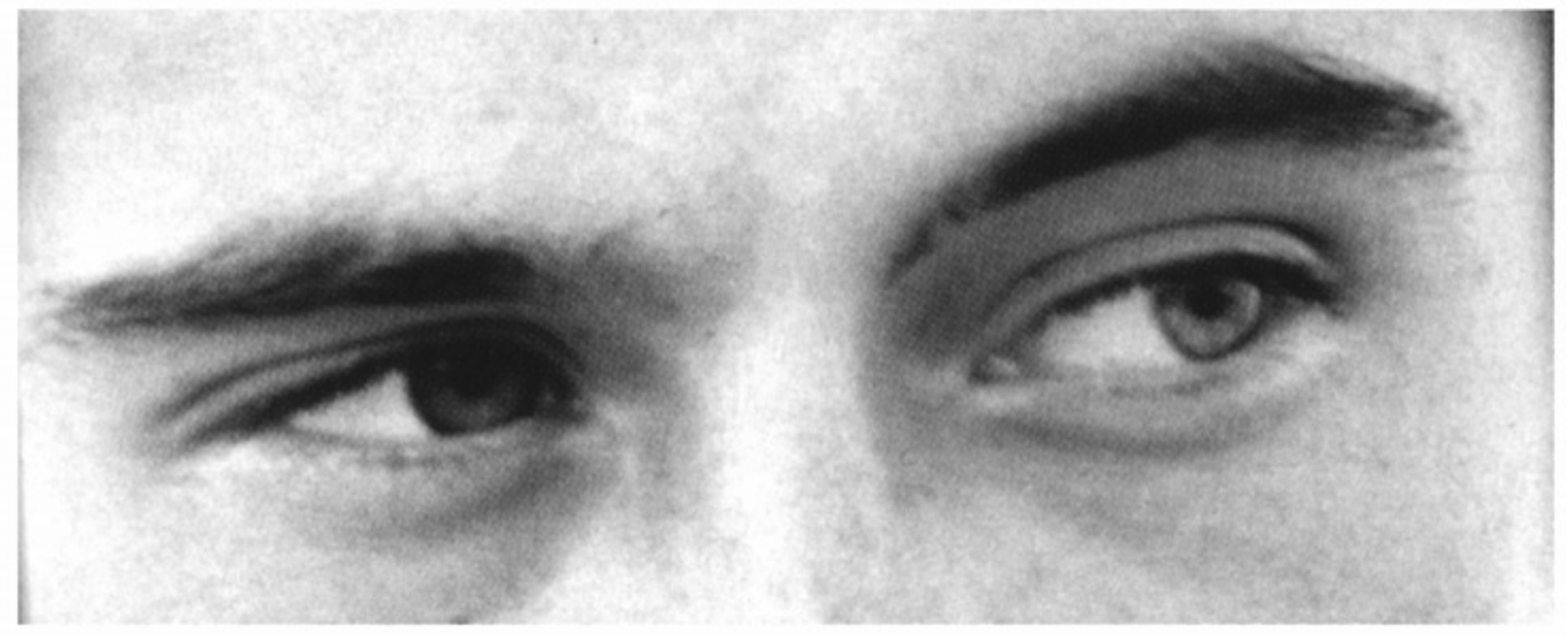

INTERESSADO

BRINCALHÃO 
8

LEMBRANDO DE CONTENTE ALGUMA COISA

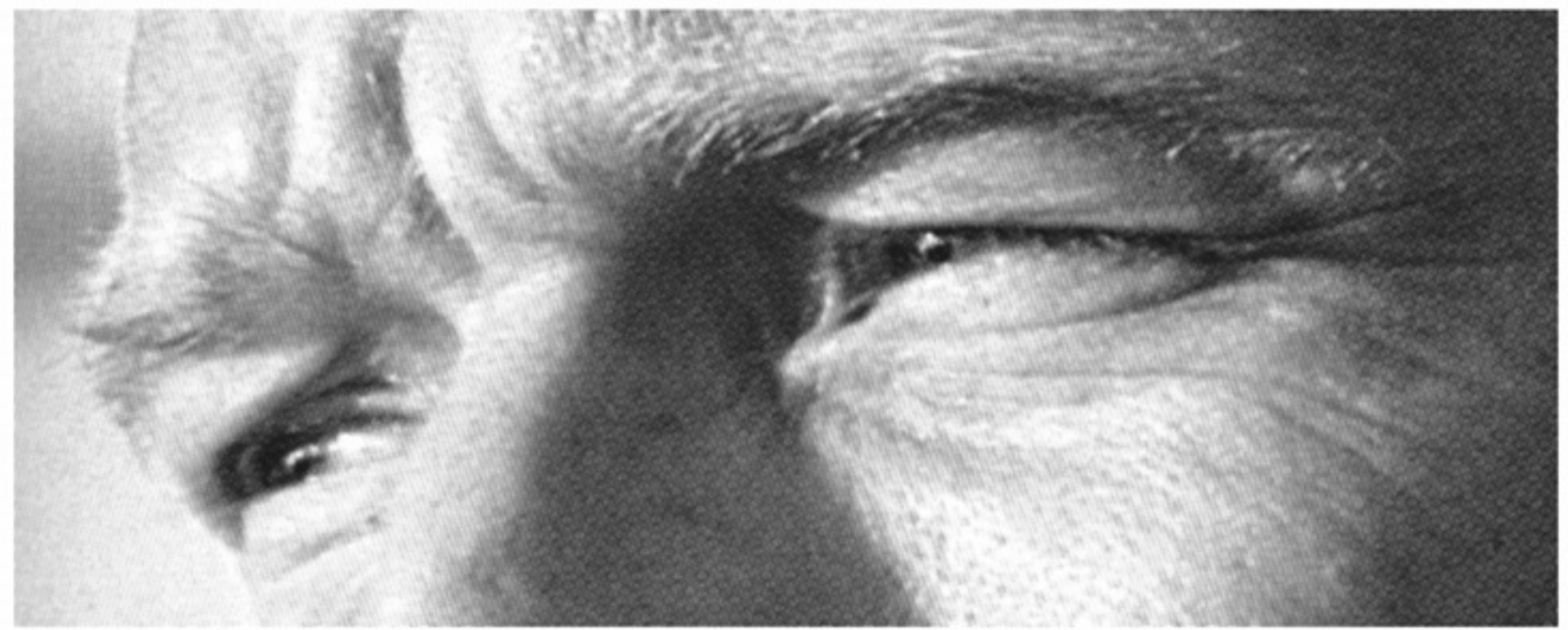

SIMPÁTICO

ZANGADO 
9

IRRITANTE

(TENTANDO

IRRITAR ALGUÉM)
CARA DE ÓDIO

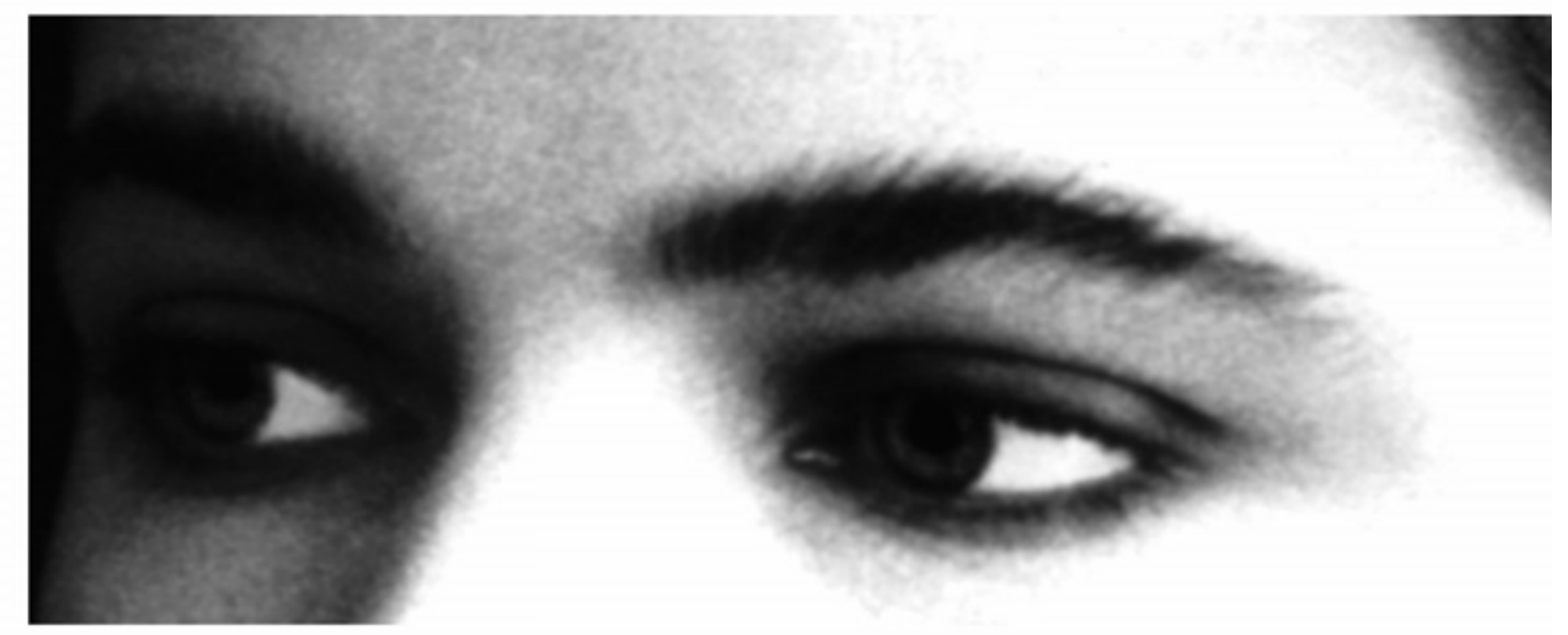

SURPRESO

PENSATIVO 
10

AMÁVEL

(GENTIL)
TÍMIDO

(COM VERGONHA)

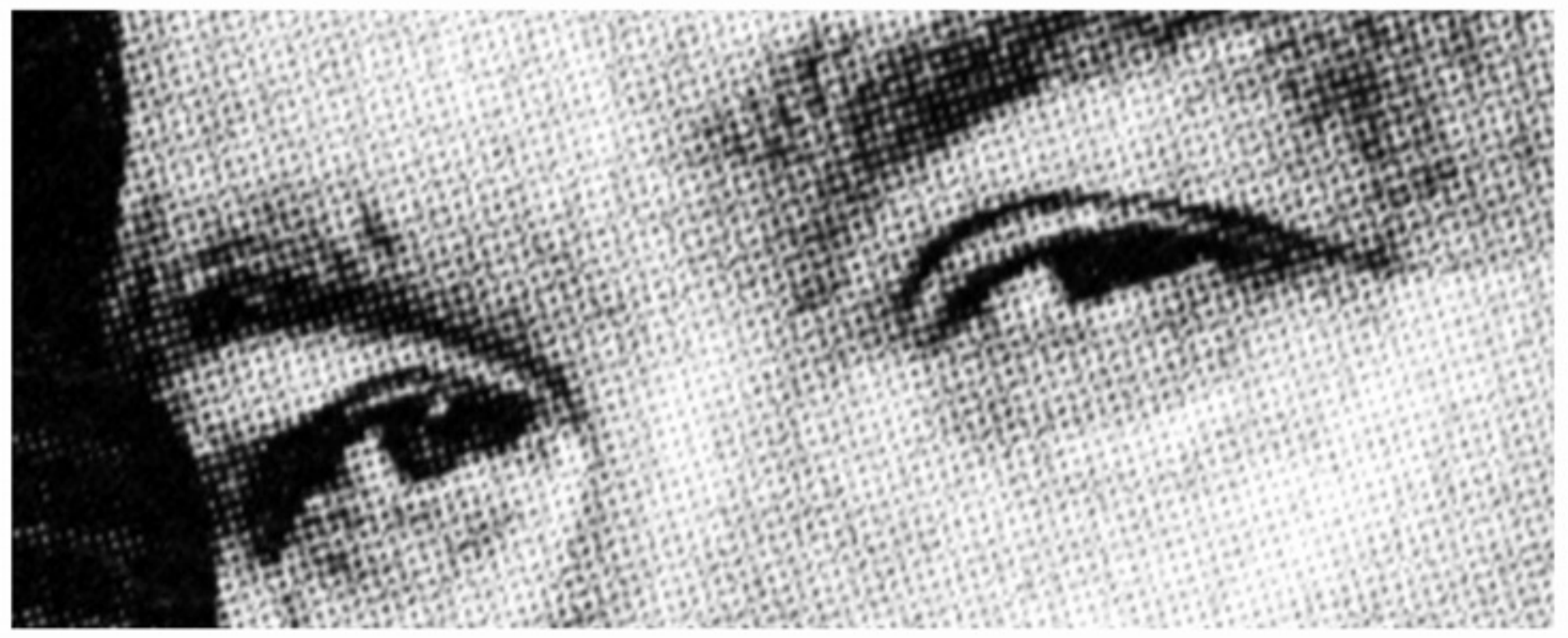

DUVIDANDO

TRISTE

(COM CARA DE QUEM

NÃO ESTÁ ACREDITANDO) 


\section{1}

MANDÃO

ESPERANÇOSO

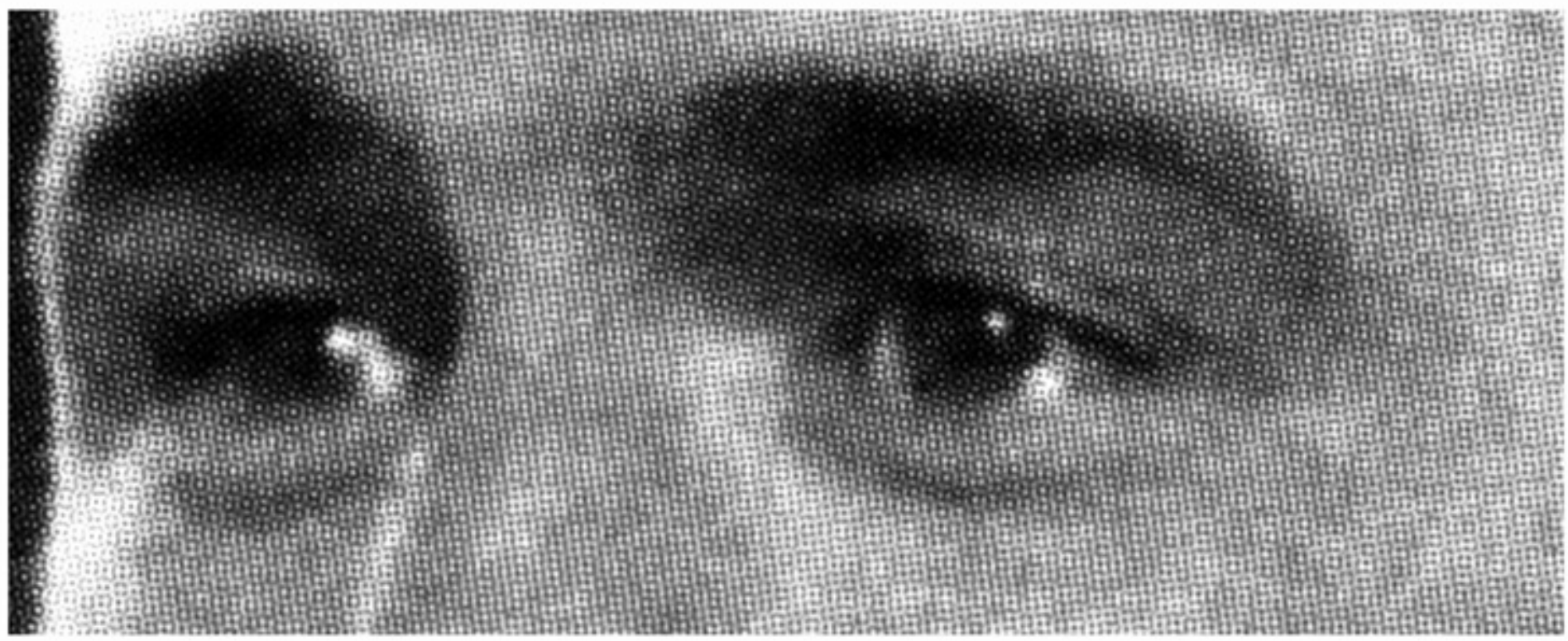




\section{2}

CONFUSO

\section{BRINCALHÃO}

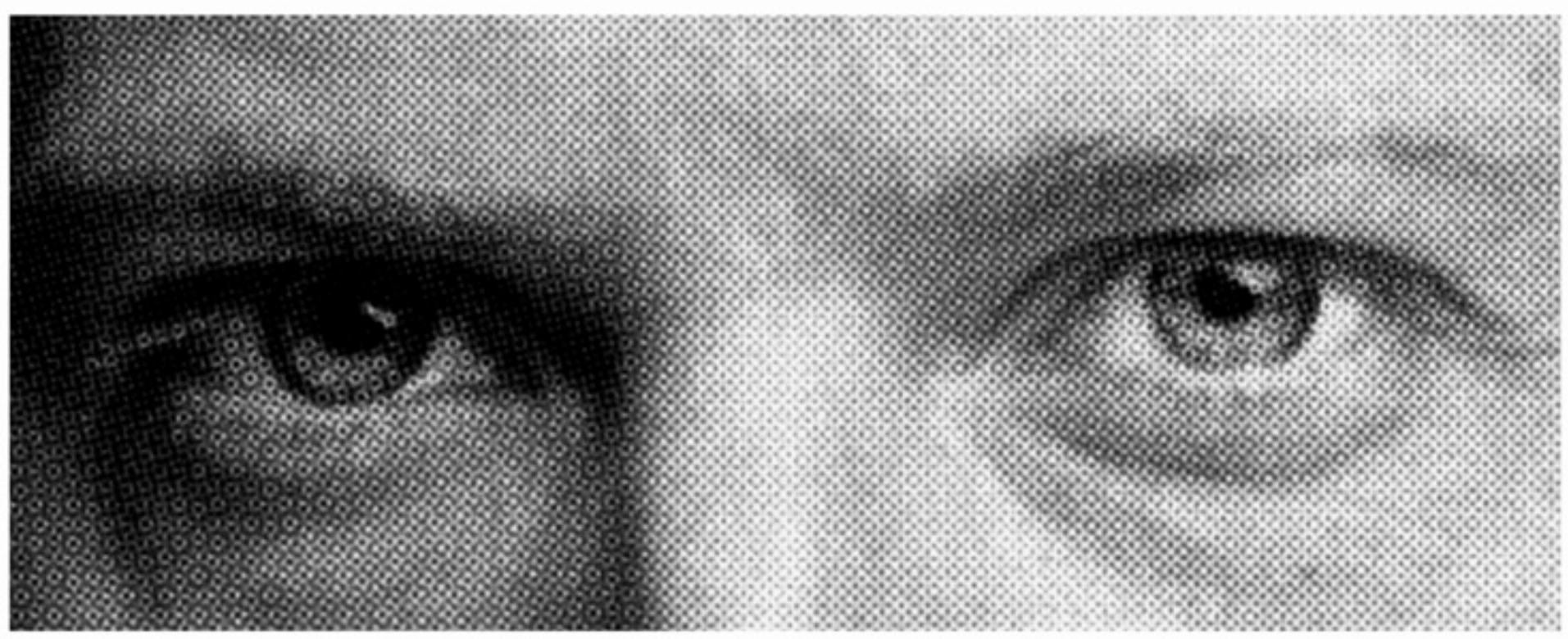




\section{3}

PENSATIVO
ABORRECIDO

(CHATEADO)

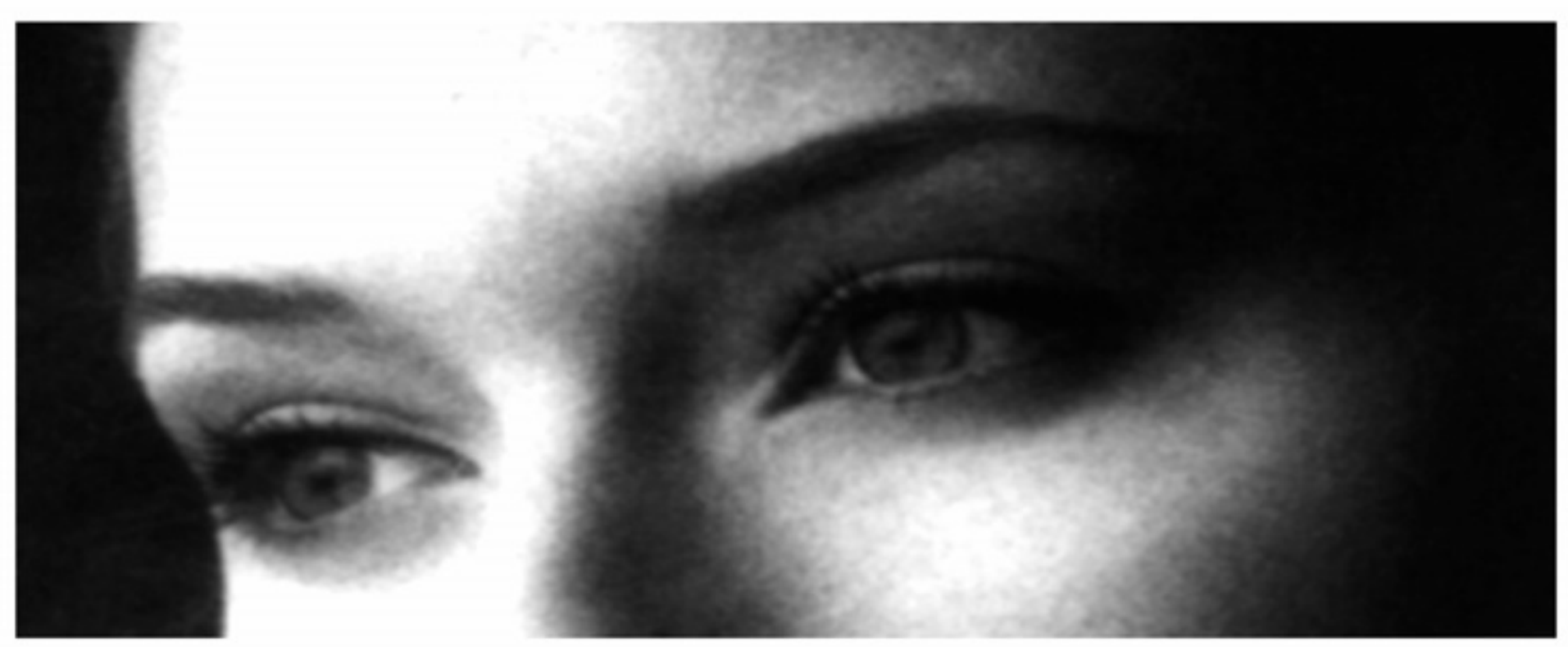

ANIMADO 


\section{4}

CONTENTE

(FELIZ)

\section{PENSATIVO}

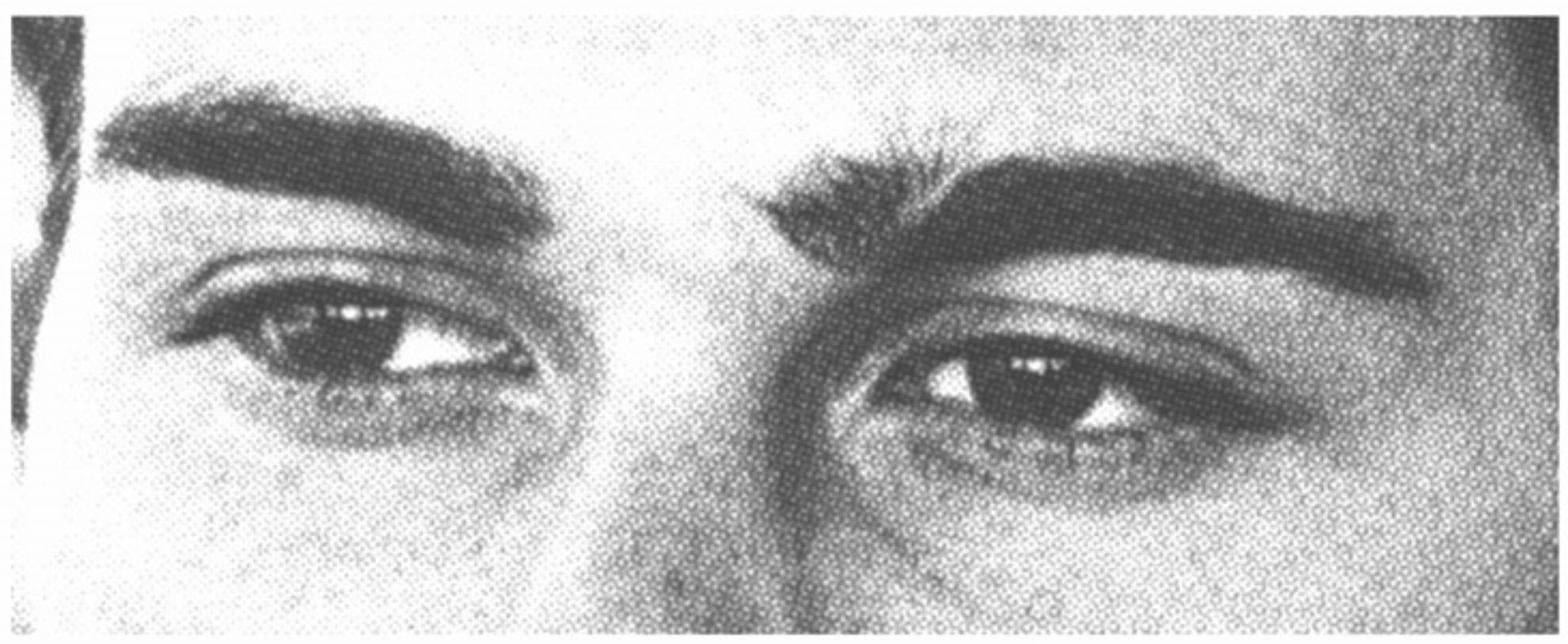

ANIMADO

AMÁVEL

(GENTIL) 


\section{5}

INCRÉDULO

SIMPÁTICO

(DUVIDANDO)

QUERENDO BRINCAR

TRANQUILO 


\title{
16 \\ DECIDIDO
}

\author{
BRINCALHÃO
}

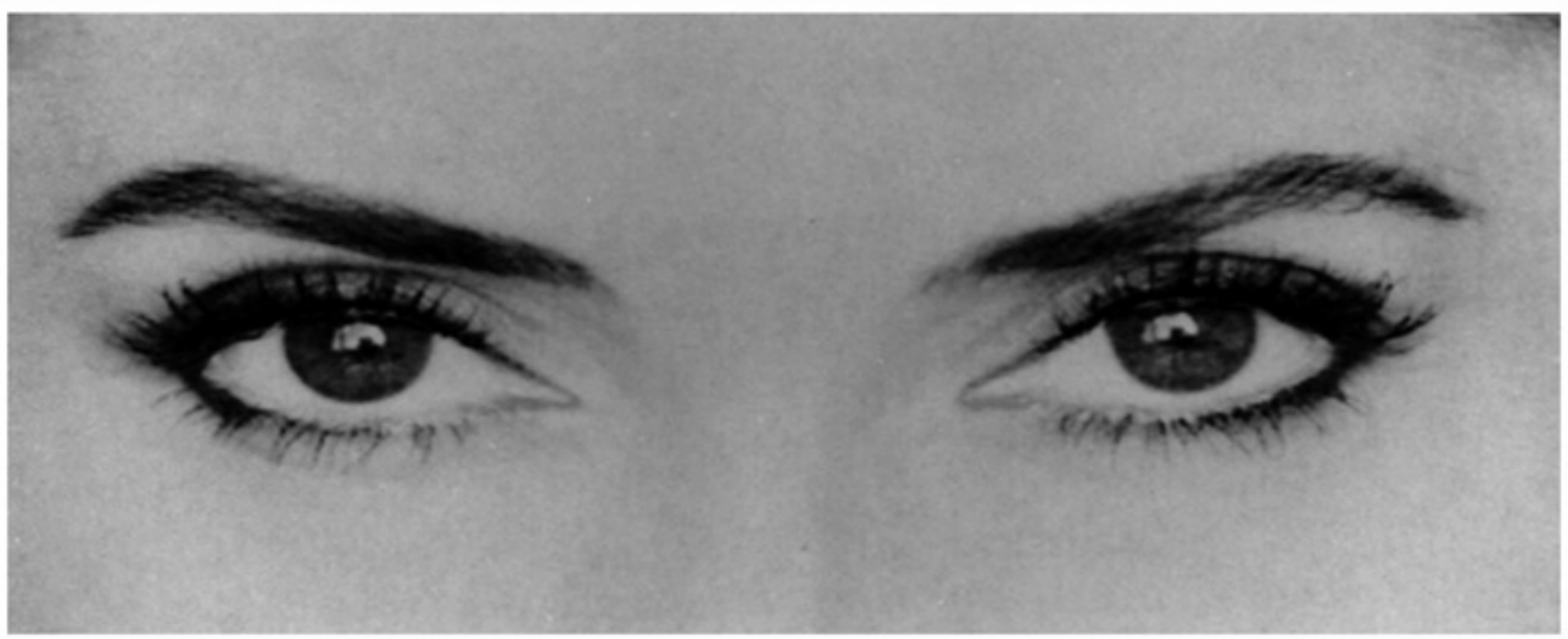

SURPRESO

ACHANDO CHATO 


\section{7}

ZANGADO
SIMPÁTICO

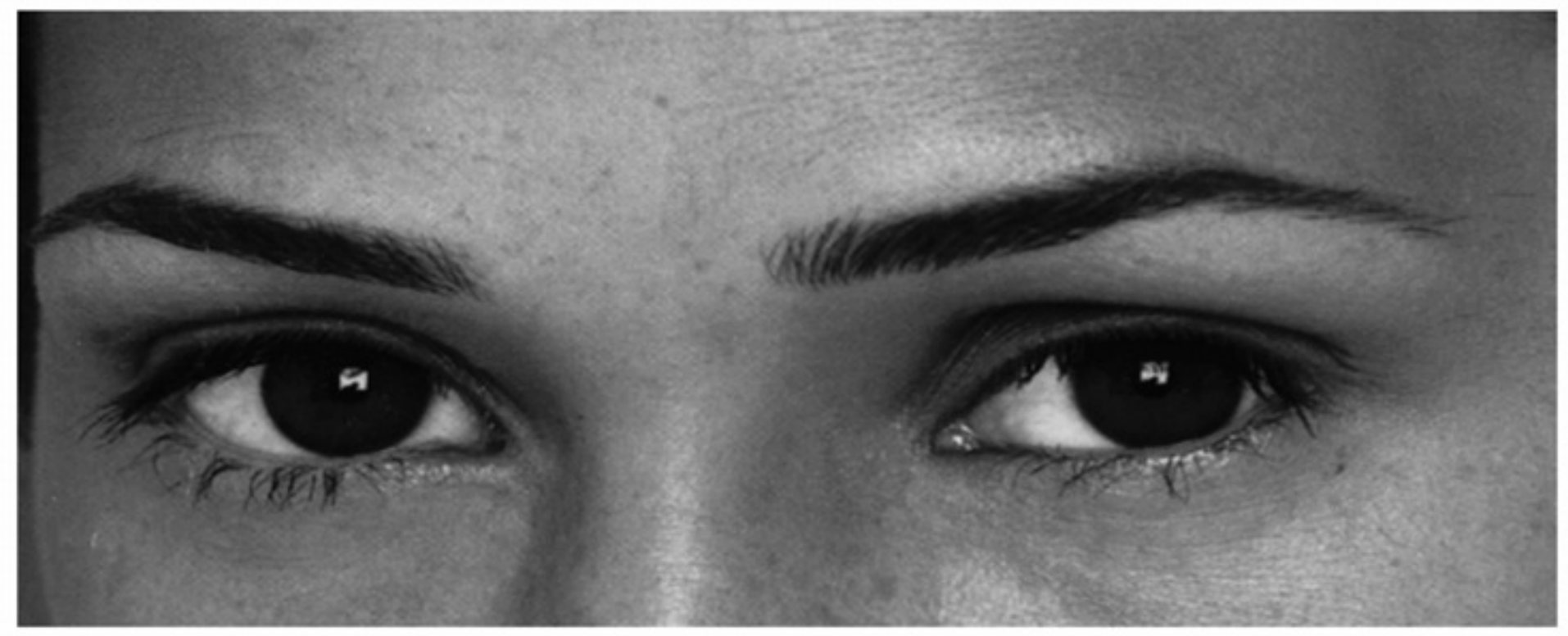

RUDE

UM POUCO PREOCUPADO

(MEIO BRAVO) 


\section{8 \\ PENSANDO EM ALGO \\ TRISTE}

ZANGADO

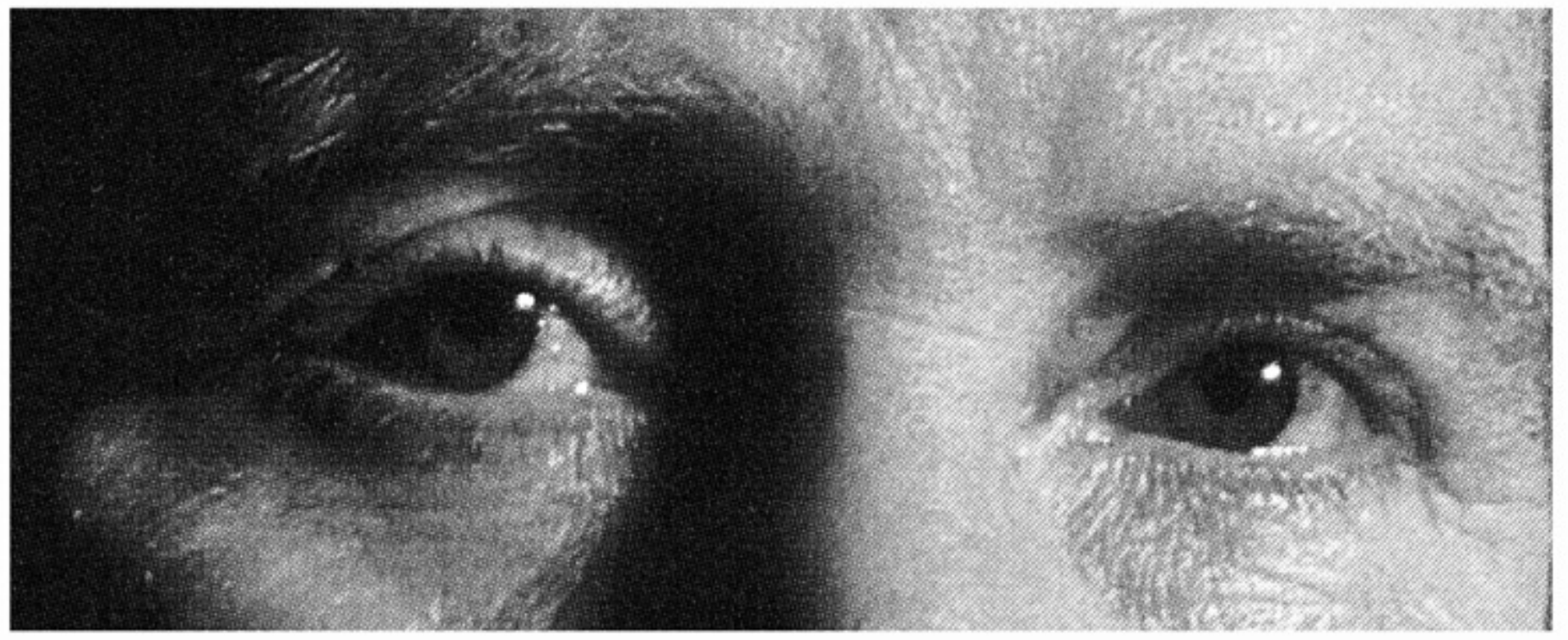

MANDÃO

(CARA DE QUEM ESTÁ

MANDANDO EM ALGUÉM)

SIMPÁTICO 
19

ZANGADO
SONHANDO ACORDADO (IMAGINANDO UMA HISTÓRIA) 


\section{0 AMÁVEL \\ (GENTIL)}

SURPRESO

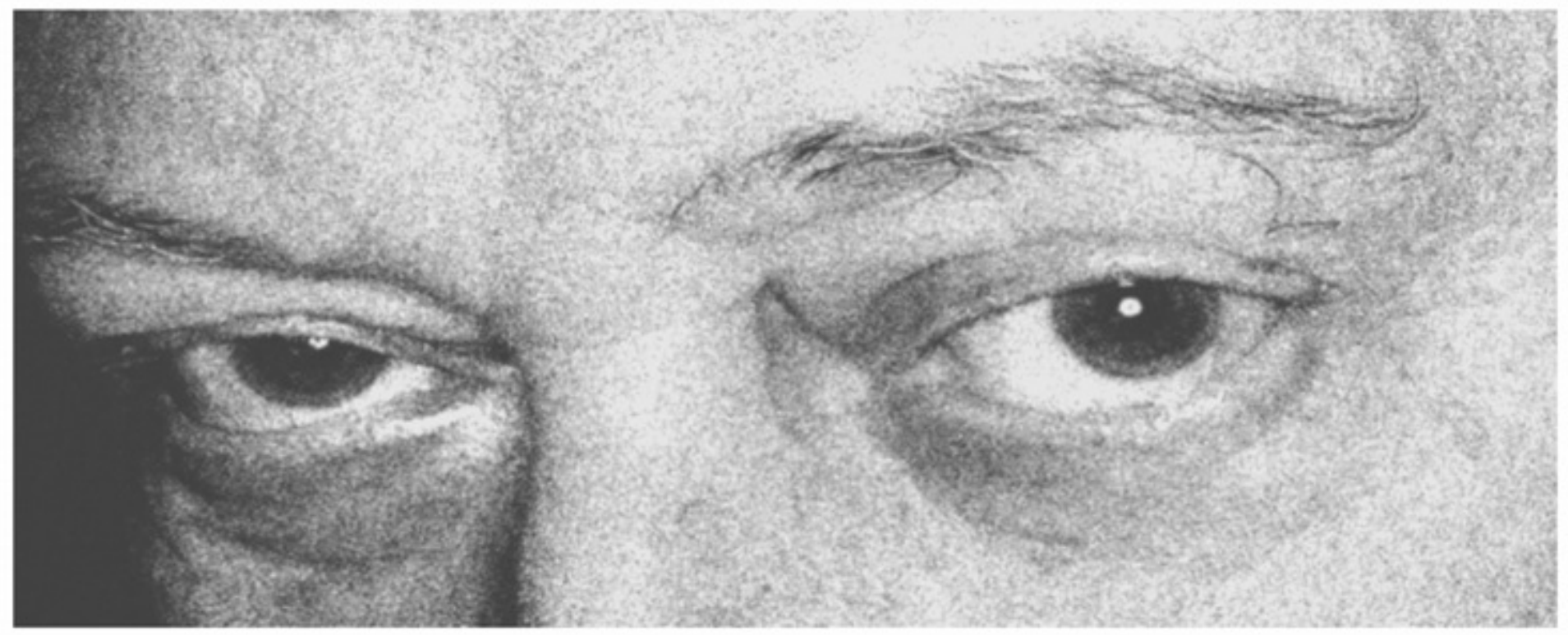

INSATISFEITO

ANIMADO 


\section{1}

INTERESSADO

BRINCALHÃO

(GOSTANDO DO

QUE VÊ)

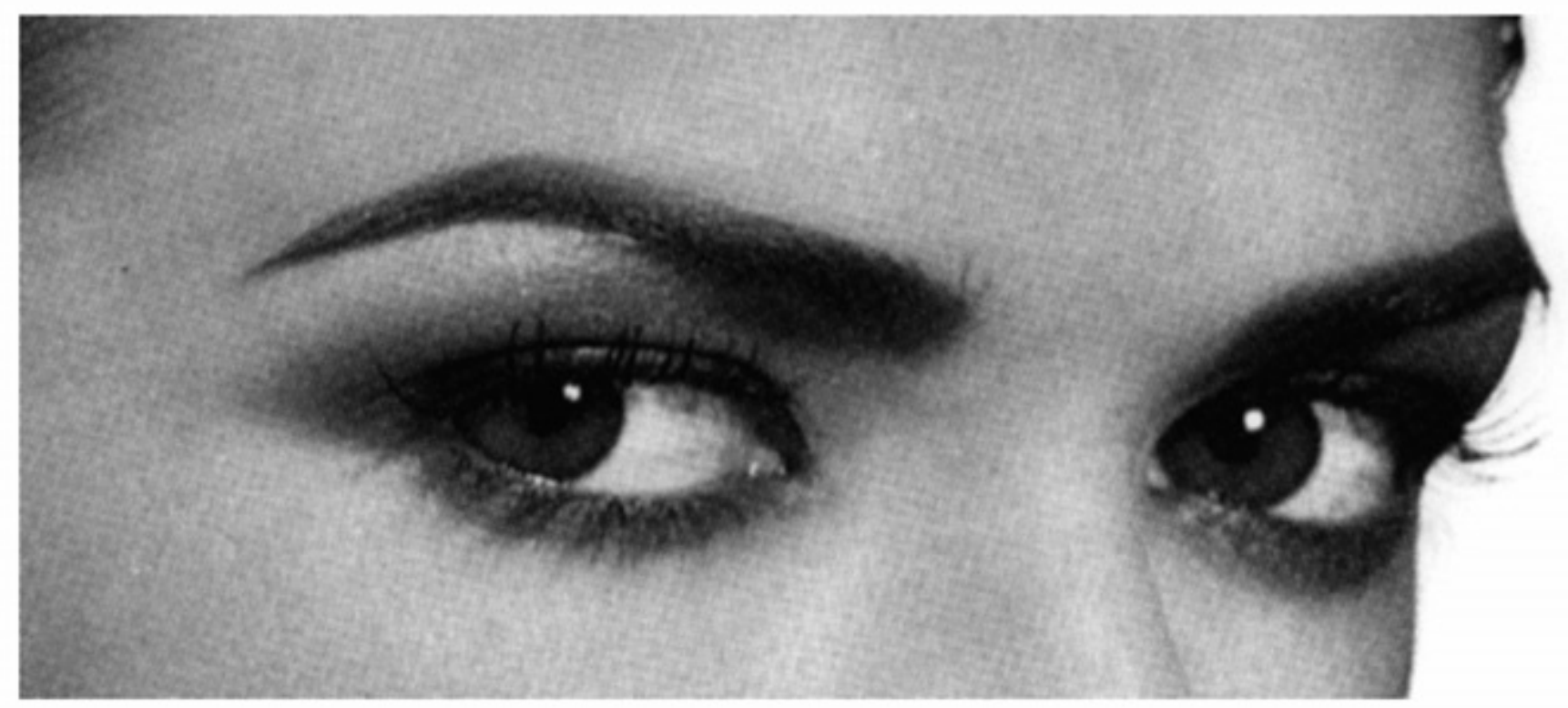

TRANQUILO

CONTENTE 


\section{2 \\ BRINCALHÃO}

AMÁVEL

(GENTIL)

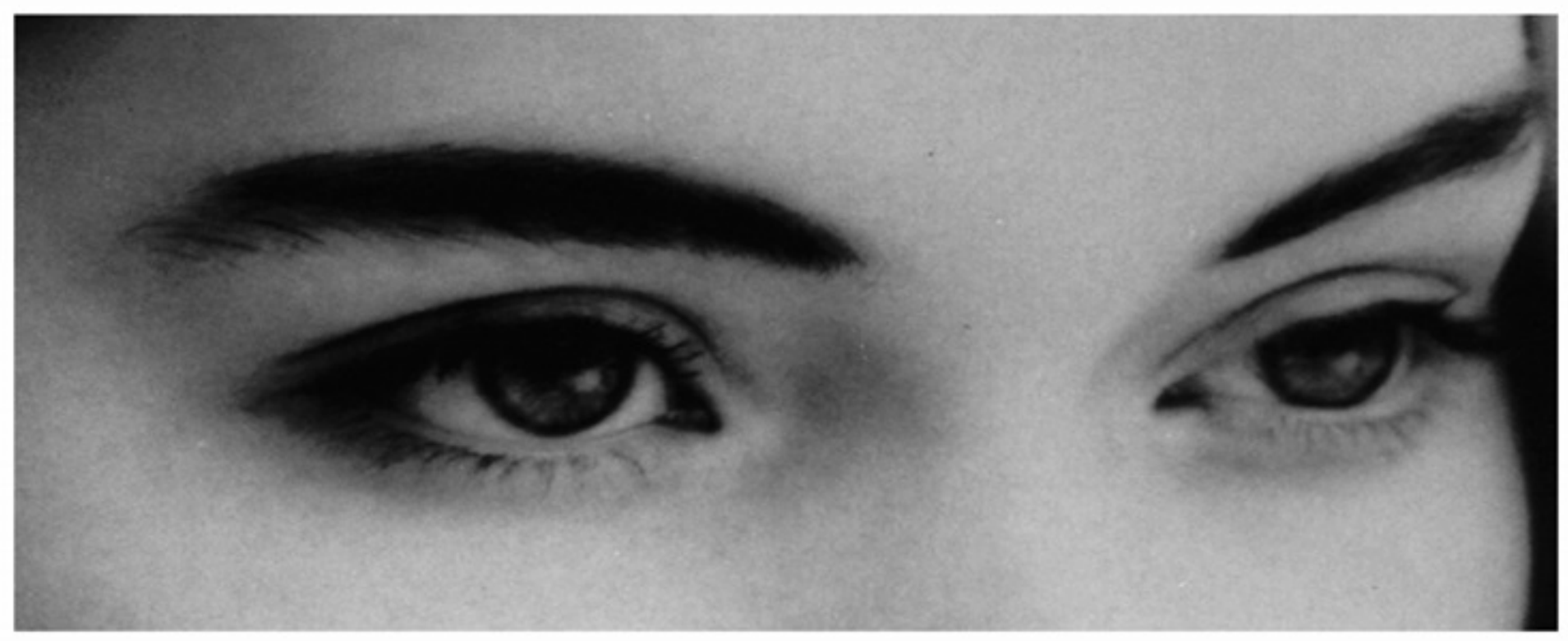

SURPRESO

PENSATIVO 
23

SURPRESO
SEGURO DE ALGO

(COM CARA DE QUEM

TEM CERTEZA)

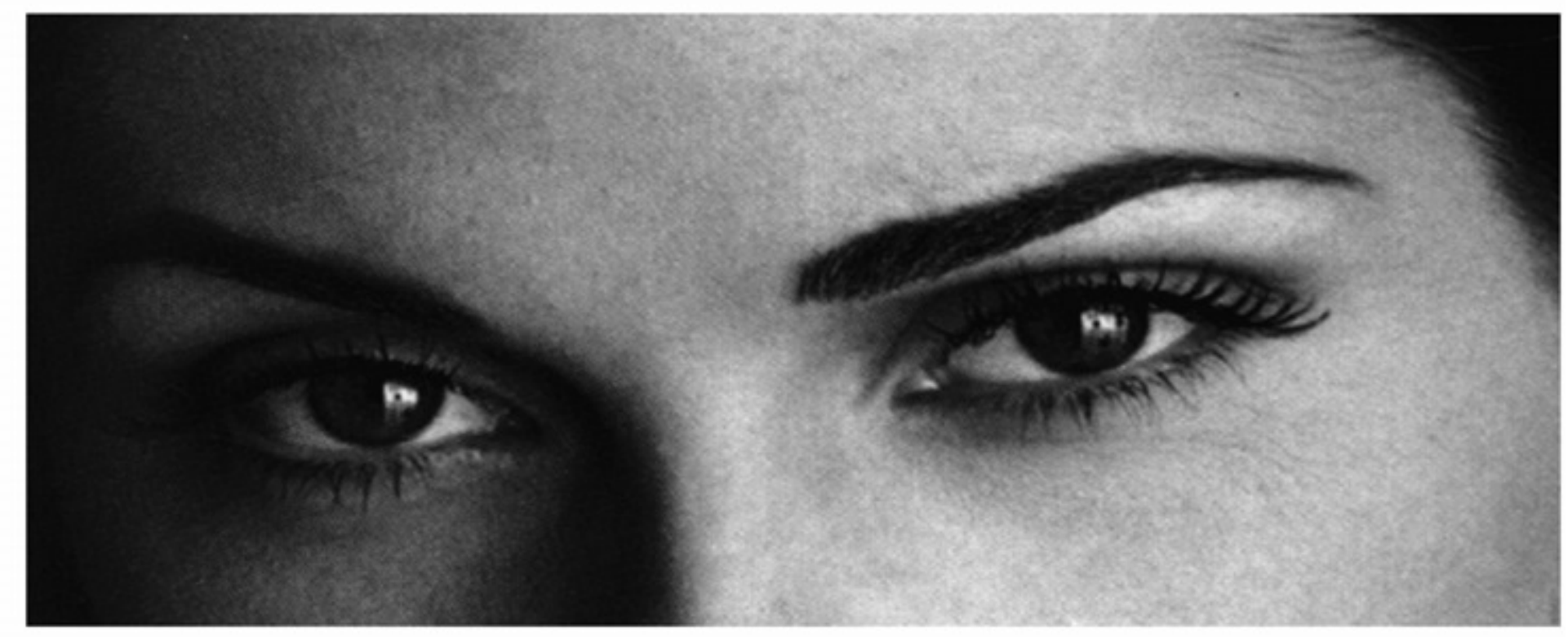

BRINCALHÃO

CONTENTE 
24

SÉRIO
ENVERGONHADO

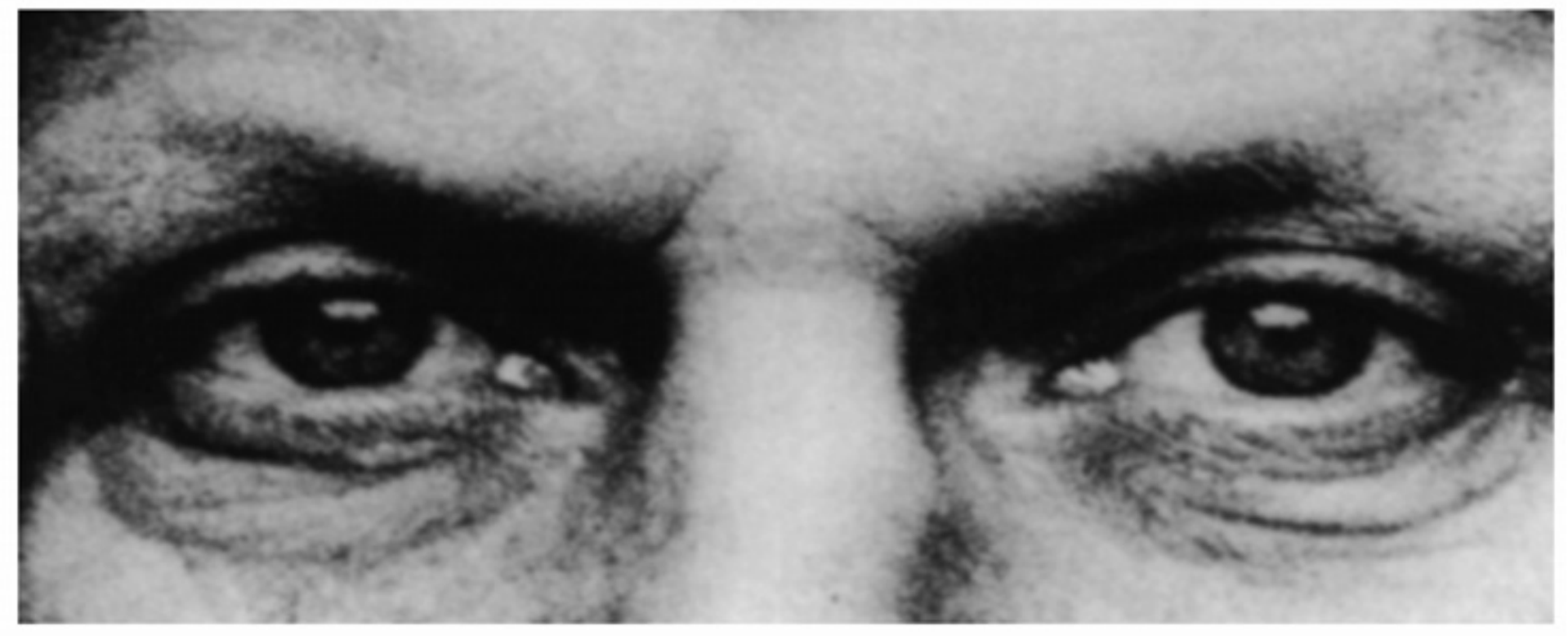

CONFUSO

SURPRESO 


\section{5 \\ TÍMIDO}

CULPADO

(COM CARA DE QUEM

FEZ ALGO ERRADO) 
26

BRINCALHÃO
TRANQUILO

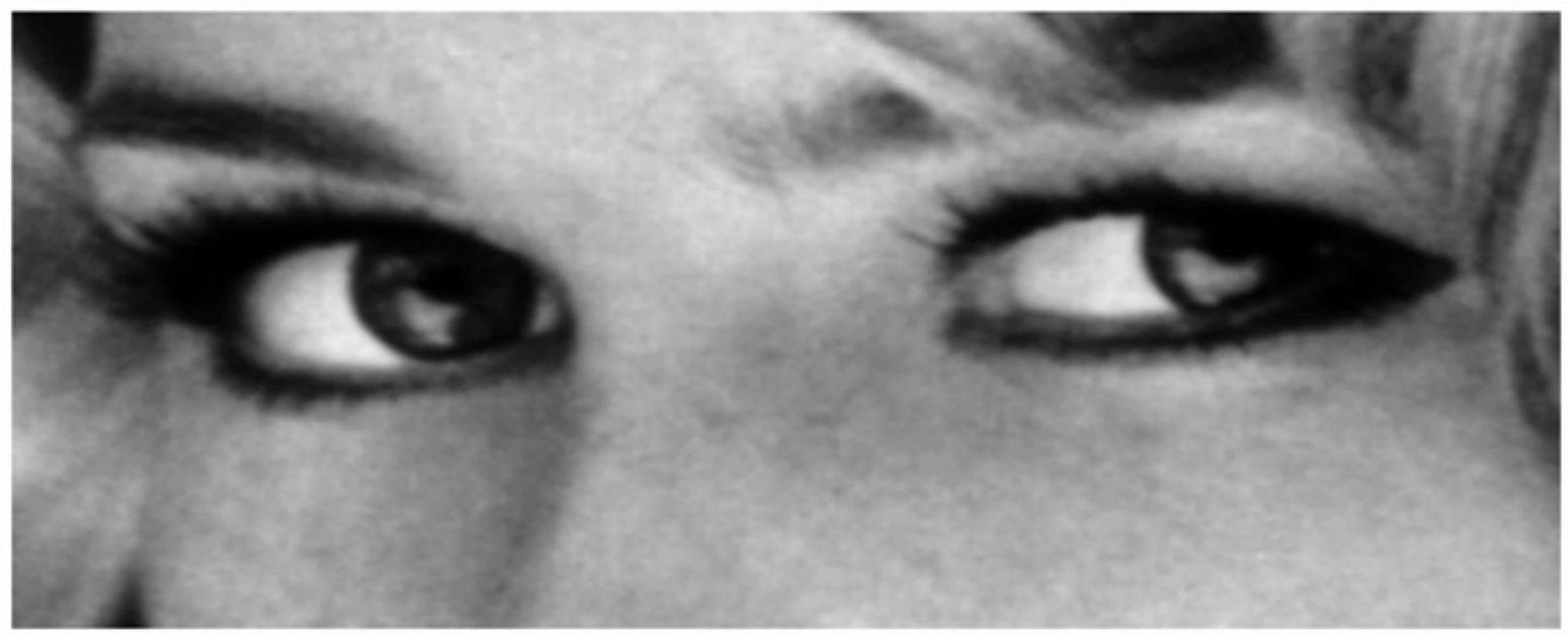

NERVOSO

ARREPENDIDO

(BRAVO) 
27

ENVERGONHADO

\section{ENTUSIASMADO}

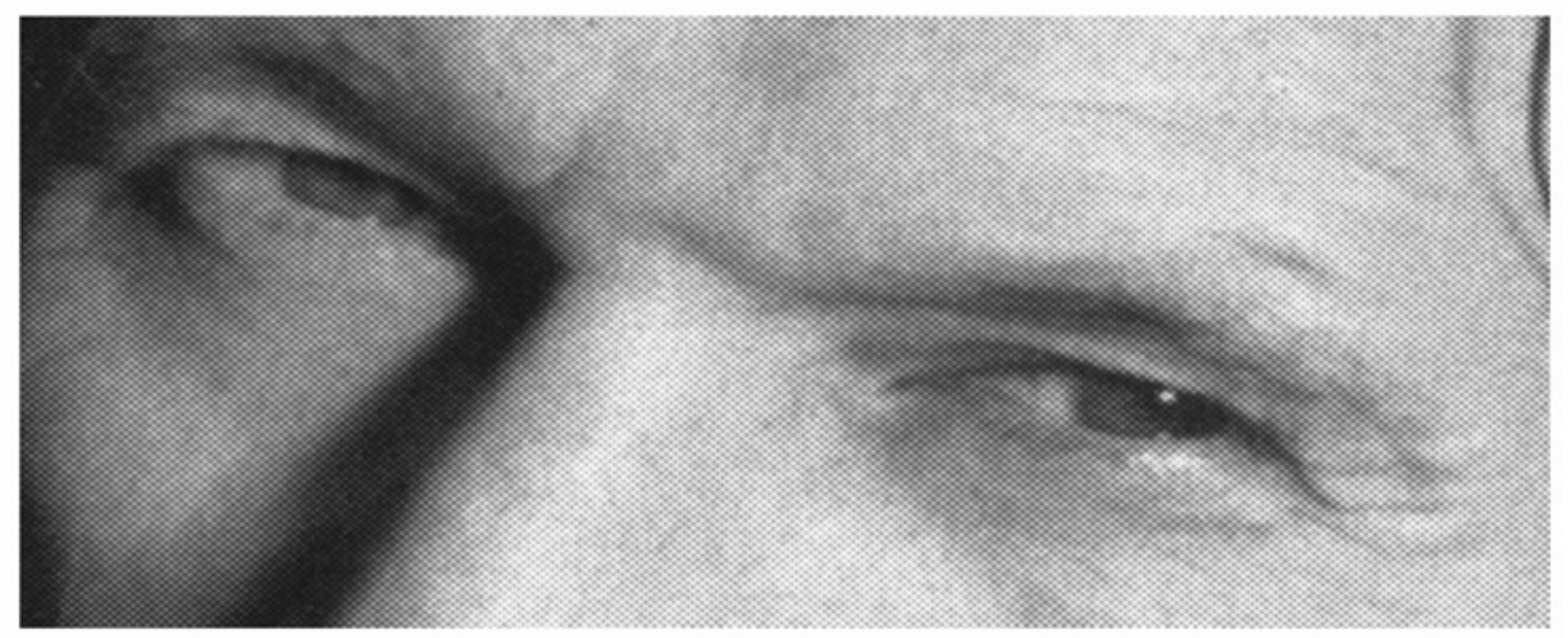

INCRÉDULO

(COM CARA DE QUEM NÃO ESTÁ ACREDITANDO)

SATISFEITO 


\title{
28 \\ CARA DE NOJO \\ CARA DE ÓDIO
}

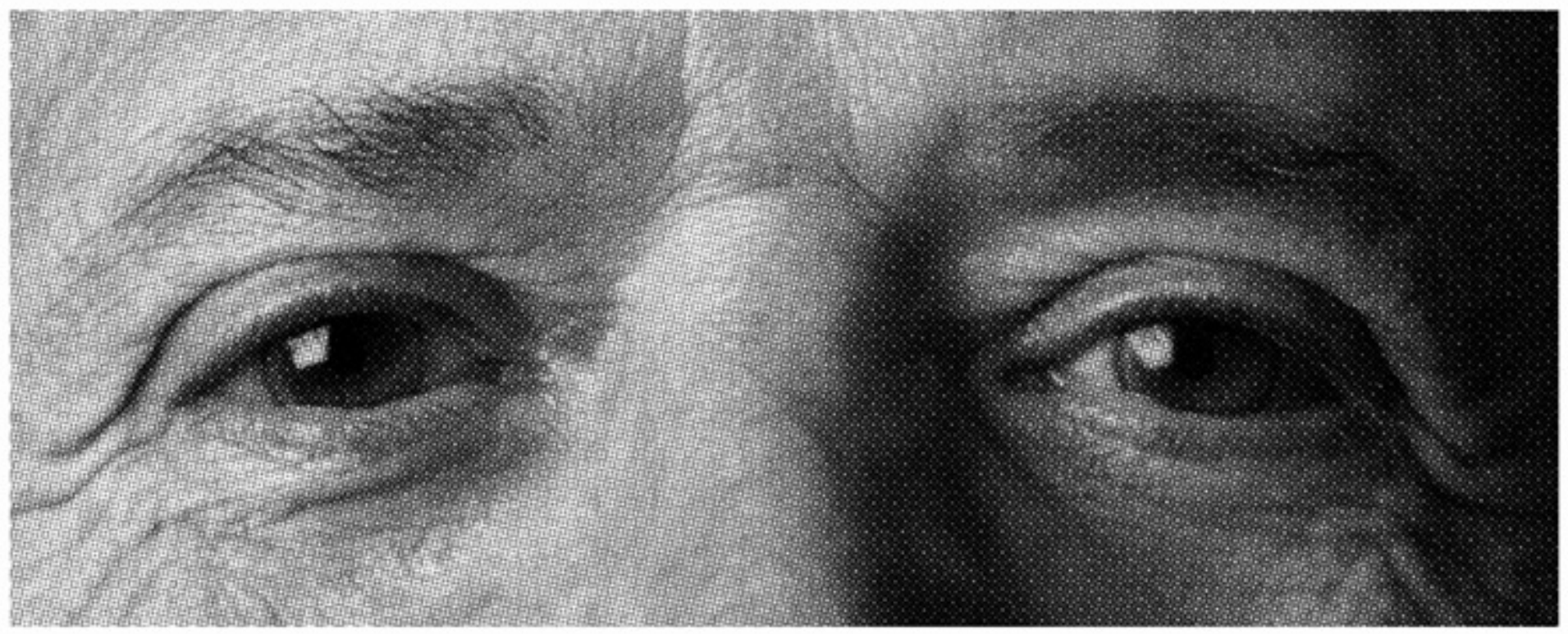

CONTENTE

\author{
ENTEDIADO \\ (ACHANDO CHATO)
}




\section{APÊNDICE B - Caracterização da Amostra Clínica}

\begin{tabular}{|c|c|c|c|c|}
\hline Sexo & $\begin{array}{c}\text { ATA } \\
\text { (Pontos) }\end{array}$ & $\begin{array}{c}\text { Subteste } \\
\text { vocabulário } \\
\text { WISC III } \\
\text { (Pontos } \\
\text { Ponderados) } \\
\end{array}$ & Idade & $\begin{array}{c}\text { Eyes-C } \\
\text { (Pontos) }\end{array}$ \\
\hline masculino & 35 & 17 & 10,5 & 20 \\
\hline masculino & 34 & 10 & 11,1 & 15 \\
\hline masculino & 35 & 13 & 11,0 & 11 \\
\hline masculino & 36 & 15 & 9,0 & 11 \\
\hline masculino & 32 & 9 & 7,4 & 10 \\
\hline masculino & 30 & 19 & 7,2 & 15 \\
\hline masculino & 38 & 14 & 11,2 & 16 \\
\hline masculino & 34 & 8 & 13,3 & 16 \\
\hline masculino & 29 & 19 & 7,7 & 16 \\
\hline masculino & 32 & 12 & 7,2 & 20 \\
\hline masculino & 30 & 9 & 11,0 & 17 \\
\hline feminino & 36 & 10 & 6,4 & 4 \\
\hline masculino & 39 & 18 & 8,7 & 12 \\
\hline masculino & 39 & 12 & 6,6 & 11 \\
\hline masculino & 26 & 18 & 8,9 & 20 \\
\hline masculino & 30 & 8 & 8,6 & 7 \\
\hline feminino & 24 & 11 & 10,0 & 15 \\
\hline masculino & 28 & 9 & 12,0 & 13 \\
\hline feminino & 39 & 8 & 11,7 & 13 \\
\hline masculino & 36 & 15 & 10,7 & 15 \\
\hline Média & 31,1 & 12,7 & $\mathbf{9 , 5 1}$ & 13,9 \\
\hline
\end{tabular}

